\author{
Universidade de São Paulo \\ Faculdade de Filosofia, Ciências e Letras de Ribeirão Preto \\ Departamento de Psicologia \\ Programa de Pós-Graduação em Psicologia
}

\title{
Preditores de barreiras em cursos de pós-graduação ofertados a distância
}

PRISCILA MIQUELINO DA SILVA

Ribeirão Preto 


\title{
Preditores de barreiras em cursos de pós-graduação ofertados a distância
}

\author{
PRISCILA MIQUELINO DA SILVA
}

Dissertação apresentada à Faculdade de Filosofia, Ciências e Letras de Ribeirão Preto da Universidade de São Paulo como parte das exigências para a obtenção do título de Mestre em Psicologia.

Área de Concentração: Psicologia em Saúde e Desenvolvimento

Ribeirão Preto 
Educação A Distância. Barreiras. Evasão. Cursos de Pós Graduação.

Catalogação na publicação

Serviço de Biblioteca e Documentação

Faculdade de Filosofia, Ciências e Letras de Ribeirão Preto - USP

Silva, Priscila Miquelino da.

Preditores de barreiras em cursos de pós-graduação ofertados a distância / Priscila Miquelino da Silva; orientadora: Thais Zerbini Ribeirão Preto, 2019.

$128 f$.

Dissertação de Mestrado, apresentada à Faculdade de Filosofia, Ciências e Letras de Ribeirão Preto, Universidade de São Paulo - USP. Área de concentração: Psicologia em Saúde e Desenvolvimento.

1. Educação A Distância. 2. Barreiras. 3. Evasão. 4. Cursos de Pós Graduação. 
Título: Preditores de barreiras em cursos de pós-graduação ofertados a distância

Dissertação apresentada à Faculdade de Filosofia, Ciências e Letras de Ribeirão Preto da Universidade de São Paulo para obtenção do título de Mestre em Psicologia

Aprovada em:

Banca Examinadora

Prof. Dr.

Instituição:

Assinatura:

Prof. Dr.

Instituição: Assinatura:

Prof. Dr.

Instituição: Assinatura: 
À Thaís Zerbini por todos os incentivos, ensinamentos e direcionamentos, por acreditar na minha capacidade e aceitar me orientar durante esses dois anos e meio de caminhada. Trabalhar com ela foi de extrema importância para que eu pudesse me desenvolver como profissional acadêmica.

À Instituição de Ensino parceira que me deu total apoio, passando todas as informações necessárias para que a pesquisa fosse realizada.

Ao pessoal do LabPOT por todo o auxílio, pelas trocas de conhecimento e grupos de estudo que foram essenciais para o meu desenvolvimento. Em especial gostaria de agradecer a Andresa e Luana, pelo apoio, ensinamentos, por ouvir a cada momento de angústia neste processo que para mim foi um grande desafio.

Ao CNPQ que ao apoiar financeiramente a minha pesquisa, que proporcionou que eu pudesse me dedicar a ela.

Aos meus pais Aparecida e Edson, por todo apoio que deram desde quando decidi tentar o mestrado, por acreditarem que eu sou capaz de realizar os meus sonhos, por todos os conselhos, os chás e chocolates levados enquanto escrevia, à vocês não basta só um muito obrigada.

Ao meu noivo Herbert, por todo apoio, por toda a paciência e os conselhos para que meu desempenho fosse sempre melhor.

Aos meus irmãos Patrícia e Júnior que sempre acreditaram em mim, ao meu cunhado/irmão João, pelas valiosas conversas sobre o mestrado.

À minha amiga Jéssica por ouvir meus desabafos e preocupações ao longo desses anos.

A todos os que fizeram parte dessa trajetória, e de alguma forma ajudaram para esta aqui hoje. 


\section{SUMÁRIO}

APRESENTAÇÃ

CAPÍTULO 1. TREINAMENTO DESENVOLVIMENTO E EDUCAÇÃO ..................... 15

CAPÍTULO 2. EDUCAÇÃO A DISTÂNCIA.................................................................... 25

2.1 Educação a distância: definições, características e políticas públicas ............................ 25

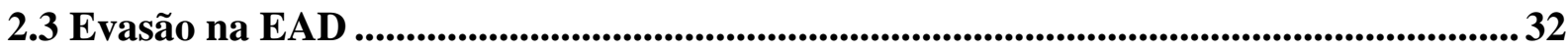

CAPÍTULO 3. ANÁLISE DA LITERATURA: DESCRIÇÃO E RESULTADOS DE

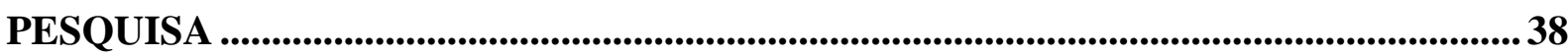

3.1 Revisão de literatura: descrição de percurso ......................................................... 38

3.2 Componentes do modelo de investigação: resultados de pesquisa.................................... 38

3.2.2 Estratégias de aprendizagem .......................................................................................................46

3.2.4 Barreiras em EAD (variável critério): definições e características ............................... 54

CAPÍTULO 4. CARACTERÍSTICAS METODOLÓGICAS DA PESQUISA .................59

4.1 Delimitação do problema, objetivos de pesquisa e modelo de investigação .................59

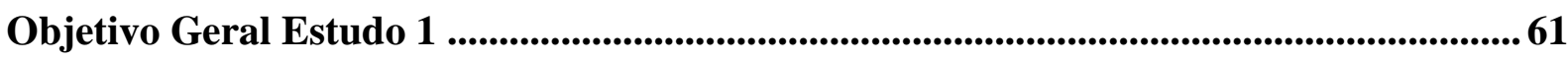

Objetivos Específicos do Estudo 1..........................................................................61

Objetivo Geral Estudo 2 ................................................................................................................................. 61

Objetivos Específicos do Estudo 2............................................................................................61

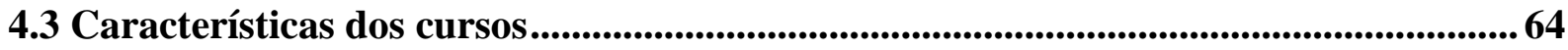

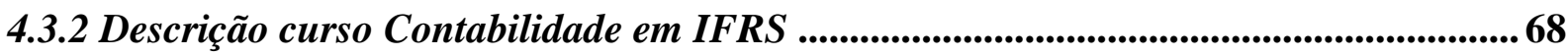

4.3.3 Descrição curso Economia Brasileira para Negócios.............................................69

4.3.4 Descrição Curso Gestão em Saúde .....................................................................69

4.3.5 Descrição curso Gestão Estratégica ............................................................................................... 70

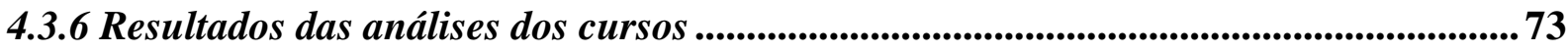

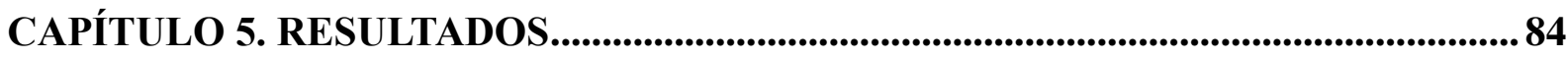

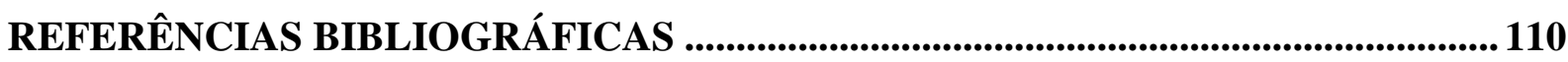

ANEXO A - QUESTIONÁRIO SOCIODEMOGRÁFICO............................................. 121

ANEXO B - QUESTIONÁRIO DE BARREIRAS E FACILITADORES EM EAD ..... 122

QUESTIONÁRIO DE BARREIRAS E FACILITADORES EM EAD............................. 122

QUESTIONÁRIO DE ESTRATÉGIAS DE APRENDIZAGEM................................. 123

APÊNDICE A - TERMO DE CONSENTIMENTO LIVRE E ESCLARECIDO........... 128 


\section{RESUMO}

A crescente necessidade de desenvolvimento de competências individuais e organizacionais nas organizações e ambientes de trabalho tem influenciado no aumento de cursos ofertados a distância, que nos últimos anos cresceu consideravelmente. Neste sentido as ações educacionais são de extrema importância para o preenchimento das lacunas dessas competências. A Educação a Distância (EAD), oferece uma metodologia flexível, adaptandose à rotina dos alunos e ao mesmo tempo oferece a possibilidade de desenvolvimento das competências destes. Contudo, mesmo com todos os pontos positivos dos cursos EAD, não é possível evitar a evasão. Por isso, é importante que novos estudos sejam realizados sobre esta temática, buscando se aprofundar nos motivos que contribuem para que a evasão ocorra. $\mathrm{O}$ objetivo deste estudo, portanto, é identificar variáveis preditoras de evasão relacionadas às características da clientela, estratégias de aprendizagem e a barreiras em EAD, em cursos de pós-graduação ofertados a distância em uma Instituição de Ensino de Pós-Graduação, situada em Ribeirão Preto/SP. Os instrumentos de medida empregados na investigação para o Estudo 1 foram: 1) Estratégias de Aprendizagem; e 2) Barreiras em EAD. Para o Estudo 2 foi elaborado um roteiro semiestruturado de Barreiras em EAD, este instrumento foi validado por juízes. Sobre os instrumentos do Estudo 1 foram adaptados e verificadas as evidências de validade em pesquisas precedentes. Os dados do Estudo 1 foram coletados por meio de questionários que foram enviados por e-mail aos alunos e ex-alunos dos programas de EAD da instituição de ensino parceira contatada. Os dados do Estudo 2 foram coletados através de entevistas via skipe. Para aplicação dos procedimentos de análise de dados do Estudo 1, foram consultadas as orientações de pesquisadores renomados na área de psicometria. Para aplicação dos procedimentos de análise de dados do Estudo 1, foram consultadas as orientações de pesquisadores renomados na área de psicologia. Foram realizadas análises descritivas e exploratórias para investigar a exatidão da entrada dos dados, a presença de casos extremos, a distribuição dos casos omissos, a distribuição de frequência das variáveis e o tamanho das amostras. Para a verificação de evidências de validade dos instrumentos de medida, foram realizadas análises fatoriais exploratórias, utilizando os métodos de fatoração dos eixos principais e de consistência interna. As análises descritivas, exploratórias e fatoriais foram feitas no SPSS (Statistical Package for the Social Science) versão 19.0. No estudo 1, não foram encontradas barreiras nas análises feitas com os estudantes dos cursos de pósgraduação a distância, porém um ponto alarmante foi encontrado nas características dos alunos, em relação a conciliação das atividades do curso com compromissos familiares, outras atividades de estudo e de trabalho. Os alunos utilizaram com mais frequência as estratégias cognitivas, controle da emoção e motivação, reflexão para aplicação prática. As estratégias menos utilizadas foram as de busca por ajuda interpessoal, isso pode refletir em uma necessidade maior do EAD em promover ações de integração entre os alunos, que podem trocar experiências e enriquecer a aprendizagem ao longo do curso. No estudo 2, foram apontadas falhas no que se refere aos conteúdos dos cursos serem muito teóricos e pouco aplicados à prática. No estudo 2, foram apontadas falhas na conexão durante as aulas ao vivo, e a ferramenta de acesso ao aluno que segundo afirmações, eram muito atrasadas, também citaram a falta de interação nos forúns com o tutor e demais alunos.

Palavras chave: Educação a distância, Evasão, Barreiras, Cursos de pós-graduação. 


\begin{abstract}
The increasing need to develop individual and organizational competencies in organizations and work environments has influenced the increase of courses offered at a distance, which in recent years has grown considerably. In this sense, educational actions are extremely important to fill the gaps in these competencies. Distance Education (EAD), offers a flexible methodology, adapting to the routine of the students and at the same time offers the possibility of developing their skills. However, even with all the good points of EAD courses, avoidance cannot be avoided. Therefore, it is important that new studies are carried out on this theme, seeking to delve into the motives that contribute to avoidance occurring. The objective of this study, therefore, is to identify barriers related to evasion in the EAD modality, in postgraduate courses offered at a Distance Learning Institution, located in Ribeirão Preto / SP. The measurement instruments used in the research were: 1) Learning Strategies; and 2) EAD barriers. These instruments were adapted and verified the evidences of validity in previous researches. Data were collected through questionnaires that were sent by e-mail to the students and ex-students of the EAD programs of the partner teaching institution contacted. For the application of the procedures of data analysis, the orientations of renowned researchers in the area of psychometry were consulted. Descriptive and exploratory analyzes were carried out to investigate the accuracy of data entry, the presence of extreme cases, the distribution of missing cases, frequency distribution of variables and sample size. In order to verify the validity of the measuring instruments, exploratory factorial analyzes were performed using the main axis factorization methods and internal consistency. The descriptive, exploratory and factorial analyzes were done in the SPSS (Statistical Package for the Social Science) version 19.0 No barriers were found in the analyzes made with the students of the distance graduate courses, but an alarming point was found in the characteristics of the students, in relation to the conciliation of the activities of the course with family commitments, other activities of study and work. Students used cognitive strategies more often, emotion control and motivation, reflection for practical application. The least used strategies were the search for interpersonal help, this may reflect a greater need of EAD to promote integration actions among students, who can exchange experiences and enrich learning throughout the course.
\end{abstract}

Keywords: Distance education, Dropout, Barriers, Postgraduate courses. 


\section{Lista de Figuras}

Figura 1. Modelo de Avaliação Integrado e Somativo - MAIS ( Borges-Andrade, 1982, 2006).

Figura 2. Modelo de Avaliação do Impacto do Treinamento no Trabalho - IMPACT (Abbad, 1999)

Figura 3. Modelo geral de avaliação da Transferência de Treinamento via web no Trabalho (Zerbini, 2007) 26

Figura 4. Modelo de investigação (Umekawa,2014). 27

Figura 5. Modelo Teórico Multinível de Predição de Impacto de Treinamento a Distância no Trabalho e de Persistência/Evasão em Cursos Ofertados Nessa Modalidade" ( Brant, 2014) .28

Figura 6. Modelo de investigação proposto (Martins ,2016) 30

Figura 7. Modelo das variáveis do Estudo 1 .67 


\section{Lista de Tabelas}

Tabela 1. Causas endógenas da evasão (Biazus, 2004, Bittencourt \& Mercado, 2014). 39

Tabela 2. Causas exógenas da evasão segundo (Biazus, 2004, Bittencourt \& Mercado, 2014)

Tabela 3. Etapas da revisão da literatura sobre as variáveis de interesse do presente estudo.

Tabela 4. Resultados Quantitativos da Revisão de Literatura. 45

Tabela 5. Resultados qualitativos da busca. .48

Tabela 6. Resultados do controle de busca sobre Barreiras 48

Tabela 7. Classificação e definições das estratégias de aprendizagem .53

Tabela 8. Pesquisas sobre Estratégias de Aprendizagem (Martins, 2016) .54

Tabela 9. Barreiras à EAD nas Organizações (Mendonça, 2015).......................................64

Tabela 10. Características dos cursos de pós-graduação ......................................................73

Tabela 11. Disciplinas do curso de pós-graduação Gestão em Marketing Estratégico............75

Tabela 12. Disciplinas do curso de pós-graduação Contabilidade em IFRS...........................76

Tabela 13. Disciplinas do curso de pós-graduação Economia Brasileira para

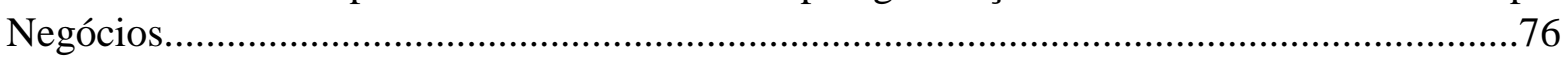

Tabela 14. Disciplinas do curso de pós-graduação Gestão em Saúde.....................................77

Tabela 15. Disciplinas do curso de pós-graduação Gestão em Marketing

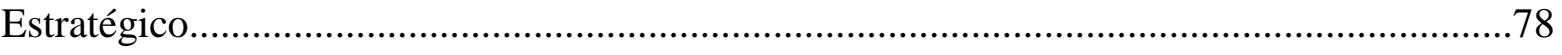

Tabela 16. Resumo das informações sobre os instrumentos utilizados no Estudo 1 (Martins, Zerbini \& Medina 2018).

Tabela 17. Resumo das informações sobre os instrumentos utilizados no Estudo 2. 82

Tabela 18. Número de questões referente a cada tema do roteiro de Barreiras a Conclusão do Curso em EAD 82

Tabela 19. Valores de assimetria e curtose e os desvios-padrão associados às Estratégias de Aprendizagem.

Tabela 20. Valores de assimetria e curtose e os desvios-padrão associados às Barreiras em EAD. 
Tabela 21. Diretrizes da análise temática (Braun e Clarke, 2006).........................................90

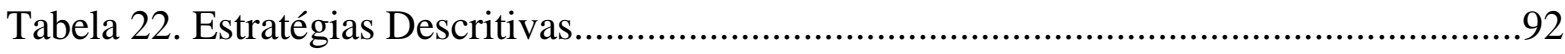

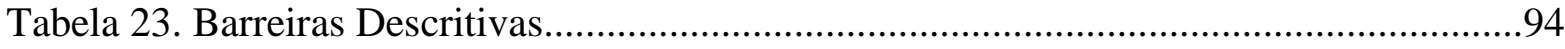

Tabela 24. Estrutura Empírica do Questionário Estratégias de Aprendizagem......................97

Tabela 25. Estrutura Empírica do Questionário Barreiras em EAD.....................................99

Tabela 26. Informações psicométricas Instrumentos Estratégias de Aprendizagem e Barreiras

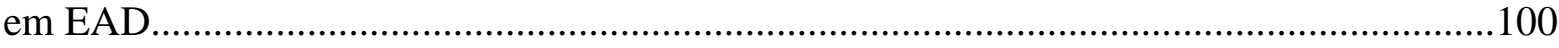

Tabela 27. Regressão Múltipla para a variável dependente Suporte Institucional

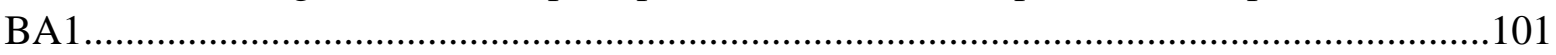

Tabela 28. Regressão Múltipla para a variável dependente Contexto Externo ao Curso

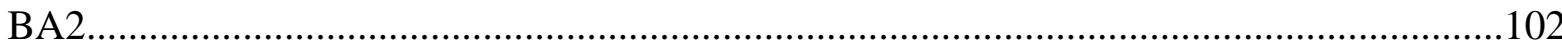

Tabela 29. Regressão Múltipla para a variável dependente Desenho do Curso

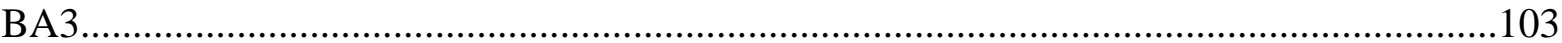

Tabela 30. Regressão Múltipla para a variável dependente Características do Aluno

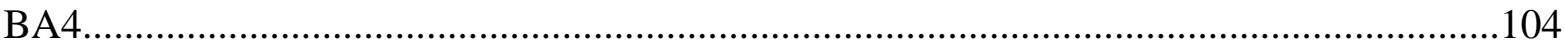

Tabela 31. Categorização por Temas Roteiro de Barreiras em

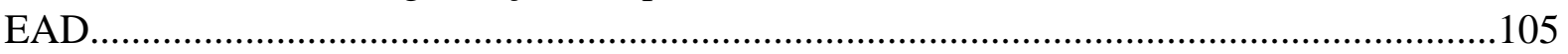




\section{Lista de Siglas}

TD\&E Treinamento, Desenvolvimento e Educação

CHA Conhecimento, habilidade e atitude

ANT Análise necessidades de treinamento

MAIS Modelo Avaliação Integrado Somativo

IMPACT Avaliação do Impacto do Treinamento

IES Instituição de Ensino Superior

MEC Ministério da Educação

MBA Master Business Administration

EAD Educação à distância

TICs Tecnologias de informação e comunicação

NTIC Novas tecnologias de informação e comunicação 


\section{APRESENTAÇÃO}

Em decorrência das mudanças e da competitividade no âmbito empresarial, cresce a necessidade de desenvolvimento de competências individuais e organizacionais. Neste sentido, a Educação a Distância (EAD), oferece a oportunidade de desenvolvimento do aluno por meio de uma metodologia flexível, intermediada pela internet, entre outras tecnologias de comunicação e informação, surgindo como uma alternativa viável, uma vez que essa modalidade de ensino cria mecanismos que favorecem a aprendizagem e a qualificação contínuas, além de apresentar benefícios como otimização do tempo, atendimento a um maior número de pessoas e redução de custos a médio e longo prazo, sem prejudicar a aquisição de conhecimentos (Carvalho \& Abbad, 2006; Martins \& Zerbini, 2015; Salas \& Cannon-Bowers, 2001; Zerbini, 2007). A modalidade EAD, vem sendo utilizada em programas de qualificação e formação de profissionais, na educação geral e em educação corporativa, se encontra vinculada a aprendizagem aberta, aprendizagem ao longo da vida ou educação permanente, e foca no processo de aquisição de competências de adultos (Abbad, 2007).

A evasão se caracteriza pela saída definitiva do aluno de um curso ou ação educacional, segundo a definição do MEC (2007), a evasão é considerada um problema que afeta tanto na educação presencial quanto o ensino a distância. Segundo Sales (2009), a problemática da evasão na educação a distância ainda apresenta sérias deficiências no tocante aos estudos empíricos desenvolvidos, sendo estes pouco numerosos e conclusivos (Abbad, Carvalho \& Zerbini, 2006; Walter, 2006).

Segundo o Censo EAD (2015) as taxas de evasão em cursos regulamentados totalmente a distância apresentam um intervalo médio de 25 a 50\%, a maior causa apontada pelas instituições de ensino é a falta de tempo para o estudo e a adaptação as metodologias e o acúmulo das atividades do trabalho. Nesse sentido, é importante ampliar as discussões acerca dos motivos que influenciam a evasão nos cursos ofertados a distância, por meio da realização de pesquisas que visem avaliar quais são as estratégias de aprendizagem adotadas pelos alunos, compreender o perfil da clientela participante dos cursos e identificar possíveis barreiras na conclusão dos cursos.

Segundo Umekaua e Zerbini (2018), os elementos relacionados à saída e permanência do aluno na modalidade a distância apresentam uma natureza diversificada, por isso é necessário cuidar para que os atributos do curso, aluno e ambiente externo que engloba a sua vida não causem um fracasso ao esforço dedicado por ele. 
O presente estudo, portanto, tem o objetivo de identificar variáveis preditoras de evasão relacionadas às características da clientela, estratégias de aprendizagem e a barreiras em EAD, em cursos de pós-graduação ofertados a distância em uma Instituição de Ensino de Pós-Graduação, situada em Ribeirão Preto/SP.

O Capítulo 1 apresenta as características específicas do sistema de Treinamento, Desenvolvimento e Educação (TD\&E), evolução e os modelos de avaliação da área.

O Capítulo 2 discorre sobre as definições e características da modalidade EAD e a contextualiza, perpassando pelas políticas públicas nacionais, considerando as potencialidades e os desafios estabelecidos frente às inovações no campo educacional. Discute ainda a EAD no contexto das Instituições de Ensino Superior (IES) no Brasil.

O Capítulo 3 tem por objetivo de descrever o percurso da revisão de literatura sobre as variáveis de interesse do estudo. Além disso, são expostos os conceitos, características e resultados do processo sistemático e onde se apresentam as variáveis foco deste estudo: Características da Clientela, Estratégias de Aprendizagem, Evasão e Barreiras em EAD (Variável Critério).

O Capítulo 4 visa apresentar a delimitação do problema, a justificativa e os objetivos da pesquisa do Estudo 1 (Quantitativo) e Estudo 2 (Qualitativo), apresentar o modelo de investigação, e apresentar as características da instituição de ensino superior participante, a análise dos cursos da instituição parceira, instrumentos de medida, assim como dos procedimentos de coleta e análise estatística dos dados.

O Capítulo 5 apresenta os resultados das análises dos dados do Estudo 1 (Quantitativo) e da análise temática realizada no Estudo 2 (Qualitativo), e também são apresentados as conclusões do estudo. 


\section{CAPÍTULO 1. TREINAMENTO DESENVOLVIMENTO E EDUCAÇÃO}

\section{Objetivo do Capítulo 1}

Este capítulo tem por objetivo apresentar as características específicas do sistema de Treinamento, Desenvolvimento e Educação (TD\&E), bem como a evolução e os modelos de avaliação.

Segundo Moraes (2016) quando se trata de qualificação profissional, pode-se afirmar que é um fator de grande importância para o desenvolvimento organizacional e individual, contribuindo para o crescimento e vantagem competitiva das organizações e dos colaboradores que nelas atuam. Por isso, torna-se de suma importância a realização de estudos que busquem compreender tais ações que visam à qualificação dos profissionais. A autora afirma que ações desenvolvidas no campo de TD\&E cada vez mais se destacam em termos de importância e necessidade, pois os novos contextos de ensino e trabalho necessitam de iniciativas capazes de sanar lacunas de competências e que promovam sua constante atualização visando o bom desempenho acadêmico e profissional.

Quando se refere às definições de TD\&E, elas podem ser delimitadas em Treinamento: ação direcionada para atividades atualmente exercidas, com o intuito de preparar o indivíduo e melhorar seu desempenho no cargo atual; programas de Desenvolvimento: consistem em ações que estimulam o livre crescimento pessoal e profissional dos membros da organização e não possuem vínculo estreito com as atividades demandadas por esta; e Educação: refere-se às oportunidades dadas ao indivíduo para capacitá-lo a ocupar cargos diferentes em outro momento dentro da organização (Abbad \& Borges-Andrade, 2014; Abbad, Meneses \& Zerbini \& Abbad, 2010).

É possível afirmar que as ações de TD\&E são estruturadas a partir de três subsistemas principais: Avaliação de necessidades de ações instrucionais, Planejamento e Execução e Avaliação de treinamento. Se estes três subsistemas forem aplicados de acordo os métodos e teoria da área, podem garantir a obtenção efetividade das ações de treinamento. O processo de avaliação de necessidades (ANT) é responsável por determinar onde a ação instrucional é necessária, qual conteúdo deve ser treinado e quem são os sujeitos a participarem da ação. Seu início acontece a partir da verificação de uma necessidade específica de treinamento (BorgesAndrade, 2006). 
$\mathrm{Na}$ avaliação de necessidades (ANT) foi identificado um problema que necessita de uma análise, devido às frequentes queixas, consequências das condições inadequadas de trabalho ou de desmotivação para o exercício profissional, estas condições não são alvo das ações educacionais de TD\&E (Gondin \& Silva, 2004). Com a confirmação de que o problema de desempenho pode ser solucionado por meio de remoção de deficiências de conhecimentos, habilidades e atitudes (CHA), inicia-se o processo de avaliação de necessidades, realizado a partir da análise organizacional, de análise de tarefas e análise individual (Borges-Andrade, 2006).

Após a identificação das lacunas de competências a serem treinadas, o subsistema seguinte, Planejamento Instrucional, se origina na definição dos desempenhos e competências a serem desenvolvidos pelos participantes. Com estes elementos e peças de informação, o processo de planejamento de ações de TD\&E é iniciado pela definição dos objetivos educacionais, ou seja, pela determinação dos desempenhos esperados da parte dos treinandos ao final do evento. O passo seguinte do planejamento de TD\&E corresponde a escolha da modalidade de entrega: para que o planejador se decida por ações presenciais, a distância ou semipresenciais é preciso que o mesmo realize uma análise, verificando o perfil demográfico, funcional e profissional dos agentes envolvidos no evento. Os desempenhos almejados pelos objetivos educacionais estabelecidos também devem ser levados em conta, pois possibilitam compreender sua complexidade e a necessidade de maior contato, por parte do aprendiz, com determinadas situações. A eficácia de cada modalidade de ensino, a disponibilidade, quanti e qualitativa, dos recursos financeiros, materiais, tecnológicos e humanos também devem ser considerados durante a escolha a ser feita. O próximo passo é a definição de critérios de aprendizagem, estes devem servir de parâmetro (qualitativo e/ou quantitativo) para a mensuração do alcance de cada objetivo educacional. Indicam o grau de proficiência a ser atingido pelo aprendiz durante e após a instrução e, portanto, devem ser específicos, mensuráveis e precisos. Sobre a preparação de materiais escritos, é uma das consequências das fases anteriores do planejamento instrucional e deve servir para apoiar a instrução em cursos presenciais ou transformar-se na própria instrução em cursos a distância autoinstrucionais (Abbad, Zerbini, Carvalho \& Meneses, 2006).

Há uma necessidade de superar as limitações diminuem a eficiência do sistema de TD\&E, e que comprometem o estado científico da área, como por exemplo, as restrições culturais e técnicas no uso de avaliações de aprendizagem; dificuldades de realizar avaliações em níveis mais altos; falta de ajustes e utilização dos efeitos gerados por ações de TD\&E; deficiência de orientações teóricas e metodológicas que embasem avaliações e resultados 
organizacionais (Umekawua, 2014). Dentre as ações de TD\&E, a modalidade da educação a distância se faz presente como ferramenta que através de cursos profissionalizantes, graduação ou pós-graduação, possibilita o desenvolvimento de competências do colaborador em seu atual cargo na organização, bem como, pode oferecer possibilidades de desenvolvimento de competências em cargos futuros.

\subsubsection{Modelos de avaliação de treinamento presencial e à distância}

Ao se referir sobre o subsistema de avaliação de TD\&E, Borges-Andrade (2006) afirma que este é o principal responsável pelo provimento de informações, retroalimentação e aperfeiçoamento constante do referido sistema. Moraes (2016) acrescenta que, com as avaliações dos efeitos resultados pelas ações de TD\&E, é possível afirmar que o referido subsistema tem por objetivo exercer um controle sobre o processo, proporcionando feedback aos seus componentes, tomada de decisões acerca do treinamento e capacitá-lo a promover alterações no ambiente.

A avaliação de ações de TD\&E abarca sempre algum tipo de coleta de dados, estes dados são utilizados para elaborar um diagnóstico sobre as necessidades. O objeto da avaliação pode ser uma ação isolada de TD\&E ou um conjunto dessas atividades, que é o programa de treinamento. Segundo os autores Kirkpatrick (1976) e Hamblin (1978) as ações de treinamento podem obter resultados imediatos que são avaliados em dois níveis: A reação, que contempla as opiniões dos participantes em relação ao grau de utilidade e dificuldade do curso, bem como em relação à satisfação com o mesmo e aprendizagem, ou aquisição, por esses participantes de CHA. Ainda segundo esses autores, as ações de TD\&E podem ter efeitos em longo prazo, sendo eles em três níveis. O comportamento no cargo ou utilização no trabalho dos conhecimentos, habilidades de atitudes pelos participantes das ações de TD\&E, a organização ou mudanças que podem ter ocorrido no funcionamento da organização em que trabalham esses participantes ou o valor final ou alterações na produção ou nos serviços prestados por essa organização ou outros benefícios sociais e econômicos.

Os autores Hayes, Scott, Braczinskas, Scaccia, Stout e Wandersman (2016) afirmam que o modelo de Kirkpatrick não é satisfatoriamente útil para avaliação da formação ou para todo o processo de treinamento, incluindo a efetividade do treinamento por meio da análise de variáveis do contexto, mesmo assim, a maioria dos modelos de avaliação encontrados na literatura são geralmente embasados nos quatro níveis originais, e o modelo continua a ser muito utilizado em cenários nacionais e internacionais (Praslova, 2010; Martins, 2012; Reio, 


\section{Rocco, Smith \& Chang, 2017).}

Em seu estudo Reio et al. (2016) afirma que de acordo com a Sociedade Americana de Treinamento e Desenvolvimento (ASTD) 98\% das organizações avaliam no Nível 1 (reação), $88 \%$ avaliam no Nível 2 (aprendizagem), 76\% avaliam no Nível 3 (comportamento) e mais de $50 \%$ avaliam no Nível 4 (resultados). Borges-Andrade $(1982,2006)$ em sua contribuição para a área de TD\&E afirma que outros componentes devem ser considerados, por isso propôs o modelo de avaliação integrado e somativo (MAIS). Este modelo é integrado, pois indica que necessidades de desempenho e características individuais dos participantes, dos procedimentos e processos de TD\&E, bem como ações de disseminação e de apoio à ação, predizem aqueles resultados imediatos e efeitos a longo prazo. Dessa forma a avaliação deve além de julgar o alcance de objetivos e verificar os resultados e efeitos, assume o papel de predizer tais resultados e efeitos.

O modelo MAIS é somativo, pois visa obter informações para avaliar TD\&E já desenvolvido, com o objetivo de verificar a capacidade deste de produzir resultados. Apesar de ter sido concebido como um modelo somativo, também apresenta grande contribuição para avaliações formativas, na medida em que prevê a análise dos insumos do ambiente e dos processos e procedimentos relativos às ações de TD\&E (Borges-Andrade, Zerbini, Abbad \& Mourão, 2013).

Figura 1. Modelo de Avaliação Integrado e Somativo - MAIS

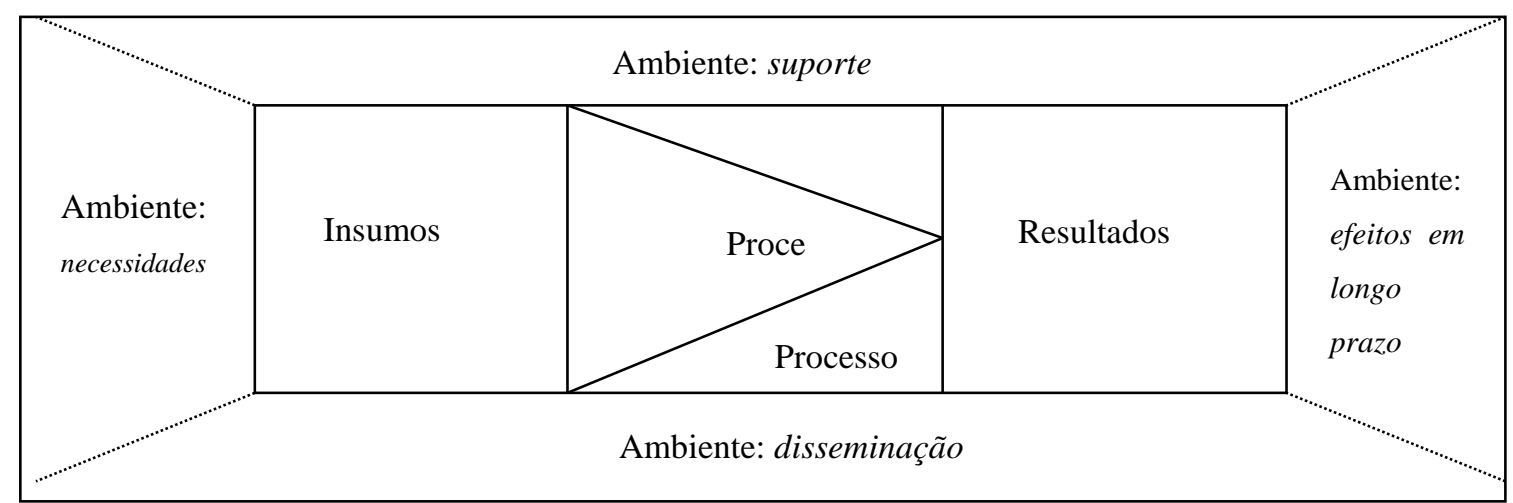

Fonte: Borges-Andrade, 1982, 2006.

O modelo MAIS tem por base a suposição de que um modelo de avaliação de um programa de TD\&E deve seguir um método de formulação de questões e levantamento de dados referentes as características (insumos, procedimentos, processos e resultados) desses eventos ou programa e ao ambiente no qual eles ocorrem. 
O primeiro componente do modelo MAIS, insumos, se refere aos fatores físicos e sociais e aos estados comportamentais e cognitivos, anteriores à instrução, que podem afetá-lo ou seus resultados. $\mathrm{O}$ conhecimento sobre os insumos possibilita ao profissional selecionar eventos de TD\&E efetivos e relevantes para resolver um problema de desempenho ou contribuir para diminuir uma necessidade de TD\&E. As informações sobre os insumos podem estar associadas a resultados e efeitos em longo prazo.

O segundo componente, procedimentos, destaca as operações necessárias para facilitar ou produzir resultados instrucionais ou aprendizagem. Os dados sobre essa variável possibilitam a descrição detalhada do sistema instrucional vigente no evento ou programa de TD\&E e a verificação de sua associação com os resultados. Essas informações possibilitam a identificação das características de ensino relevantes em TD\&E.

O terceiro componente, nomeado processos, se refere ao que acontece a aspectos significantes do comportamento do aprendiz, à medida que os procedimentos são implementados. Esses aspectos podem começar a ocorrer logo após a introdução dos procedimentos e tendem a se somar, à medida que estes são implementados. Variáveis de processos são concernentes aos comportamentos dos aprendizes, enquanto variáveis de procedimentos são geralmente concernentes a decisões de planejamento instrucional ou não desempenho de instrutores.

O quarto componente, resultados, descreve o que é produzido pelos eventos ou programas de TD\&E. É um dos principais focos de interesse de avaliação e corresponde aos dois primeiros níveis indicadores de efetividade de modelos como os de Kirkpatrick (1976) e Hamblin (1978). Essas variáveis se referem ao desempenho final imediato decorrente de TD\&E. O último componente do MAIS, nomeado ambiente, se refere a todas as condições, atividades e eventos na sociedade, na comunidade, na organização ou na escola, incluem tanto o apoio quanto a disseminação que TD\&E teve nesses contextos, quanto às necessidades que o determinaram quanto os resultados em longo prazo que produziu. $\mathrm{O}$ componente ambiente determina e modifica TD\&E e é afetado por este.

A autora Abbad (1999) também contribui com um modelo de avaliação de TD\&E, propondo um Modelo Integrado de Avaliação do Impacto do Treinamento no Trabalho IMPACT (Abbad, 1999), que visa investigar o relacionamento existente entre variáveis referentes ao indivíduo, ao treinamento, ao contexto organizacional, aos resultados imediatos do treinamento, reação e aprendizagem e à variável critério impacto do treinamento no trabalho. Sobre os componentes 4,5 e 6 pode-se afirmar que lembram os níveis propostos por Kirkpatrick (1976) e Hamblin (1978) e os componentes 1, 2, 3, 5, 6 e 7 estão associados a 
componentes e subcomponentes do MAIS. Foi realizado um teste empírico por meio de uma pesquisa com delineamento metodológico multivariado que integrou três níveis de avaliação: reação, aprendizagem e impacto do treinamento no trabalho e utilizou procedimentos diversificados de coleta e análise dos dados para investigar o relacionamento existente entre os sete componentes mencionados anteriormente. Abbad (1999) concluiu que os efeitos do treinamento no desempenho e nas atitudes dos participantes dependem fortemente de um ambiente organizacional propício ao uso das novas habilidades.

Figura 2. Modelo de Avaliação do Impacto do Treinamento no Trabalho - IMPACT

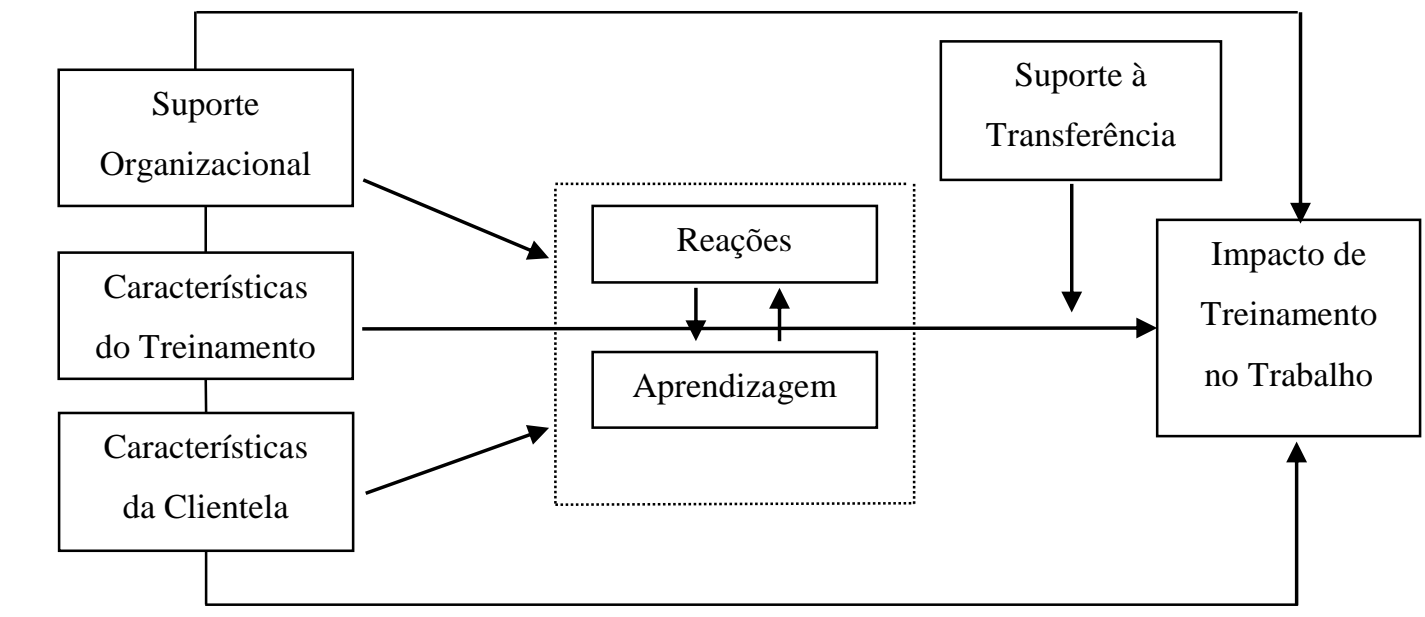

Fonte: Abbad, 1999.

Com base nos modelos MAIS e IMPACT, Zerbini (2007) também contribui para os estudos de modelos de avaliação, desenvolvendo um modelo específico para a avaliação de treinamentos a distância, ofertados pela internet, que tem como foco a identificação das variáveis preditivas da transferência de treinamento em cursos de qualificação profissional. A autora analisou o curso gratuito IPGN - "Iniciando um Pequeno Grande Negócio" do SEBRAE (Serviço Brasileiro de Apoio às Micro e Pequenas Empresas), oferecido integralmente pela internet. O referido modelo avalia o poder preditivo de variáveis individuais (estratégias de aprendizagem), de contexto de estudo (ambiente e procedimentos) e de reações (reação aos procedimentos e ao tutor) quanto à transferência de treinamento para o ambiente de trabalho. A Figura 3 apresenta o Modelo. 
Figura 3. Modelo geral de avaliação da Transferência de Treinamento via web no Trabalho

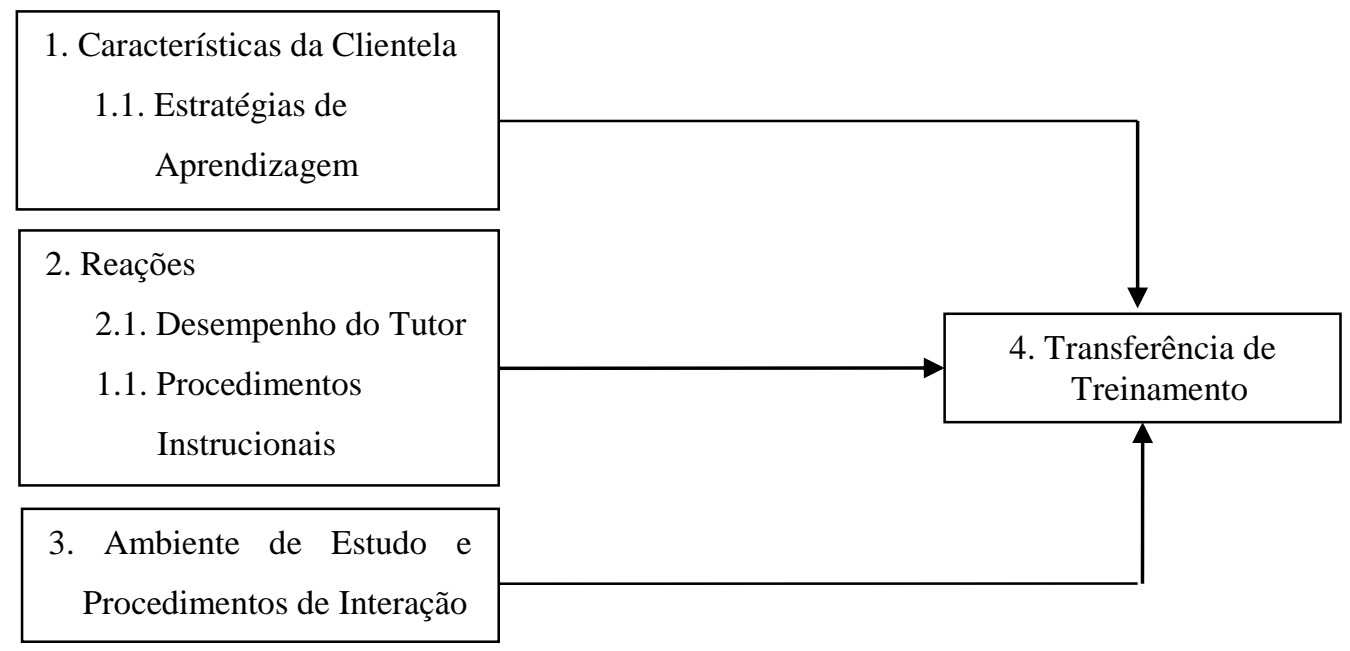

Fonte: Zerbini, 2007.

As variáveis envolvidas no modelo são definidas como:

1. Estratégias de Aprendizagem: capacidades cognitivas complexas aprendidas pelo indivíduo ao longo da vida. Envolvem capacidades cognitivas, habilidades comportamentais e de autocontrole emocional, empregadas pelo aprendiz para controlar os próprios processos psicológicos de aprendizagem, como atenção, aquisição, memorização e transferência.

2. Reações ao Curso: satisfação dos participantes com características instrucionais do curso e com o desempenho do tutor.

3. Ambiente de estudo e Procedimentos: aspectos do contexto pessoal de estudo do aluno e do próprio curso que podem dificultar a permanência do aluno no curso.

4. Transferência de Treinamento: refere-se à aplicação dos CHA aprendidos no curso no contexto de trabalho do participante. É medido em termos das respostas dos participantes à escala de frequência de aplicação do aprendido no curso no ambiente de trabalho, e das respostas dos participantes à pergunta "Você elaborou o plano de negócios ao final do curso?".

Segundo Umekawa e Zerbini (2018) a soma do desenvolvimento dos docentes, a adaptação dos cursos ao ambiente de estudo dos alunos, o emprego adequado das novas ferramentas disponíveis, as estratégias de aprendizagem e hábitos de estudo do aprendiz são elementos que possivelmente se encontram relacionados aos desafios instrucionais e dificultam os retornos dos altos valores investidos na implementação dessa modalidade de ensino. Este modelo oferece elementos que auxiliam na compreensão dos fatores ligados ao abandono/persistência acadêmica no ensino a distância. A autora analisou as possíveis relações existentes entre a variável critério "Fatores Relacionados à Evasão e Persistência em 
EAD” (contexto de estudo, desenho do treinamento e características internas do estudante) e as variáveis antecedentes pertencentes às características da clientela (dados sociodemográficos e estratégias de aprendizagem). Este modelo é demonstrado na figura 4.

Figura 4. Modelo de investigação proposto por Umekawa e Zerbini (2018).

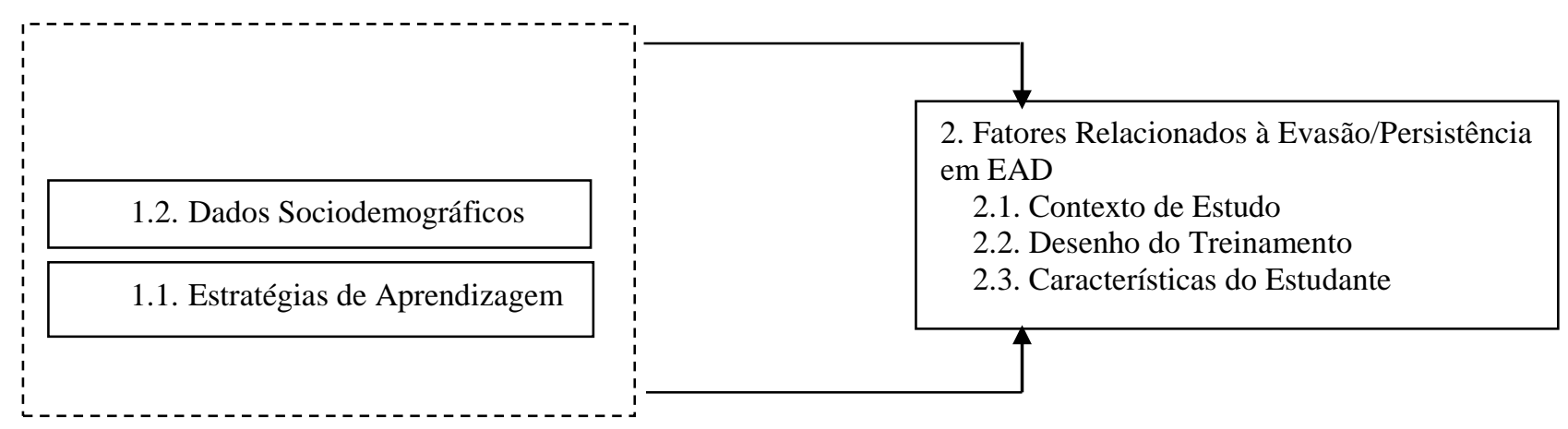

Os resultados encontrados por Umekawa e Zerbini (2018) fornecem contribuições para investigações sobre planejamento instrucional, os resultados mostram quais são as estratégias de aprendizagem mais utilizadas pelos estudantes para a realização das tarefas de aprendizagem mediadas pelas TICs. Os resultados contribuem para a compreensão das variáveis relacionadas ao abandono e permanência dos alunos em programas a distância, fornecem a todos os envolvidos nestas ações, apontamentos em relação aos principais aspectos que comprometem o sucesso educacional tanto para instituições de ensino como para os demais envolvidos, profissionais da área e alunos.

Em seu estudo Brant (2014) propôs o "Modelo Teórico Multinível de Predição de Impacto de Treinamento a Distância no Trabalho e de Persistência/Evasão em Cursos Ofertados Nessa Modalidade" representado pela Figura 5. 
Figura 5. Modelo Teórico Multinível de Predição de Impacto de Treinamento a Distância no Trabalho e de Persistência/Evasão em Cursos Ofertados Nessa Modalidade"

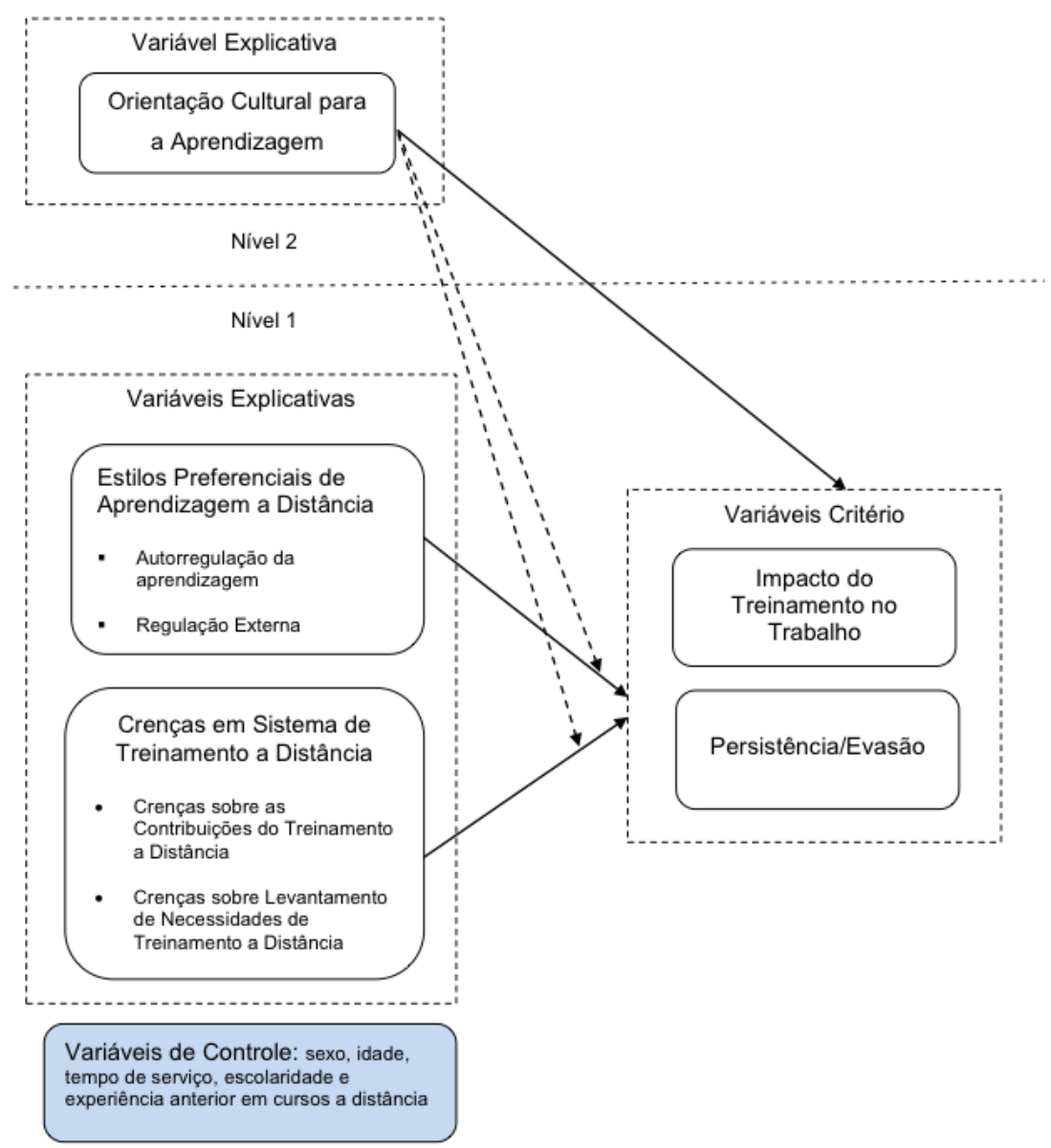

Fonte: Brant, 2014.

A figura acima mostra que a autora testou relações teóricas entre diferentes níveis de análise para a predição de impacto e de persistência/evasão. Foram controlados os efeitos de variáveis relacionadas ao perfil demográfico dos participantes. O nível 1 apresentou características individuais (Estilos de Aprendizagem e Crenças em Sistema de Treinamento a Distância) e o segundo nível apresentou uma característica organizacional denominada Orientação Cultural para a Aprendizagem.

As variáveis critério inseridas foram o Impacto de Treinamento do Trabalho e a Persistência/Evasão da ação educacional. Os dados sociodemográficos (sexo, idade, escolaridade, tempo de serviço e experiência anterior em treinamentos a distância) foram consideradas variáveis de controle pertencentes ao nível individual (Nível 1). Os resultados encontrados pela autora concluíram que para os participantes do estudo, variáveis de diversos níveis tanto individual como organizacional podem contribuir para explicar, de forma mais integrada e abrangente, $\mathrm{o}$ impacto do treinamento a distância no trabalho e a persistência/evasão em cursos nessa modalidade. Segundo o estudo os estilos preferenciais de 
aprendizagem e as crenças em sistemas de treinamento influenciam significativamente a percepção de impacto e a decisão de evasão dos alunos.

Mais recente podemos citar o modelo proposto por Martins (2016) que propõe identificar preditores de aprendizagem vinculados às características da clientela (estratégias de aprendizagem e frequência nos recursos da web) e às reações aos procedimentos instrucionais e ao tutor. Para tanto, foram administradas presencial e virtualmente escalas de medida referentes a Estratégias de aprendizagem, Reação aos procedimentos instrucionais e Reação ao desempenho do tutor junto a graduandos matriculados em disciplinas semipresenciais ofertadas a todos os estudantes de uma instituição de ensino superior da rede privada. A Figura 6 ilustra o modelo em questão.

Figura 6. Modelo de investigação proposto por Martins (2016).

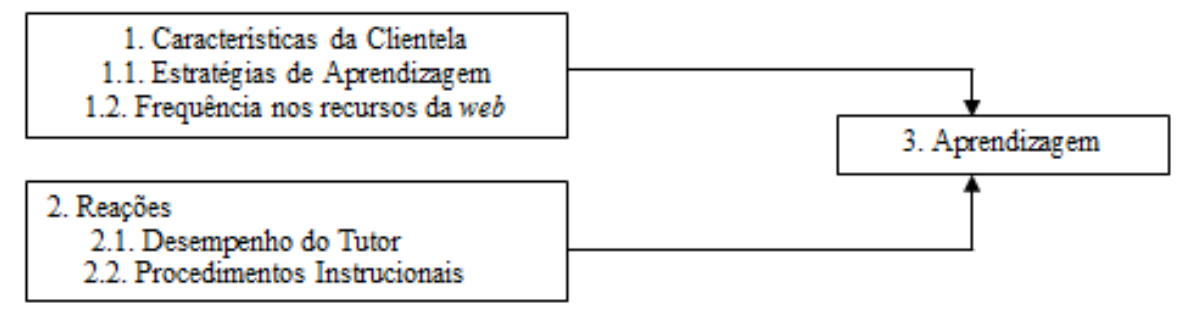

A partir da aplicação do modelo proposto por Martins (2016), a autora verificou que as Estratégias de Aprendizagem Autorregulatórias, a frequência no uso de recursos da web e as Reações favoráveis aos Procedimentos Instrucionais estão relacionadas com a aprendizagem na amostra considerada em seus estudos. Martins (2016) apresentou a importância do ambiente virtual de aprendizagem no processo de comunicação entre os envolvidos na ação educacional (tutores e alunos), bem como a utilização de estratégias que permitam o autogerenciamento da aprendizagem, a autorregulação da motivação, ansiedade e atenção com objetivo do alcance dos resultados almejados por tais ações.

Bell,Tanneunbaum, Ford, Noe \& Kraiger (2017) relatam que após os anos 2000 o desenvolvimento de novos modelos teóricos e a elaboração de ferramentas de avaliação foram os estudos que tiveram maior número de publicações. Compreender o percurso das avaliações de TD\&E, nas modalidades presencial e a distância pode colaborar para que o planejamento instrucional seja mais efetivo, gerando impacto no trabalho e desenvolvendo as competências nos alunos. Os modelos de avaliação expostos acima estudaram variáveis que compõe o modelo da pesquisa aqui apresentada, como: características da clientela, estratégias de aprendizagem, barreiras e evasão, por isso se tornam relevantes para o embasamento teórico deste estudo. 


\section{CAPÍTULO 2. EDUCAÇÃO A DISTÂNCIA}

\section{Objetivo do Capítulo 2}

O objetivo deste capítulo é discorrer sobre as definições e características da modalidade EAD e a contextualizar, perpassando pelas políticas públicas nacionais, considerando as potencialidades e os desafios estabelecidos frente às inovações no campo educacional. Discute ainda a EAD no contexto das Instituições de Ensino Superior (IES) no Brasil e no mundo.

\subsection{Educação a distância: definições, características e políticas públicas}

O termo Educação a Distância, recebe diversas conceitualizações, uma delas, segundo Vargas e Abbad (2006), se define como uma abordagem de ensino-aprendizagem, mediada ou não por mídias tecnológicas, isso faz com que seja possível ocorrer diversas formas de interação entre professores e alunos. (Associação Brasileira de Educação a Distância [ABED], 2012; Reis, 2009). Dentre as características da EAD, aponta-se ao fato de ser adaptável uma vez que é planejada para atender uma grande variedade de indivíduos com diferentes habilidades, preferências e Estilos de Aprendizagem (Brusilovsky \& Peylo, 2003).

Todas as definições são semelhantes, caracterizando a EAD como modalidade de ensino, em que atividades propostas acontecem sem haver a necessidade da presença de professores e aprendizes no mesmo tempo e espaço (ABED, 2012). Segundo Walter (2006), as características essenciais da EAD poderiam ser indicadas como o distanciamento físico entre professor e aluno, a administração do processo de aprendizagem é responsabilidade do próprio aluno, tutor possui um papel auxiliar e facilitador, a relação professor-aluno é apoiada por mídias tecnológicas diversas como: televisão, internet, intranet, rádio, $C D-R O M$, etc. e a flexibilidade de conteúdos a serem aprendidos.

Sobre os principais fatores complicadores do desenvolvimento e êxito de cursos a distância, pode-se citar a dificuldade apresentada pelos professores de manterem o engajamento de seus aprendizes, esta tarefa é considerada difícil já que o estudante na situação de EAD é possui um número maior de elementos que tiram a sua atenção do que quando está presente em sala de aula (Appana, 2008; Belloni, 1999). Segundo Palloff e Pratt 
(2004) no modelo de ensino a distância, é fundamental que o aluno domine as ferramentas tecnológicas, mas que também utilize os instrumentos disponibilizados e tenha tolerância sobre alguns aspectos inerentes à modalidade, como a limitação dos processos de interação professor-aluno e aluno-aluno.

Anderson (2005) em seu estudo sobre educação a distância, relata que especialmente as formas que maximizam liberdade individual, permitindo a inscrição contínua e o ritmo individual, é frequentemente percebida como uma maneira solitária de aprender. É provável que o requisito implícito de motivação própria reduz a acessibilidade a muitos alunos que têm pouca exposição ou experiência suficiente com programação que não é estruturada e orquestrada por um professor ao vivo.

Sobre área da tecnologia da informação e comunicação (TIC), seu crescimento contribuiu para os diferentes recursos e estratégias instrucionais aplicados nos processos de ensino e aprendizagem. Considerando as transformações sofridas pelo campo de TD\&E, decorrente das inovações e melhorias cibernéticas (Aguinis \& Kraiger, 2009; Raymond, Clarke \& Klein, 2014; Salas \& Cannon-Bowers, 2001). Os autores Iglesias e Salgado (2012) apontam que as ferramentas das TIC estão sendo utilizadas como formas de reduzir custos financeiros com os programas de treinamento, e estender o número de potenciais beneficiários das ações de TD\&E. Apesar do aumento da procura por cursos ofertados na modalidade distância após o reconhecimento dos benefícios e vantagens dos mesmos, ainda restam graves lacunas na produção e sistematização dos conhecimentos da área de forma que análises e discussões que abordem sobre ações educacionais a distância. (Abbad, Carvalho \& Zerbini, 2006; Carvalho \&Abbad, 2006; Castro \& Ferreira, 2006; Martins, 2012; Umekawa, 2014; Zerbini, 2007).

Segundo Martins e Zerbini (2014) o crescimento da inserção da EAD como meio de ensino implica a questões que necessitam de discussão e a efetividade dessas ações precisa ser analisada através de investigações que busquem medir se os resultados obtidos estão alinhados aos objetivos previamente estabelecidos pela ação educacional, explicar como ocorre o processo de aquisição da aprendizagem e as possíveis correlações das variáveis para atingir resultados satisfatórios, buscando reduzir as falhas e otimizar ganhos pelo alcance de um maior número de pessoas.

O planejamento da ação instrucional deve levar em conta as estratégias a fim de facilitar, através de planos de treinamento, exercícios, tarefas e simulações, Devido ao fato de que a adoção, uso e influência das estratégias de aprendizagem parecem depender muito das características da amostra, curso e organização. (Martins, Zerbini \& Medina, 2018) 
Sobre a terminologia "Políticas Públicas" segundo Chrispino (2016), tem um forte caráter polissêmico e seu sentido pode ser diverso como os valores, ideologias e contexto que a formula, podemos entender as políticas públicas em termos de ações intencionais de governo afim de entender às necessidades de uma coletividade. Em 2001 a Lei $\mathrm{n}^{\mathrm{o}} 10.172$ instituiu o Plano Nacional da Educação (PNE) definindo a educação como direito de todos os cidadãos; como fator de desenvolvimento social e econômico para o país e como instrumento de combate a pobreza e inclusão social. Para a educação superior, foram instituídos alguns direitos, como por exemplo: investir na oferta de cursos noturnos, modulares e sequenciais; ofertar até o final da década passada, educação superior para cerca de $30 \%$ dos jovens de 18 a 24 anos; estabelecer amplo sistema de EaD, entre outros (MEC, 2007; Costa, Barbosa \& Goto, 2011).

Educação a Distância faz parte das principais legislações, quando referida às políticas públicas educacionais nacionais tem o papel de possibilitar a promoção de modificações consideráveis de ordem jurídico-institucional (Martins \& Zerbini, 2014). Perpassando por sua trajetória no Brasil, em 1988 foi aprovada na Constituição Federal e importantes alterações na legislação da área educacional. A Lei de Diretrizes e Bases da Educação Nacional - LDB (Lei $n^{\circ}$ 9.394/1996) que reestrutura e define as diretrizes e bases da educação escolar no Brasil, aborda a EAD e estabelece que o "Poder Público incentivará o desenvolvimento e a veiculação de programas de ensino a distância, em todos os níveis e modalidades de ensino, e de educação continuada" (caput do artigo 80 da LDB), responsabiliza-se a União de credenciar e avaliar as instituições que oferecem cursos dessa modalidade, sendo esta organizada com abertura e regime especiais.

Além da LDB, existem outras legislações com grande importância para a educação podem ser apontadas, destas , algumas específicas a modalidade EAD:

- O Plano Nacional de Educação - PNE (Lei 13.005, de 25 de junho de 2014) apresenta novas políticas e ações governamentais na educação;

- A Resolução CNE/CES no 1/2001 determina as normas que regulamentam o funcionamento da pós-graduação;

- Portaria Normativa no 20, de 21 de dezembro de 2017 prevê o credenciamento e recredenciamento de IES, para oferta de cursos superiores a distância;

- O Decreto $\mathrm{n}^{\circ}$ 5.622/2005 regulamenta o artigo 80 da LDB;

- O Decreto No 9.057/2017, que moderniza a legislação sobre o tema e regulamenta a Educação à Distância no país, definindo, que a oferta de pós-graduação lato sensu EaD autoriza as instituições de ensino superior a obter o credenciamento 
$\mathrm{EaD}$, não sendo necessário o credenciamento específico, como a modalidade presencial.

Das ações e programas governamentais brasileiros referentes à EAD que são apresentados pelo Ministério da Educação (MEC) entre eles estão: Escola Técnica Aberta do Brasil, Programa Nacional de Acesso ao Ensino Técnico e Emprego (Pronatec), Universidade Aberta do Brasil (UAB), Rede Nacional de Formação Continuada de Professores, Mídias na Educação, ProInfo, ProInfo Integrado e e-ProInfo. A Escola Técnica Aberta do Brasil e o Pronatec têm como objetivo expandir e democratizar a oferta de cursos de educação profissional técnica e tecnológica a distância. A UAB possui o papel aumentar o oferecimento de cursos voltados para a educação superior através da EAD, com foco na formação inicial e contínua de professores e profissionais de educação básica da rede pública, também tem um papel importante na redução da desigualdade na oferta de ensino superior e o desenvolvimento do sistema nacional de educação superior a distância (Martins \& Zerbini, 2014).

Segundo Santos (2006) a estruturação efetiva da modalidade EAD como política, amparada pela internet e pelas NTIC, contribui para democratização dos sistemas de ensino, isto permite que os alunos do país todo tenham acesso às instituições de ensino em cidades onde não possuem estas instituições. De acordo com Martins (2012) ainda existem deficiências sobre a normatização de parâmetros para a avaliação destes programas, o Ministério da Educação (MEC) tem se esforçado para definir princípios, diretrizes e critérios para acompanhar os cursos oferecidos na modalidade a distância. Pode-se afirmar que a EAD tem se firmado, no Brasil e no mundo, como modalidade de ensino, e as possibilidades de ampliação das estratégias de ensino uma ampla escala torna essa modalidade educacional um grade atrativo para as organizações (Abbad, Mourão, Zerbini \& Correia, 2015).

Em uma perspectiva mundial, Santos (2006) realiza uma comparação da realidade brasileira a várias universidades estrangeiras que utilizam a EAD há décadas: American World University, United Kingdom's Open University, Vancouver's Open Learning Agency, Norway's NKS e NKI Distance Education, o Brasil encontra-se atrasado no que se refere a esta modalidade de ensino. Segundo Martins (2012) em outros países não se discute mais sobre a mercantilização ou precarização do ensino EAD, no exterior está temática já foi superada. Segundo a autora é preciso desmistificar os preconceitos associados à EAD em contexto nacional, pois não há inferioridade presente nesta modalidade, mas sim, percepções sem comprovação científica, de que a educação on-line é inferior à presencial. 
Segundo o Censo EAD.BR (2017), as dez maiores instituições de ensino superior detêm $80 \%$ dos polos presenciais e $73 \%$ dos estudantes na modalidade a distância, sendo que a maior parte dessa concentração se deu por aquisição e não por crescimento orgânico institucional. Na prática, a regulação atual não ofereceu inovações e qualidade, mas uma grande concentração de alunos nos grandes grupos educacionais privados no Brasil. Esse cenário evidencia o problema da falta de uma regulação que permita mais mobilidade e celeridade aos órgãos reguladores. Dentro desse contexto, o $\mathrm{MEC}$, em suas várias administrações em um período de 12 anos, tem feito movimentos tais como a criação do Conselho Consultivo do Programa de Aperfeiçoamento dos Processos de Regulação e Supervisão da Educação Superior (CC-Pares), em 2008, e do Conselho Nacional de Educação (CNE), em 2012, entre outros. Embora as iniciativas citadas anteriormente tenham envolvido diversos segmentos da sociedade, isto incluir também ABED, elas não avançaram em termos efetivos de inovação da regulação. Em 2017, o MEC editou o Decreto n. 9.057 (Brasil, 2017), que estabelece uma nova base de estrutura regulatória para a oferta de EAD no país. Os representantes do MEC apontaram que mudanças no Decreton. 5.773/2006 e na Portaria n. 40/2007, principais regulações do setor, também sofrerão alterações no sentido de aumentar a flexibilidade regulatória. Apesar desses avanços, ainda temos muito a debater no âmbito regulatório nacional.

\subsection{Educação a Distância em Instituições de Ensino Superior}

A modalidade EAD tem sido uma alternativa viável para o processo de desenvolvimento educacional, pois atende uma demanda que vem crescendo devido às altas exigências do mercado de trabalho. Por consequência, há um aumento crescente de universidades e centros de formação que oferecem cursos à distância com recursos tecnológicos com o objetivo de fortalecer a informação ao aluno como a "virtualização" da sala de aula tradicional. Essas redes telemáticas oferecem recursos para caminhar junto ao aprendiz, com isso, cria-se uma abordagem de EAD que ressalta as interações e o trabalho colaborativo entre os participantes. A abordagem do estar junto virtual possibilita que o professor acompanhe e assessore os alunos constantemente (Prado \& Valente, 2002).Em seu estudo, Martins e Zerbini (2014) realizaram um panorama mundial indicando a presença de várias universidades que mostram o grande impacto no que se refere à introdução da educação a distância. Com sua fundação há mais de 30 anos, a Universidade Aberta do Reino Unido 
(Open University) foi uma pioneira da educação a distância e atendendo em torno de 200 mil alunos quando o estudo acima citado foi realizado. Na Índia, fica situada a maior universidade aberta do planeta, Universidade a Distância Indira Gandhi, que possuía em média 1,5 milhão de alunos (Bohadana \& Valle, 2009). Segundo as autoras, existem outras universidades a distância que possuem um corpo discente que supera o número de alunos das universidades totalmente presenciais e citam alguns exemplos: Fern Universität (Alemanha); Universidade Nacional de Educação a Distância (Espanha); Universidade do Ar (Japão); Universidade Aberta (Portugal); Télé-Université (Canadá); Universidade Nacional Aberta (Venezuela); Universidade Payame Noor (Irã); Universidade da África do Sul.

Já o panorama nacional os estudos mostram que as ofertas de cursos da modalidade EAD têm crescido nos últimos anos, segundo pesquisa realizada pelo portal E-learning Brasil (2003), os investimentos acumulados em educação a distância (e-learning) no Brasil chegaram a US\$ 80 milhões em 2002. O número representa um aumento de 33\% em relação a 2001. Foi observado um crescimento da oferta de EAD em instituições privadas entre 2011 e 2015, representando um adicional de 51\%. Contudo, quando comparados o número de estudantes atendidos pelo sistema público e pelo sistema privado, as proporções ficam muito diferentes. Com base nos dados do INEP (Instituto Nacional de Estudos e Pesquisas Educacionais Anísio Teixeira, 2015), verificou-se que as instituições públicas respondem por 9\% das matrículas totais, enquanto que $91 \%$ dos estudantes estão matriculados em instituições privadas. A discussão sobre a expansão da EAD no Brasil apresenta, de fato, contradições importantes sobre a qualidade do ensino superior, denotando algumas das estratégias do poder público para o incremento dos índices de acesso a esse nível de ensino. Se há, por um lado, programas de financiamento que canalizam recursos da esfera pública para a esfera privada, como o Programa Universidade Para Todos (PROUNI), a EAD é claramente tomada como modalidade de ensino para aceleração rápida da expansão de vagas no ensino superior (Alonso, 2010).

Segundo o Censo EAD BR (2017), sobre os índices de crescimento entre instituições públicas e privadas que ofertam EAD, observa-se uma predominância de instituições privadas. Identificaram entre os anos 2014 e 2016 o envolvimento de uma média de $65 \%$ de instituições privadas e $35 \%$ de instituições públicas, sendo que as públicas têm aumentado sua participação no censo. Já a proporção de instituições públicas e privadas segundo o censo do INEP (Instituto Nacional de Estudos e Pesquisas Educacionais Anísio Teixeira, 2015), é de $44 \%$ e $56 \%$, respectivamente. 
As discussões sobre a EAD no ensino superior, vão além de suas características e singularidades, mas vêm acompanhadas muitas vezes, do que seriam possibilidades e limites de seu uso. É frequente questionar quais especialidades ou campos da formação poderiam se prestar, mais ou menos, à sua organização. Vemos surgir assim "feudos", em que se convenciona trabalhar, ou não, com a EAD, isso como forma/modo de se conservar a qualidade na formação. E o termo qualidade se converte no critério para afirmar ou negar a EAD como possibilidade educativa (Alonso, 2010).

Sobre os desafios enfrentados pelas universidades que têm se lançado na EAD, podese citar a busca por uma linguagem pedagógica apropriada à aprendizagem mediada pelas diversas mídias disponíveis. O controle e o acompanhamento permanente pela coordenação geral do curso do trabalho de professores, dos tutores, dos estagiários de atendimento e da secretaria, são igualmente cruciais, pois a interação com o aluno pode se dar de inúmeras formas e todas elas são essenciais ao sucesso da aprendizagem. A estruturação de uma equipe especializada, composta de pessoas que entendam de tecnologia e de pedagogia e, que trabalhem de forma lógica, podem garantir o melhor desenvolvimento da aprendizagem do aluno. Podem contar com o uso intensivo dos meios técnicos e tecnológicos na preparação dos materiais didáticos distribuídos para grandes quantidades de alunos espalhados por todo o território nacional. Aplicam técnicas de produção e distribuição de materiais em escala industrial, buscam otimizar os recursos humanos, físicos, financeiros e tecnológicos de que dispõem (Mugnol, 2009).

Em seu estudo Martins e Zerbini (2014) realizaram uma análise de resumos e artigos completos mostrando que os temas sobre EAD têm sido estudados ao redor do mundo, com pesquisas presentes em vários países, como Estados Unidos, Reino Unido, Espanha, China, Austrália, Canadá, Irã, Malásia, Hong Kong, Japão, África do Sul, entre outros. Os estudos que relatam as experiências da EAD em diferentes países mostram que se trata de um tema recente, pois as discussões emergem simultaneamente ao andamento dos cursos existentes.

Em seu estudo sobre a inclusão no contexto da educação a distância e virtual na Colômbia, Salazar e Melo (2013), afirmam que essa modalidade educacional, por si só, já promove a inclusão social e a mobilidade, pois permite que todos os alunos tenham acesso a serviços educacionais de qualidade e completem sua formação profissional. Para que o projeto final e implementar estratégias de ensino e aprendizagem que respondem a formação em diversidade, com base em metodologias de aprendizagem e autoconhecimento autônomas, no âmbito das relações pedagógicas assíncronas e assíncronas entre alunos, professores e instituição. Nessas relações, predomina o uso de tecnologias de informação e comunicação; 
de recursos, mídia e mediações técnicas e tecnológicas que nos permitem romper barreiras espaço-temporais, idade, condições políticas, sociais, de gênero e incapacidades, entre outras, onde o trabalho complementa perfeitamente o processo de formação cotidiana. Instituições que oferecem programas a distância executam exercícios indispensáveis inerentes à sua razão de ser e responsabilidade social.

No tocante dos estudos sobre ensino a distância, pode-se observar que cresce cada a cada dia a demanda por estes cursos, acompanhada pela oferta, diante deste cenário o tema tem sido estudado em diversos países, porém ainda existem lacunas a serem preenchidas que podem favorecer a aprendizagem dos discentes, bem como reduzir os números de evasão.

\subsection{Evasão na EAD}

Mesmo com todos os fatores que contribuem para as formas de aprendizagem nos cursos EAD, há um número considerável de evasão nos cursos ofertados a distância. O MEC define a evasão como a saída definitiva do curso inicial sem a sua conclusão, ou a diferença entre ingressantes e concluintes, após uma geração completa. Uma geração completa, se refere a ideia de que o tempo entre ingresso e conclusão é definido como o prazo máximo de conclusão do curso (Fritsch; Rocha \& Vitelli, 2015).

A evasão é um problema antigo no cenário educacional brasileiro e internacional (Amidani, 2004). A literatura nacional e estrangeira aponta estudos desenvolvidos no campo da EAD voltados à investigação dos altos índices de abandono em contextos de ensino superior e suas possíveis causas (Henke \& Hussum, 2000; Walter, 2006). Todavia, as lacunas observadas no que se refere à investigação da evasão em contextos educacionais a distância ainda são grandes e preocupantes, por isso a realização de estudos que abordem a problemática se faz necessário(Abbad et al., 2006; Brauer, 2005).

Segundo Meneses, Zerbini e Abbad (2010) cursos de longa duração aplicados a adultos, que trabalham e possuem um tempo escasso para se dedicarem ao estudo, quando disponibilizados a distância, requerem o uso de diversas atividades, de entrega dos materiais e supervisão por tutores para evitar que a evasão de alunos não seja alta. Algumas universidades abertas costumam oferecer cursos de graduação a distância por meio de material impresso e apoio de professores ou tutores de ensino. Uma outra alternativa foi criar mecanismos de contato entre os alunos de modo a otimizar sua interação. Mesmo com todas estas ações, essas 
universidades contabilizam índices de 20 a 30\% de desistência. Muitos fatores externos ao curso determinam esses índices de evasão, entre os quais a falta de apoio familiar, dificuldade de conciliar trabalho, família e estudos, e, ainda, problemas pessoais como morte, adoecimento e/ou perda de familiares.

No mundo todo, são mencionados altos índices de evasão, em média 40 e 50\%, considerar a rotina diária do participante, anteriormente à seleção da modalidade de ensino, torna-se imprescindível, principalmente nos casos de programas realizados totalmente a distância. Segundo Silva Filho et al. (2007), a evasão pode ser calculada através de dois aspectos, sendo eles a evasão anual média onde a quantidade de alunos matriculados em um ano é comparada com a quantidade de alunos matriculados do ano anterior e a evasão total: compara a quantidade de alunos ingressantes e que não obtiveram o diploma ao final do período de integralização do curso.

Biazus (2014) cita os fatores relacionados ao perfil do aluno, define seus fatores exógenos (externos) e endógenos (internos) que influenciam no fenômeno da evasão, as definições foram atualizadas por Bittencourt e Mercado (2014) para o contexto a distância.

Tabela 1. Causas endógenas da evasão (Biazus, 2004, Bittencout e Mercado2014)

\begin{tabular}{|c|c|}
\hline \multicolumn{2}{|c|}{ Atitude comportamental } \\
\hline Didática dos professores & \multirow{5}{*}{$\begin{array}{l}\text { Parte do princípio que o aluno a distância é } \\
\text { diferente do presencial e o contato e a } \\
\text { didática dos professores e tutores tem que } \\
\text { ser voltada e focada no aluno. }\end{array}$} \\
\hline Orientação da Coordenação do curso & \\
\hline Motivação e incentivo por parte do tutor & \\
\hline Insatisfação com o tutor & \\
\hline Contato com professores & \\
\hline \multicolumn{2}{|c|}{ Motivos institucionais } \\
\hline Ausência de tutores nos polos & \multirow{7}{*}{$\begin{array}{l}\text { Proporciona ao aluno condições para o } \\
\text { estudo. Com uma estrutura para que o aluno } \\
\text { possa ter acesso a bibliotecas, laboratórios. }\end{array}$} \\
\hline Acesso a bibliotecas & \\
\hline Estrutura dos polos de ensino & \\
\hline Laboratório de informática nos polos de ensino & \\
\hline Interatividade no AVA & \\
\hline Meios de comunicação oferecidos para contato & \\
\hline Tecnologia inadequada utilizada & \\
\hline
\end{tabular}

Tabela 1. Continuação.

\begin{tabular}{|l|l|}
\hline \multicolumn{2}{|c|}{ Requisitos didático-pedagógicos } \\
\hline Carga horária curricular do curso & \\
\cline { 1 - 1 } Relação do Currículo com o mercado & \\
\hline Critérios de avaliação do aluno & \\
\hline
\end{tabular}




\begin{tabular}{|l|l|}
\hline Associação entre a teoria e a prática & Estimula a cooperação e relação entre os \\
aluos do curso, estimulando uma criação \\
Relação entre conteúdos das disciplinas \\
colaborativa que dê subsídios para a \\
Encontros presenciais & $\begin{array}{l}\text { latizagem dos alunos. Deve possibilitar } \\
\text { feedback ao aluno imediato de suas } \\
\text { atividades e ações no curso. Com o devido } \\
\text { retorno os tutores e professores podem } \\
\text { identificar as possíveis causas de erros nas } \\
\text { atividades. }\end{array}$ \\
\hline Complexidade das atividades & \\
\hline Reprovação em mais de duas disciplinas no Semestre & \\
\hline Prazos de entrega das atividades & \\
\hline Avaliação dos exercícios & \\
\hline Material didático oferecido & \\
\hline Falha de elaboração do curso & \\
\hline
\end{tabular}

Tabela 2. Causas exógenas da evasão (Biazus, 2004, Bittencout e Mercado2014)

\begin{tabular}{|c|c|}
\hline \multicolumn{2}{|c|}{ Sócio-político-econômicos } \\
\hline Apoio da instituição que trabalha & \multirow{8}{*}{$\begin{array}{l}\text { Relacionadas às condições sócio- } \\
\text { político-econômicas do aluno. }\end{array}$} \\
\hline Valorização do diploma no mercado & \\
\hline Tempo para estudar & \\
\hline Carga horária semanal de trabalho & \\
\hline Deslocamento até polo de ensino & \\
\hline Dificuldades de acesso à Internet & \\
\hline Entendimento das matérias & \\
\hline Adequação do conteúdo com o trabalho & \\
\hline \multicolumn{2}{|c|}{ Vocação Pessoal } \\
\hline Aptidão para a profissão & \multirow{6}{*}{$\begin{array}{l}\text { Relacionadas ao aluno diretamente, } \\
\text { ou seja, aptidão para o curso e } \\
\text { profissão que escolheu, interesses } \\
\text { pessoais e prévios do curso. }\end{array}$} \\
\hline Possuir outro curso superior & \\
\hline Adaptação ao sistema universitário & \\
\hline Mudança de interesse pessoal ou profissional & \\
\hline Estar cursando paralelamente outro curso & \\
\hline $\begin{array}{l}\text { Desconhecimento prévio a respeito do cur } \\
\text { Administração a distância }\end{array}$ & \\
\hline \multicolumn{2}{|c|}{ Características Individuais } \\
\hline Problemas de saúde & \multirow{4}{*}{$\begin{array}{l}\text { Relacionada a características que } \\
\text { vão além da condição do aluno em } \\
\text { continuar o curso. }\end{array}$} \\
\hline Atendimento do curso às expectativas prévias & \\
\hline Dificuldade de assimilação da cultura de EaD & \\
\hline Falta de habilidade para usar as TIC & \\
\hline \multicolumn{2}{|c|}{ Conjunturais } \\
\hline Problemas financeiros & \multirow{5}{*}{$\begin{array}{l}\text { Assim como as características } \\
\text { individuais, essas vão além da } \\
\text { condição do aluno. Como } \\
\text { problemas familiares e financeiros, } \\
\text { o que mais afeta. }\end{array}$} \\
\hline Influência familiar & \\
\hline Mudança de residência ou cidade & \\
\hline Mudança de estado civil & \\
\hline Responsabilidade econômica no sustento da Família & \\
\hline
\end{tabular}

O estudo de Xenos et al. (2002) apontou a relação da evasão com o domínio dos recursos tecnológicos, e também às características do aluno como, idade e gênero. Da mesma 
forma, Abbad, Carvalho e Zerbini (2006) demonstram que os alunos que menos participaram das interações no ambiente virtual são os que mais evadiram. Wang, Four-Szocki, Griffin, O’Conn e Sceiford (2003) afirmam que a incompatibilidade dos Estilos de Aprendizagem com o desenho do curso pode ser uma causa da evasão em EAD.

Além das causas citadas acima, referentes às características pessoais do aluno, os estudos encontrados apontam como causa da evasão a falta de tempo do aluno. É importante relembrar, que segundo Abbad (2007), o aluno de EAD geralmente é ativo profissionalmente, restando pouco tempo para se dedicar aos estudos. O professor e/ou tutor também recebe destaque nos achados da literatura. A evasão aparece relacionada com o relacionamento com o professor e/ou tutor e os alunos. Destacam-se também problemas em sua atuação, além da dificuldade de entrar em contato.

Em seus estudos, Zerbini $(2003,2007)$ propõe a investigação do relacionamento de características de cunho individual do estudante com os níveis de reação, aprendizagem e impacto de treinamento. De acordo com a pesquisadora, estas variáveis contribuem para a compreensão da evasão e da persistência em treinamento a distância.

Cookson (1990) observa que as intervenções que as instituições podem fazer para minimizar os efeitos da evasão de seus cursos podem ser de dois tipos: reativas e proativas. As primeiras dizem respeito à tentativa de compensar certas limitações do método de ensino a distância em si. A segunda se refere à construção de características metodológicas que vão ao encontro de estilos individuais e às circunstâncias devida do aluno a distância para que este se acomode ao máximo ao método oferecido.

Percebe-se uma grande necessidade e uma área muito ampla de investigação sobre a temática da evasão em ações educacionais ofertadas à distância. Mesmo havendo pesquisas importantes sobre a importância do perfil do aluno, do ambiente de estudo e do próprio curso como variáveis influentes nesse processo, o número de investigações ainda não é suficiente para compreender a fundo a problemática da evasão. Nas pesquisas são feitos apontamentos sobre a preocupação em relação aos instrumentos com o papel de mensurar e identificar os elementos preditores da Evasão em EAD. Além de serem necessárias pesquisas voltadas para uma melhor adaptação e validação desses instrumentos, existe uma necessidade de construção de novos instrumentos para medir outros fatores até então não investigados de forma focal (Moraes, 2016).

Segundo as pesquisas que fazem referência aos índices de evasão na $\mathrm{EaD}$ da AbraEAD (2007; 2008) e CensoEaD.BR (2010), os primeiros anos de curso do aluno são primordiais para sua permanência na instituição, visto que o aluno ainda não está 
familiarizado com o ambiente universitário, com os colegas de sala, com a metodologia do curso e ainda não familiarizar-se com o curso e/ou não foi o que escolheu efetivamente.

A evasão de alunos na EAD tem sido abordada como um dos problemas que está muito presente em todas as instituições educacionais e em todos os níveis de ensino. São vários os motivos pelos quais levam as instituições, sejam elas públicas ou privadas, a ter uma maior preocupação com o problema da evasão na EAD. De acordo com Motejunas et al. (2007), os problemas de cursos na EAD são: para o setor público, os recursos investidos sem o devido retorno; para o setor privado, importante perda de receita; para ambos os setores, fonte de ociosidade de professores, funcionários, equipamentos e, em algumas situações, espaço físico.

Em uma revisão dos estudos da área, Walter (2006), encontrou resultados de vários estudos que indicavam ser elevada a taxa de evasão em cursos a distância. Entre esses estudos, Coelho (2003) investigou as causas da evasão e os fatores que contribuíram para a permanência de participantes em um curso de formação continuada ofertado para 55 docentes de uma instituição federal. A pesquisa contabilizou um índice de evasão de aproximadamente $50 \%$ e identificou, como motivos, os seguintes aspectos: falta de tempo; falta de condições de estudo em casa e no local de trabalho; falta de organização pessoal; problemas com a tecnologia; e falta de atendimento às expectativas pessoais.

A EAD representa uma mudança na cultura dos professores e estudantes, que têm como comparação o modelo pedagógico do curso presencial, que é caracterizado pela presença física de professores e estudantes num mesmo tempo e espaço. Ainda é preciso considerar as diferenças sociais e culturais dos estudantes, uma vez que a EAD com o uso de meios de comunicação de massa, atinge um público de regiões diferentes dentro de um mesmo país e também de países diferentes. Isto provoca insegurança tanto nos professores quanto nos alunos e, portanto, exige novos comportamentos de ensino e aprendizagem. Tais hesitações, por vezes, resultam em altas taxas de evasão nessa modalidade educacional (Mugnol, 2009).

Novas pesquisas poderiam incluir as características motivacionais (valor instrumental do curso para o participante), segundo Lacerda e Abbad (2003) em avaliação de cursos presenciais e características cognitivas (estratégias, estilos e hábitos de estudo) dos alunos, segundo Zerbini e Abbad (2008) em seus modelos de: diagnóstico de necessidades de treinamento, de avaliação de treinamento e em modelos de investigação de evasão em cursos a distância mediados pelas TIC. 
A problemática da evasão ainda apresenta sérias deficiências em relação aos estudos desenvolvidos. Há um consenso entre vários autores de que a evasão é um fenômeno multidimensional e que ainda precisa muito explorado (Almeida, 2007; Parker, 2003; Santos et al., 2008; Sales, Abbad, \& Rodrigues, 2011; Walter, 2006).

Umekawa (2014) afirma que existe uma produção limitada de estudos relacionados à investigação da efetividade de ações educacionais a distância. Existe uma urgente necessidade de aprimoramento da modalidade relacionada ao desenvolvimento dos tutores, há necessidade de adaptação ao ambiente de estudo dos alunos, empregar adequadamente as novas ferramentas disponíveis, adaptar os estilos de aprendizagem e hábitos de estudo do aluno, possivelmente há uma relação entre estes dados e os elevados índices de evasão e que se tornam barreiras em relação ao retorno dos investimentos da modalidade de ensino. Entre as características do aluno que influenciam o abandono de cursos em EaD aponta-se a falta de habilidades do estudante de utilizar as ferramentas eletrônicas disponibilizadas, dificuldade de organizar o tempo de estudo e a autodisciplina (Deimann \& Bastiaens, 2010; Romero \& Barberá, 2011). A autora Umekawa e Zerbini (2015) afirmam que apesar dos esforços em identificar as variáveis ligadas à problemática da evasão, o campo da educação a distância sofre com a perda significativa de sua clientela. Os elementos ligados diretamente ao desenho instrucional, como os procedimentos adotados pelas IES, também são apontados como fatores que contribuem para a desistência dos estudantes (Umekawa, 2014; Umekawa \& Zerbini, 2018).

Em seu estudo Costa e Santos (2017) destacam a relevância de compreender que a evasão não é um problema com uma causa única. Não só de metodologia, ou somente de atendimento, ou por problemas financeiros ou das características do aluno. Mas é resultado de diversas questões que juntas convencem o aluno de que a melhor opção é desistir do curso.

Com a revisão da literatura, pode-se concluir que mesmo com todos os estudos relacionados à evasão de cursos ofertados a distância, ainda é uma problemática que necessita de ser explorada, na busca pela melhor compreensão deste fenômeno. O estudo 2 da presente pesquisa objetiva abordar especificamente as barreiras influenciadoras da evasão em cursos de pós-graduação à distância. 


\section{CAPÍtUlo 3. ANÁlise dA LITERATURA: DESCRIÇÃO E RESULTADOS DE PESQUISA}

\section{Objetivo do capítulo 3}

Este capítulo tem como objetivo descrever o percurso da revisão de literatura sobre as variáveis de interesse do estudo. Além disso, são expostos os conceitos, características e resultados advindos de tal processo sistemático e que se ocupam das variáveis foco do estudo ora em questão, a saber: Características da Clientela, Estratégias de Aprendizagem, Barreiras em EAD (Variável Critério).

\subsection{Revisão de literatura: descrição de percurso}

A presente seção trata do levantamento bibliográfico efetuado nas bases de dados tidas como relevantes em revisões de TD\&E. A seção perpassa pelos objetos de pesquisa, panoramas e abordagens verificados nas investigações realizadas sobre as barreiras na Educação Superior à Distância em âmbito nacional e internacional.

\subsection{Componentes do modelo de investigação: resultados de pesquisa}

Nesta seção são descritos e discutidos conceitos, características e resultados de pesquisas relacionadas às variáveis de interesse deste estudo. Esta busca partiu da revisão de resultados de pesquisa entre o período de 2006 a 2018 e da análise das revisões de literatura realizadas recentemente. A escolha da busca pelos estudos neste período, se deve ao fato de obter um panorama dos últimos doze anos das variáveis estudadas. A Tabela 3 apresenta, resumidamente, as etapas para o posicionamento das variáveis Características da Clientela, Estratégias de Aprendizagem, Barreiras em EAD (Variável Critério). 
Tabela 3. Etapas da revisão da literatura sobre as variáveis de interesse do presente estudo

\begin{tabular}{|c|c|}
\hline Estratégias de aprendizagem & $\begin{array}{l}\text { - Revisão dos resultados de pesquisa dos últimos dez anos; } \\
\text { - Análise da revisão de literatura realizada por Martins } \\
\text { (2016). }\end{array}$ \\
\hline Característica da Clientela & $\begin{array}{l}\text { - Levantamento bibliográfico de pesquisas sobre a temática de } \\
\text { interesse (dados sociodemográficos e uso de ferramentas } \\
\text { eletrônicas), dos últimos doze anos. }\end{array}$ \\
\hline Barreiras em EAD (Variável Critério) & - Revisão dos resultados de pesquisa dos últimos doze anos; \\
\hline
\end{tabular}

Para organização dos resultados de pesquisa, foram realizadas revisões bibliográficas em bases de dados eletrônicos, que abarcou o período de 2006 a 2018, a partir da estrutura de percurso de revisão desenvolvida por Martins (2012).

Foi realizada uma análise de produções científicas nacionais e estrangeiras disponíveis na biblioteca eletrônica SciELO, Google Acadêmico, nas bases de dados Web Of Sciences, nas bases de dados ProQuest, além dos bancos de dissertações e teses da Universidade de Brasília (UnB) e da Universidade de São Paulo (USP). Os resultados do levantamento realizado nas bases de dados serão apresentados na Tabela 4.

Tabela 4. Resultados Quantitativos da Revisão de Literatura

\begin{tabular}{lcc}
\hline \multicolumn{1}{c}{ Bases de Dados } & Resumos & Selecionados \\
\hline SciELO & Levantados & 119 \\
Google Scholar & 704 & 99 \\
Web of Science & 741 & 18 \\
ProQuest & 1991 & 15 \\
Banco de dissertações e teses & 1801 & 10 \\
USP* & 195 & 21 \\
Banco de dissertações e teses & 330 & 282 \\
UnB** & 5762 & \\
\hline \multicolumn{2}{c}{ Total: } & \\
*USP: Ciências Humanas - Educação, Filosofia e Língua Portuguesa, Administração, Interfaces Sociais da \\
Comunicação e Psicologia. \\
*UnB: Departamento de Psicologia Social, do Trabalho e das Organizações. \\
Este processo teve como objetivo buscar informações com validação científica sobre o
\end{tabular}


Em seguida apresenta-se o percurso do levantamento de pesquisas científicas realizadas na revisão bibliográfica, resultados é exposto o quadro com os estudos encontrados e seus resultados. O passo inicial do processo foi a definição do tema de principal relevância deste trabalho e determinação das as palavras-chave. As palavras-chave trabalhadas foram: Educação a Distância, Treinamento e Educação, Políticas Públicas de Educação a Distância, Avaliação de Cursos a Distância de IES, Distancelearning. E-learning, Efectiveness Teaching, Evaluation Instrument, foi realizado o cruzamento destes termos com os seguintes: Estratégias de Aprendizagem, Dados Sociodemográficos, Barreiras em EAD, Evasão, Dropout. Para que a busca fosse realizada, utilizou-se palavras nos idiomas português e inglês.

A SciELO - Scientific Eletronic Library Online define-se como uma biblioteca eletrônica de periódicos brasileiros, com pesquisas publicadas em diversos países como: Brasil, Chile, Cuba, Espanha, Portugal e Venezuela. A partir do tema central da pesquisa foram escolhidas as palavras chaves do estudo e na sequência foi realizado o levantamento bibliográfico. Muitas palavras conduziram a estudos que não eram do contexto deste estudo, por isso foram selecionados 119. As buscas foram realizadas no mês de dezembro de 2016 até Dezembro/2018.

O Google Scholar — Google Acadêmico é um instrumento de pesquisa do Google, ele possibilita a realização de pesquisas de trabalhos acadêmicos de literatura escolar, como, jornais de universidades e artigos diversos. Oferece buscas em língua Portuguesa em 10 de janeiro de 2006. Para a realização das buscas o Google Acadêmico classifica os resultados por ordem de relevância, seguindo os seguintes critérios: a íntegra de cada artigo e seu autor, local onde foi publicado e a frequência de suas citações na literatura acadêmica. A partir do tema central da pesquisa foram escolhidas as palavras chaves do estudo e na sequência foi realizado o levantamento bibliográfico. Muitas palavras conduziram a estudos que não eram do contexto deste estudo, por isso foram selecionados 99. As buscas foram realizadas no mês de dezembro de 2016 até Dezembro/2018.

A Web of Science é definida como uma base de dados de trabalhos das áreas de Ciências, Humanidades, Ciências Sociais e Artes. Nele encontram-se resumos presentes nas revistas ou jornais, das áreas da Saúde, Educação, Educação e Tecnologia e Sociais. A partir do tema central da pesquisa foram escolhidas as palavras chaves do estudo e na sequência foi realizado o levantamento bibliográfico. Muitas palavras conduziram a estudos que não eram do contexto deste estudo, por isso foram selecionados 18 . As buscas foram realizadas no mês de dezembro de 2016 até Dezembro/2018. 
Foram escolhidos para as buscas deste estudo os bancos de dissertações e teses das universidades de São Paulo (USP) e Universidade de Brasília (UnB) devido ao grande volume de publicações através deles e também por serem referência na área de pesquisa, mais em especial na área de Psicologia Organizacional do Trabalho. Na base de dados da USP foram encontrados 195 estudos no período de 2006 a 2018, sendo selecionados 10 resumos. No banco de dados da Universidade de Brasília UnB, foi pesquisado o banco de dissertações e teses do Departamento de Psicologia Social do Trabalho e das Organizações, resultando em 330 defesas do período de 2006 a 2018, sendo selecionados 21 resumos.

O levantamento realizado na biblioteca eletrônica SciELO, Google Acadêmico, nas bases de dados Web Of Science, e nos bancos de dissertações e teses da Universidade de Brasília - UnB e da Universidade de São Paulo - USP apontaram para um total de 5762 estudos científicos nacionais e estrangeiros, sendo selecionados 282 resumos sobre o tema estudado tendo como base os tipos de publicação (empírica, revisão teórica, histórica, relato de experiências), as metodologias, tendências e lacunas.

$\mathrm{Na}$ análise dos estudos selecionados foi encontrado um número amplo de estudos sobre treinamento, desenvolvimento e educação, porém apontou para um número escasso de estudos sobre a avalição de treinamentos presenciais e a distância. Sobre o tema educação a distância a foram encontrados diversos estudos sobre a sua definição, e as formas de avaliação em cursos superiores a distância, porém apontou para um número escasso de estudos sobre as políticas públicas nesta mesma modalidade. Foi encontrado um número escasso de estudos que abordem as características da clientela e estratégias de aprendizagem adotadas pelos alunos. Quando se refere aos estudos sobre a variável critério barreiras, foram encontrados poucos estudos, abordando as possíveis causas da evasão, relacionamento do aluno com a ferramenta na web, interação com o tutor.

Através do levantamento dos resumos foi possível identificar os principais resultados dos estudos das variáveis presentes neste estudo, também foram encontradas as principais lacunas a serem supridas através de estudos na área. A análise dos resumos de estudos encontrados sobre o variável critério Barreiras aponta para a necessidade de ampliar as pesquisas no contexto da educação à distância. Alguns pontos levantados foram relacionados na Tabela 5, a seguir. 
Tabela 5. Resultados qualitativos da busca

\begin{tabular}{|c|c|c|}
\hline Variável & Palavras-chave & Resultados da Busca \\
\hline Barreiras & $\begin{array}{l}\text { Educação a Distância, Distance Learning, } \\
\text { Treinamento, Desenvolvimento e Educação, } \\
\text { Learning, Efectiveness, Teaching, Evaluation } \\
\text { Instrument, Políticas Públicas de Educação a } \\
\text { Distância, Avaliação de Cursos a Distância de } \\
\text { IES, Estratégias de Aprendizagem, Dados } \\
\text { sociodemográficos, uso de ferramentas da } \\
\text { Web, Barreiras em EAD, Barriers, Evasão e } \\
\text { Dropout. }\end{array}$ & $\begin{array}{l}\text { - Poucas pesquisas que avaliam os } \\
\text { cursos a distância e os índices de evasão. } \\
\text {-Necessários mais estudos sobre as } \\
\text { barreiras em educação a distância. } \\
\text {-Necessidade de ampliar as pesquisas } \\
\text { sobre as estratégias de aprendizagem } \\
\text { adotadas pelos alunos de EAD. } \\
\text { - Poucos estudos abordando as } \\
\text { características da clientela de EAD. } \\
\text {-Poucos estudos abordando as políticas } \\
\text { públicas em EAD. }\end{array}$ \\
\hline
\end{tabular}

A revisão da literatura encontrou, sobre a variável critério barreiras em EAD, conforme a Tabela 4, o total de 512 artigos. Dentre eles foram selecionados os artigos das áreas de Psicologia e Educação, resultando em 127 artigos. Os estudos analisados abordavam a barreiras em educação a distância, foram utilizados 13 estudos. Foram analisadas produções científicas nacionais e internacionais abrangendo o período de 2006 a 2018. A Tabela 6 apresenta os resultados do controle busca realizado em torno do nível Barreiras.

Tabela 6. Resultados do controle de busca sobre Barreiras

\begin{tabular}{|c|c|c|c|}
\hline \multirow[t]{2}{*}{ Palavras-chave } & \multicolumn{3}{|c|}{ Número de artigos } \\
\hline & Encontrados & Selecionados & Lidos \\
\hline \multicolumn{4}{|l|}{ SciELO } \\
\hline $\begin{array}{l}\text { Barreiras and Educação a Distância } \\
\text { Barreiras and Treinamento, Desenvolvimento e }\end{array}$ & 36 & 7 & 1 \\
\hline $\begin{array}{l}\text { Educação } \\
\text { Evasão and Barreiras }\end{array}$ & 25 & 12 & 1 \\
\hline Barreiras em EAD & 17 & 9 & 1 \\
\hline \multicolumn{4}{|l|}{ Google Scholar } \\
\hline $\begin{array}{l}\text { Barreiras and Educação a Distância } \\
\text { Barreiras and Treinamento, Desenvolvimento e }\end{array}$ & 37 & 15 & 1 \\
\hline $\begin{array}{l}\text { Educação } \\
\text { Evasão and Barreiras }\end{array}$ & 53 & 9 & 0 \\
\hline Barreiras em EAD & 11 & 7 & 1 \\
\hline \multicolumn{4}{|l|}{ Web of Science } \\
\hline Barriers and Distancelearning & 15 & 3 & 1 \\
\hline $\begin{array}{l}\text { Barriers and EfectivenessTeaching } \\
\text { Barriers and Dropout }\end{array}$ & 57 & 6 & 0 \\
\hline Barriers and EAD & 0 & 0 & 0 \\
\hline \multicolumn{4}{|l|}{ ProQuest } \\
\hline Barriers and Distancelearning & 48 & 6 & 0 \\
\hline $\begin{array}{l}\text { Barriers and EfectivenessTeaching } \\
\text { Barriers and Dropout }\end{array}$ & 39 & 13 & 0 \\
\hline $\begin{array}{l}\text { Barriers and EAD } \\
\text { USP }\end{array}$ & 6 & 2 & 1 \\
\hline
\end{tabular}




\begin{tabular}{lccc}
\hline & Palavras-chave & Número de artigos & \\
\hline & Encontrados & Selecionados & Lidos \\
\hline $\begin{array}{l}\text { Barreiras and Educação a Distância } \\
\text { Barreiras and Treinamento, Desenvolvimento e }\end{array}$ & 75 & 5 & 3 \\
$\begin{array}{l}\text { Educação } \\
\text { Evasão and Barreiras }\end{array}$ & 15 & 9 & 1 \\
Barreiras em EAD & 13 & 2 & 0 \\
UnB & & & \\
Evasão and Educação a Distância & 39 & 16 & 1 \\
Evasão and Treinamento, Desenvolvimento e Educação & 26 & 6 & 1 \\
Evasão and Barreiras & & 0 & 0 \\
Barreiras em EAD & 512 & 127 & 13 \\
\multicolumn{1}{c}{ Total: } &
\end{tabular}

\subsubsection{Características da clientela}

Segundo Abbad, Pilati e Pantoja (2003), as pesquisas sobre características individuais estudam os aspectos motivacionais, atitudinais e afetivos, de personalidade, demográficos e funcionais dos participantes e seus efeitos sobre resultados de treinamento. Segundo os autores, cada vez mais, estudos apontam para a crescente necessidade de descrever o perfil da clientela participante de cursos, tanto presenciais quanto a distância, buscando além de conhecer a fundo as características dessa clientela e também desenhar cursos cada vez mais personalizados e ajustados a essas características.

O componente Características da Clientela foi apresentado no modelo de referência na área de TD\&E, o modelo MAIS de (Borges-Andrade, 1982, 2006), ele é composto por elementos físicos e sociais, e também de aspectos comportamentais e cognitivos dos treinandos, antecedentes ao desenvolvimento do evento educacional, que podem sofrer interferência em seus resultados. Em sua contribuição, Abbad (1999) apresenta o modelo IMPACT de avaliação de treinamento, nele concentram um conjunto de informações demográficas, funcionais, motivacionais e atitudinais dos treinandos. Já Meneses et al. (2006) categorizou estas variáveis em cinco tipos:

1. Repertório de entrada: conhecimentos, habilidades, atitudes, expectativas e experiências adquiridas pelo aprendiz previamente ao início do evento instrucional;

2. Sociodemográficas: dados referentes ao sexo, idade, nível escolar, condição socioeconômica (perfil fisionômico da clientela) e à ocupação profissional, tempo de serviço, função, cargo, lotação (perfil profissional e funcional do participante) dos mesmos; 
3. Psicossociais: variáveis autorreferentes tais como: locus de controle (percepção dos indivíduos em relação à responsabilidade pelo êxito ou fracasso de suas ações), autoeficácia (crenças do indivíduo em suas capacidades pessoais para motivar-se e acionar recursos cognitivos e cursos de ação necessários ao sucesso das atividades em que se compromete), comprometimento (sentimento de apego a uma instituição de trabalho), prazer e sofrimento relacionados à atividade profissional desempenhada;

4. Motivacionais: motivação para aprender e para transferir o aprendido e valor instrumental do treinamento;

5. Cognitivo-comportamentais: estratégias cognitivas, comportamentais e autorregulatórias empregadas pelo estudante para aprender.

Ainda sobre a temática, de acordo Zerbini e Abbad (2010), as características individuais podem exercer uma interferência mais significativa nos resultados de ações educacionais a distância do que nos resultados de ações presenciais, isso ocorre devido à aprendizagem efetiva estar na EAD mais ligada ao empenho empreendido pelo próprio aluno (autogerenciamento da aprendizagem) do que aos recursos educacionais disponíveis, por isto estas estratégias podem se diferenciar significativamente das encontradas nas ações presenciais. Possivelmente, as estratégias EAD se diferem significativamente daquelas encontradas nas ações presenciais.

Segundo Guimarães (2012) há uma associação entre o aumento de matrículas na educação superior e a elevação do poder aquisitivo de grande parte da população, que saiu de uma situação desfavorável para outra, com o apoio da educação. Desta forma, “[...] há marcadamente um novo perfil socioeconômico dos estudantes brasileiros, que aprendem de maneira diferente e desafiam o elitismo que sempre marcou a educação superior" (Guimarães, 2012, p. 126).

Sobre o perfil do novo aluno Guimarães (2012) relaciona várias características que compõem este perfil: a realização da matrícula de forma tardia na educação superior; a dedicação parcial ou total ao trabalho; manter os estudos no período noturno; independência financeira ou colaborar de maneira expressiva com a renda familiar; a existência de esposos, filhos e parentes. Os conhecimentos desenvolvidos ao longo da educação básica são diferentes dos conhecimentos adquiridos no contexto universitário tradicional; são jovens adultos, adultos ou mais velhos e possuem objetivos claros como, a busca por melhores salários ou mudar de profissão (Guimarães, 2012).

O perfil dos estudantes de educação a distância é de adultos, geralmente com a idade entre 25 e 50 anos, trabalhadores, que buscam uma aprendizagem mais voltada para a prática, 
possuem experiências de vida e de trabalho, apreciam ter o controle sobre seus atos e entendem essa modalidade como uma rica possibilidade de estudos, que não tiveram quando eram mais jovens ( Peters, 2006; Dias; Moore; Kearsley, 2011). Os autores Moore e Kearsley (2011) citam os fatores subjetivos nas características dos alunos, onde destacam a ansiedade. A falta de habilidades com a modalidade a distância e o receio de não atender às expectativas pessoais e às do curso podem colaborar para desistências..

Costa, Franco e Souza (2016) ao se referir sobre as características dos alunos, afirmam que os estudantes possuem marcas profundas dos contextos sociais, econômicos e culturais, pois são nas suas experiências de escolarização que elas foram construídas, conservam-se vestígios dessas vivências em suas expectativas em presença do curso de graduação escolhido na modalidade a distância. Sobre estas expectativas, é possivel citar a proximidade com as práticas presenciais, a necessidade do mercado de trabalho e a busca pela facilidade de aprendizagem, pela flexibilização de cronogramas e datas a cumprir, seja pelo rigor no atendimento aos alunos. Analisando estas expectativas pode-se concluir que existe uma busca pelas características da modalidade presencial nas práticas a distância.

Segundo Zerbini (2007), o planejamento instrucional de cursos não presenciais pode ser beneficiado pelo estudo das estratégias de aprendizagem utilizadas pelos discentes e das características apresentadas por eles. Estudos resultados de investigações sobre o tema podem apurar o delineamento e a excelência destes programas de ensino. O aprimoramento de informações referentes à clientela permite identificar o perfil dos alunos frequentadores de programas de ensino diversos e conhecer quais tipos de estratégias eles adotam para atingir a aprendizagem, oferecendo elementos para aprimorar as modalidades educacionais de acordo com as suas características se necessidades pessoais. Desta forma, pode-se evitar a inadequada consideração de dados sobre a personalidade, o nível de inteligência e a motivação em cenários de organizações (Zerbini, 2007).

Em seu estudo sobre Estilos de Aprendizagem, Moraes e Zerbini (2018) afirmam que ampliação de projetos de educação a distância (EAD) e seus programas de treinamento, formação e qualificação profissionais ofertados por instituições de ensino superior (IES) e outras organizações, tornam necessário um maior número estudos sistemáticos nesse contexto, principalmente estudos relacionados às variáveis do perfil da clientela

Em seu estudo Pedroso, Maracci, Kunze e Rizo (2013), afirmam que é praticamente impossível a criação de um material educacional personalizado ao perfil de cada aluno, entretanto é possível diminuir o problema do "tamanho único" utilizando a hipermídia adaptativa na produção do mesmo. Um sistema hipermídia adaptativo utiliza informações 
sobre o aluno na produção das adaptações, sejam elas de conteúdo ou navegacionais. Estas informações podem ser colhidas de diversas formas, de questionários ao acompanhamento do progresso do aluno enquanto ele utiliza o material proposto.

Os autores A. Sousa e C. Sousa (2016) afirmam que questões individuais do perfil da clientela como resiliência e questões sociais como renda e trajetória escolar, são preditoras da permanência dos alunos, estas constatações implicam em soluções estruturais, mas impedem que as instituições desenvolvam ações de interação entre os cursos na modalidade a distância e presencial, ou realizem um planejamento de intervenções nos anos iniciais da graduação, criando mecanismos para a identificação das dificuldades de aprendizagem enfrentadas pelo aluno desde seu ingresso ao curso, devido ao alto índice de ocorrências de evasão nos primeiros períodos do curso. Segundo os autores Pedroso, Maracci, Kunze e Rizo (2013), não é suficiente apenas criar um curso, com toda infraestrutura física, de pessoas, materiais e com as mais modernas tecnologias, se não se consegue reter ou mesmo cativar a parte principal no processo que é o aluno, e que este efetivamente consiga exercer a sua capacidade plena de aprendizagem, portanto conhecer as características da clientela de cada curso torna-se de extrema importância.

\subsubsection{Estratégias de aprendizagem}

Segundo Mintzberg e Quinn (2001) o termo Estratégia pode ser definido como o plano que integra as principais metas, políticas e sequências para determinadas ações, também podem ser, em um primeiro momento, afirmações voltadas para orientar determinadas providências visando resultados. Para Henderson (1998) Estratégia pode ser entendida como busca determinada de um plano de ação para desenvolver ou ajustar vantagens sobre algo.

Fazendo referência às Estratégias de Aprendizagem, elas podem ser entendidas como sendo ações sistematizadas pelos aprendizes intentando cumprir determinadas tarefas e alcançar metas estabelecidas. Oferecendo contribuições ao processamento de novos conhecimentos, as Estratégias de Aprendizagem encontram-se relacionadas com a aprendizagem exitosa, segundo trabalhos da psicologia organizacional ou do campo educacional que focalizam as características próprias do estudante (Oliveira, Boruchovitch \& Santos, 2009; Souza, 2010; Warr \& Downing, 2000). De acordo com Sonnentag, Niesse e Ohly (2004), em âmbito organizacional as chamadas Estratégias de Aprendizagem corresponderiam às ações e medidas cognitivas efetuadas pelo sujeito visando a compreensão 
de determinado objeto. A Tabela 7 mostra a classificação e definições das estratégias de aprendizagem feitas por Warr e Allan, (1998); Zerbini e Abbad, (2008).

Tabela 7. Classificação e definições das estratégias de aprendizagem

- Repetição: repetição mental do conteúdo na forma em que este foi ministrado.

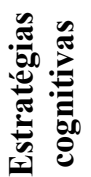

- Organização: reconhecimento de ideias centrais do material e formulação de esquemas mentais que agrupam e correlacionam elementos que foram aprendidos.

- Elaboração: reflexão sobre implicações e conexões possíveis entre o material aprendido e o conhecimento já dominado.

- Busca de ajuda interpessoal: obtenção de auxílio de outros indivíduos, como pares e professores, a fim de sanar dúvidas sobre o material (representa um comportamento

䓪 proativo do aprendiz de solicitar ajuda).

- Busca de ajuda no material didático: obtenção de informações em documentos escritos, manuais de instruções, programas de computador e outras fontes que não envolvam contato pessoal.

- Aplicação prática: aperfeiçoamento do conhecimento através da aplicação prática do que foi aprendido.

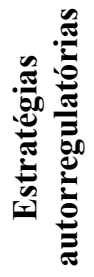

- Controle da emoção: controle da ansiedade e prevenção de dispersões de concentração, causadas por sentimentos de ansiedade.

- Controle da motivação: controle da motivação e da atenção, apesar de uma limitação de interesse envolvendo a tarefa a ser aprendida.

- Monitoramento da compreensão: avaliação do processo de aquisição de aprendizagem e alteração do comportamento do indivíduo, quando necessário.

Nota. Fonte: Warr \& Allan, 1998; Zerbini \& Abbad, 2008.

Para compreender de forma mais aprofundada as Estratégias de Aprendizagem, foi realizada uma revisão de literatura produzida por Martins (2016). A autora realizou um levantamento bibliográfico, que buscou apresentar instrumentos nacionais e internacionais construídos com o objetivo de mensurar Estratégias de Aprendizagem em contextos educacionais e resultados de pesquisa que objetivaram analisar o relacionamento entre variáveis. Na Tabela 8, seguem os principais achados da pesquisa de Martins (2016). 
Tabela 8. Pesquisas sobre Estratégias de Aprendizagem

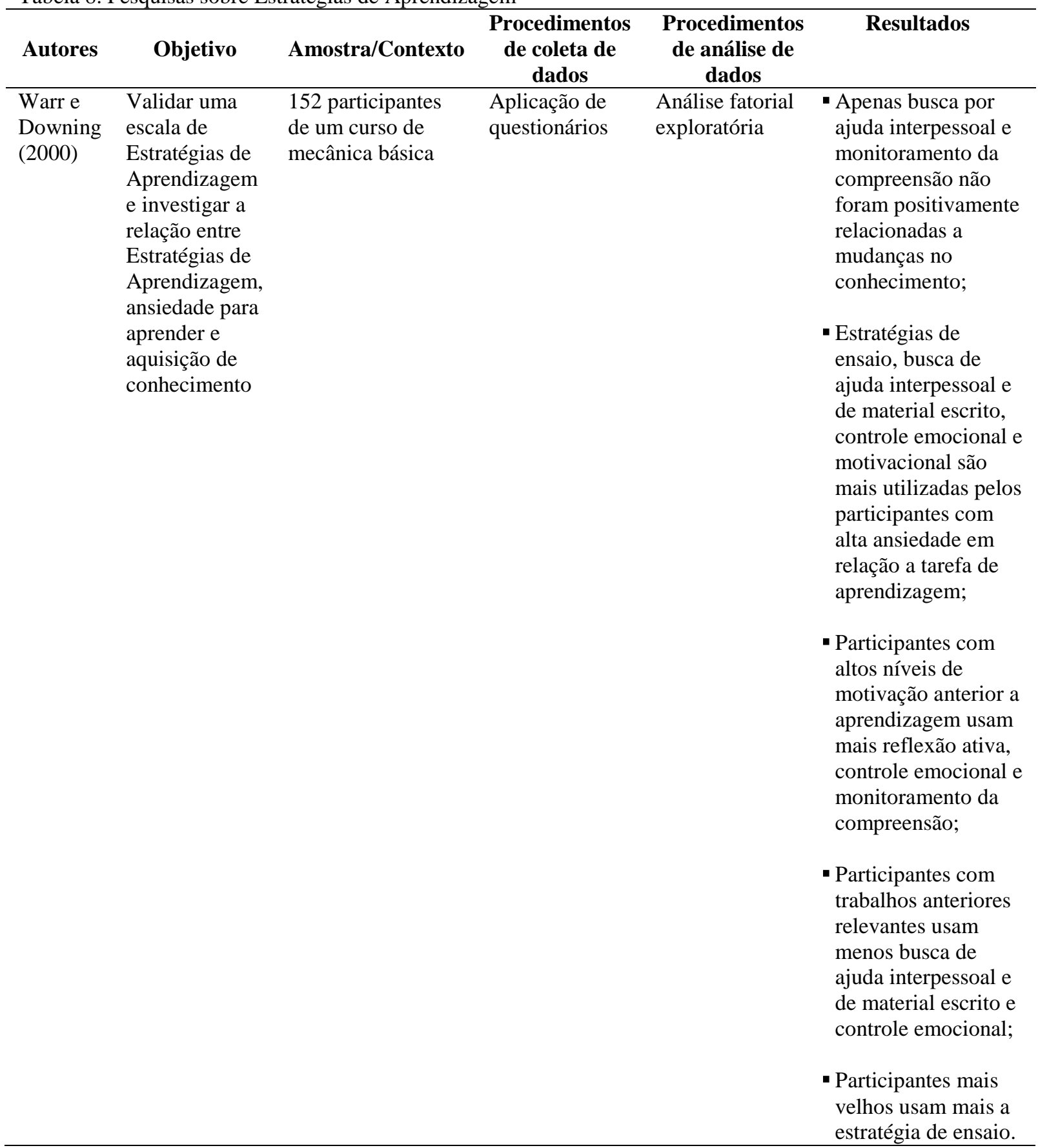


Tabela 8. Pesquisas sobre Estratégias de Aprendizagem (Continuação)

\begin{tabular}{|c|c|c|c|c|c|}
\hline Autores & Objetivo & Amostra/Contexto & $\begin{array}{c}\text { Procedimento } \\
\text { s de coleta de } \\
\text { dados }\end{array}$ & $\begin{array}{c}\text { Procedimento } \\
\text { s de análise de } \\
\text { dados }\end{array}$ & Resultados \\
\hline $\begin{array}{l}\text { Holman, } \\
\text { Epitropaki } \\
\text { e Fernie } \\
(2001)\end{array}$ & $\begin{array}{l}\text { Validar uma } \\
\text { escala de } \\
\text { Estratégias } \\
\text { de } \\
\text { Aprendizage } \\
\text { m, provinda } \\
\text { de ambiente } \\
\text { educacional, } \\
\text { em um } \\
\text { contexto } \\
\text { organizacion } \\
\text { al }\end{array}$ & $\begin{array}{l}628 \text { agentes de call } \\
\text { center de um banco } \\
\text { (Reino Unido) }\end{array}$ & $\begin{array}{l}\text { Aplicação de } \\
\text { questionários }\end{array}$ & $\begin{array}{l}\text { Análises } \\
\text { fatoriais } \\
\text { exploratórias e } \\
\text { confirmatórias }\end{array}$ & $\begin{array}{l}\text { - As Estratégias de } \\
\text { Aprendizagem } \\
\text { utilizadas por adultos } \\
\text { em contextos de } \\
\text { trabalho são similares } \\
\text { às usadas em } \\
\text { ambientes } \\
\text { educacionais. } \\
\text {-22 itens; } 6 \text { fatores } \\
\text { divididos em } 2 \text { tipos } \\
\text { de estratégias: } \\
\text { cognitivas } \\
\text { (reprodução, } \\
\text { organização e } \\
\text { elaboração) e } \\
\text { comportamentais } \\
\text { (busca de ajuda } \\
\text { interpessoal, busca de } \\
\text { ajuda ao material } \\
\text { didático e aplicação } \\
\text { prática) }\end{array}$ \\
\hline $\begin{array}{l}\text { Zerbini e } \\
\text { Abbad } \\
(2005)\end{array}$ & $\begin{array}{l}\text { Relacionar o } \\
\text { uso de } \\
\text { Estratégias de } \\
\text { Aprendizagem } \\
\text { às reações aos } \\
\text { procedimentos } \\
\text { instrucionais } \\
\text { de um curso } \\
\text { via internet e } \\
\text { reações ao } \\
\text { tutor e } \\
\text { impacto do } \\
\text { treinamento no } \\
\text { trabalho }\end{array}$ & $\begin{array}{l}188 \text { e } 354 \\
\text { participantes do } \\
\text { curso a distância } \\
\text { IPGN (SEBRAE) }\end{array}$ & $\begin{array}{l}\text { Aplicação de } \\
\text { questionários } \\
\text { online }\end{array}$ & $\begin{array}{l}\text { Análise fatorial } \\
\text { exploratória } \\
\text { Análise de } \\
\text { regressão } \\
\text { múltipla }\end{array}$ & $\begin{array}{l}\text { - Apenas as estratégias } \\
\text { de elaboração e } \\
\text { aplicação prática } \\
\text { explicaram o impacto } \\
\text { do treinamento no } \\
\text { trabalho. }\end{array}$ \\
\hline
\end{tabular}


Tabela 8. Pesquisas sobre Estratégias de Aprendizagem (Continuação)

\begin{tabular}{|c|c|c|c|c|c|}
\hline $\begin{array}{l}\text { Pantoja } \\
\text { (2004) }\end{array}$ & $\begin{array}{l}\text { Investigar o } \\
\text { relacionamen } \\
\text { to entre } \\
\text { Estratégias } \\
\text { de } \\
\text { Aprendizage } \\
\text { m, } \\
\text { característica } \\
\text { s da } \\
\text { organização } \\
\text { e percepções } \\
\text { de suporte à } \\
\text { aprendizage } \\
\text { m contínua }\end{array}$ & $\begin{array}{l}900 \text { trabalhadores } \\
\text { de } 16 \text { categorias } \\
\text { distintas atuantes } \\
\text { em diferentes } \\
\text { segmentos } \\
\text { organizacionais }\end{array}$ & $\begin{array}{l}\text { Aplicação de } \\
\text { questionários }\end{array}$ & $\begin{array}{l}\text { Teste de } 5 \\
\text { modelos } \\
\text { multiníveis } \\
\text { para } \\
\text { verificação do } \\
\text { efeito } \\
\text { específico de } \\
\text { variáveis } \\
\text { preditoras nas } \\
\text { Estratégias de } \\
\text { Aprendizagem } \\
\text { no local de } \\
\text { trabalho } \\
\text { Análise fatorial } \\
\text { exploratória }\end{array}$ & $\begin{array}{l}\text {-Diferentes correlações } \\
\text { encontradas entre as } \\
\text { variáveis individuais } \\
\text { (idade, gênero, anos de } \\
\text { estudo, categoria } \\
\text { profissional) e a } \\
\text { utilização de } \\
\text { Estratégias de } \\
\text { Aprendizagem no local } \\
\text { de trabalho; } \\
\text {-Destaque para a } \\
\text { estratégia aplicação } \\
\text { prática para a } \\
\text { aprendizagem dos } \\
\text { indivíduos nos } \\
\text { contextos } \\
\text { organizacionais } \\
\text { estudados; } \\
\text {-Há diferenças } \\
\text { significativas entre as } \\
\text { Estratégias de } \\
\text { Aprendizagem } \\
\text { utilizadas no local de } \\
\text { trabalho conforme a } \\
\text { categoria profissional. }\end{array}$ \\
\hline
\end{tabular}


Tabela 8. Pesquisas sobre Estratégias de Aprendizagem (Continuação)

\begin{tabular}{|c|c|c|c|c|c|}
\hline Autores & Objetivo & Amostra/Contexto & $\begin{array}{c}\text { Procedimentos } \\
\text { de coleta de } \\
\text { dados }\end{array}$ & $\begin{array}{c}\text { Procedimentos } \\
\text { de análise de } \\
\text { dados }\end{array}$ & Resultados \\
\hline $\begin{array}{l}\text { Pantoja e } \\
\text { Borges- } \\
\text { Andrade } \\
(2009)\end{array}$ & $\begin{array}{l}\text { Mapear } \\
\text { Estratégias de } \\
\text { Aprendizagem } \\
\text { no trabalho } \\
\text { com o objetivo } \\
\text { de classificar } \\
\text { dezesseis } \\
\text { ocupações } \\
\text { profissionais, } \\
\text { em quatro } \\
\text { categorias de } \\
\text { postos de } \\
\text { trabalho, bem } \\
\text { como } \\
\text { descrever e } \\
\text { comparar as } \\
\text { estratégias } \\
\text { utilizadas pelos } \\
\text { indivíduos para } \\
\text { aprenderem, } \\
\text { em seu dia-a- } \\
\text { dia no trabalho, } \\
\text { nessas } \\
\text { diferentes } \\
\text { categorias } \\
\text { profissionais }\end{array}$ & $\begin{array}{l}12 \text { coordenadores } \\
\text { de RH e } 55 \\
\text { representantes das } \\
\text { dezesseis } \\
\text { ocupações } \\
\text { profissionais } \\
\text { estudadas }\end{array}$ & $\begin{array}{l}\text { Entrevistas } \\
\text { semiestruturadas } \\
\text { baseadas na } \\
\text { técnica de } \\
\text { incidentes } \\
\text { críticos }\end{array}$ & $\begin{array}{l}\text { Análise de } \\
\text { conteúdo }\end{array}$ & $\begin{array}{l}\text { - As estratégias } \\
\text { aplicação prática e } \\
\text { busca de ajuda } \\
\text { interpessoal exerceram } \\
\text { papel primordial nos } \\
\text { processos de } \\
\text { aquisição, retenção e } \\
\text { transferência de novas } \\
\text { competências em } \\
\text { âmbito laboral; } \\
\text { - Diferentes } \\
\text { configurações de uso } \\
\text { de Estratégias de } \\
\text { Aprendizagem } \\
\text { estiveram associadas } \\
\text { às categorias } \\
\text { profissionais } \\
\text { estudadas. }\end{array}$ \\
\hline $\begin{array}{l}\text { Zerbini e } \\
\text { Abbad } \\
(2008, \\
2010)\end{array}$ & $\begin{array}{l}\text { Identificar } \\
\text { variáveis } \\
\text { explicativas da } \\
\text { aplicação de } \\
\text { habilidades } \\
\text { ensinadas aos } \\
\text { participantes } \\
\text { de um curso de } \\
\text { qualificação } \\
\text { profissional a } \\
\text { distância, via } \\
\text { internet }\end{array}$ & $\begin{array}{l}4.719 / 470 \\
\text { participantes do } \\
\text { curso a distância } \\
\text { IPGN (SEBRAE) }\end{array}$ & $\begin{array}{l}\text { Aplicação de } \\
\text { questionários } \\
\text { online }\end{array}$ & $\begin{array}{l}\text { Análise fatorial } \\
\text { exploratória } \\
\text { Análise de } \\
\text { regressão } \\
\text { múltipla }\end{array}$ & $\begin{array}{l}\text { - Participantes que } \\
\text { utilizaram com mais } \\
\text { frequência as } \\
\text { Estratégias de } \\
\text { Aprendizagem } \\
\text { elaboração e } \\
\text { monitoramento da } \\
\text { compreensão foram } \\
\text { os que relataram } \\
\text { maior ocorrência de } \\
\text { impacto do } \\
\text { treinamento no } \\
\text { trabalho; } \\
\text { - Os participantes que } \\
\text { elaboraram o plano } \\
\text { de negócios } \\
\text { utilizaram com mais } \\
\text { frequência a } \\
\text { estratégia de } \\
\text { aprendizagem busca } \\
\text { de ajuda } \\
\text { interpessoal. }\end{array}$ \\
\hline
\end{tabular}


Tabela 8. Pesquisas sobre Estratégias de Aprendizagem (Continuação)

\begin{tabular}{|c|c|c|c|c|c|}
\hline $\begin{array}{l}\text { Abbad, } \\
\text { Côrrea e } \\
\text { Meneses } \\
(2010)\end{array}$ & $\begin{array}{l}\text { Analisar as } \\
\text { relações entre } \\
\text { Estratégias de } \\
\text { Aprendizagem } \\
\text { e satisfação } \\
\text { com } \\
\text { treinamentos a } \\
\text { distância }\end{array}$ & $\begin{array}{l}216 \text { participantes } \\
\text { de cinco cursos } \\
\text { realizados a } \\
\text { distância }\end{array}$ & $\begin{array}{l}\text { Aplicação de } \\
\text { questionários }\end{array}$ & $\begin{array}{l}\text { Análise fatorial } \\
\text { exploratória } \\
\text { Análises de } \\
\text { correlações } \\
\text { bivariadas }\end{array}$ & $\begin{array}{l}\text { - Padrões de associação } \\
\text { entre determinadas } \\
\text { estratégias cognitivas } \\
\text { de aprendizagem e } \\
\text { satisfação com o } \\
\text { desempenho da tutoria, } \\
\text { com os procedimentos } \\
\text { e os resultados e com a } \\
\text { interface gráfica do } \\
\text { curso }\end{array}$ \\
\hline
\end{tabular}


Tabela 8. Pesquisas sobre Estratégias de Aprendizagem (Continuação)

\begin{tabular}{|c|c|c|c|c|c|}
\hline Autores & Objetivo & Amostra/Contexto & $\begin{array}{c}\text { Procedimentos } \\
\text { de coleta de } \\
\text { dados }\end{array}$ & $\begin{array}{c}\text { Procedimentos } \\
\text { de análise de } \\
\text { dados }\end{array}$ & Resultados \\
\hline $\begin{array}{l}\text { Testa e } \\
\text { Luciano } \\
(2010)\end{array}$ & $\begin{array}{l}\text { Investigar o } \\
\text { papel } \\
\text { desempenhado } \\
\text { pelas } \\
\text { Estratégias de } \\
\text { Aprendizagem } \\
\text { utilizadas na } \\
\text { regulação de } \\
\text { recursos de } \\
\text { aprendizagem } \\
\text { em ambientes } \\
\text { virtuais de } \\
\text { ensino }\end{array}$ & $\begin{array}{l}\text { Participantes: } 28 \\
\text { (entrevistados) e } \\
104 \text { (questionários) }\end{array}$ & $\begin{array}{l}\text { Entrevistas } \\
\text { semiestruturadas } \\
\text { e abertas; } \\
\text { análise de } \\
\text { documentos e de } \\
\text { registros; } \\
\text { observação } \\
\text { direta; e } \\
\text { pesquisa survey. }\end{array}$ & $\begin{array}{l}\text { Análise de } \\
\text { conteúdo } \\
\text { Análise fatorial } \\
\text { exploratória }\end{array}$ & $\begin{array}{l}\text { - Participantes que mais } \\
\text { frequentemente } \\
\text { estabeleceram } \\
\text { interações com pares e } \\
\text { professores, para tirar } \\
\text { dúvidas ou buscar } \\
\text { auxílio, atingiram as } \\
\text { mais elevadas médias } \\
\text { nos itens interesse, } \\
\text { persistência, percepção } \\
\text { de autoconfiança e } \\
\text { gestão do ambiente } \\
\text { social da escala MSLQ } \\
\text { (Motivated Strategies } \\
\text { for Learning } \\
\text { Questionnaire); } \\
\text { Correlações } \\
\text { significativas entre as } \\
\text { elevadas taxas de } \\
\text { satisfação com o estud } \\
\text { e desempenho } \\
\text { acadêmico e a utilizaçã } \\
\text { de estratégias para } \\
\text { gestão do tempo e } \\
\text { esforço. } \\
\text { - Implicações práticas: } \\
\text { estabelecer prazos } \\
\text { curtos e frequentes par } \\
\text { a conclusão das tarefas } \\
\text { fixar nos critérios } \\
\text { avaliativos elementos } \\
\text { que tratem do } \\
\text { gerenciamento de } \\
\text { tempo; investir em } \\
\text { interações viabilizadas } \\
\text { pelo recurso do chatou } \\
\text { por meio de } \\
\text { videoconferências; } \\
\text { sugerir atividades não } \\
\text { formais nas quais os } \\
\text { estudantes partilhem } \\
\text { etes, }\end{array}$ \\
\hline $\begin{array}{l}\text { Brandão } \\
\& \\
\text { Borges- } \\
\text { Andrade } \\
(2011)\end{array}$ & $\begin{array}{l}\text { Desenvolver } \\
\text { uma escala de } \\
\text { Estratégias de } \\
\text { Aprendizagem } \\
\text { no trabalho e } \\
\text { verificar a } \\
\text { frequência com } \\
\text { que estas são } \\
\text { utilizadas por } \\
\text { gestores de um } \\
\text { banco público }\end{array}$ & $\begin{array}{l}881 \text { gestores de } \\
\text { agências bancárias } \\
\text { brasileiras }\end{array}$ & $\begin{array}{l}\text { Levantamento } \\
\text { documental, } \\
\text { entrevistas e } \\
\text { questionários }\end{array}$ & $\begin{array}{l}\text { Análises } \\
\text { descritivas e } \\
\text { fatoriais } \\
\text { exploratórias }\end{array}$ & $\begin{array}{l}\text { As Estratégias de } \\
\text { Aprendizagem } \\
\text { buscam de ajuda } \\
\text { interpessoal e reflexão } \\
\text { ativa foram as mais } \\
\text { utilizadas pela } \\
\text { amostra. }\end{array}$ \\
\hline
\end{tabular}


Martins (2016) em sua revisão sobre Estratégias de Aprendizagem mapeou estudos que ocorreram ao longo de dez anos, os resultados destas buscas podem ser utilizados como base para estudos recentes. Os resultados dos estudos aprofundados das Estratégias de Aprendizagem podem colaborar para o melhor desenvolvimento do planejamento instrucional de ações a distância, pois favorecem o reconhecimento dos processos individuais de aprendizagem utilizados e dos procedimentos instrucionais mais adequados a cada aprendente envolvido na ação educacional (Santos et al., 2004; Zerbini, 2007; Zerbini \& Abbad, 2010).

Umekawa e Zerbini (2015) testaram modelos de predição que proveram evidências de que quanto mais forem aplicadas específicas estratégias de aprendizagem, maiores serão as chances de o corpo discente perceber um conjunto específico de variáveis como muito influentes sobre a permanência ou saída dos mesmos de seus cursos. Os alunos que solicitam ajudam a outras pessoas e atentam-se para os processos de aquisição de conhecimento perceberam como muito importantes as condições tecnológicas e o suporte oferecido a eles. Já os alunos que utilizam mais as estratégias de monitoramento da compreensão, busca de ajuda interpessoal e cognitivo - comportamentais, os eventos sociais prejudicarão em maior amplitude a permanência do discente no curso.

Ainda, com base na revisão de Martins (2016), é possível identificar um campo extenso de pesquisas que podem ser desenvolvidas buscando compreender a influência das estratégias que os alunos adotam para aprender, para a aprendizagem efetiva dos alunos. Outra área que se beneficiará dos estudos sobre as estratégias de aprendizagem é o planejamento instrucional, que pode se basear nestas estratégias para delinear o curso. As estratégias adotadas pelo aluno para aprender, dependendo da situação, podem caracterizar barreiras para a conclusão do curso a distância, sendo assim é uma variável fundamental para a maior compreensão deste estudo.

\subsubsection{Barreiras em EAD (variável critério): definições e características}

Segundo Martins (2016), as Barreiras são definidas como diferentes características do próprio sujeito e do contexto, que podem da mesma forma auxiliar ou prejudicar o desempenho durante um treinamento, desta forma, gerando impacto em seus resultados.

Sobre as razões que levam o aluno a não concluir um programa de ensino a distância, a literatura indica um grande número de fatores que correspondem tanto a variáveis internas à própria ação instrucional como a elementos externos a ela. Aspectos referentes à elevada 
complexidade da vida pessoal, laboral, financeira e familiar configuram entre os inúmeros motivos relacionados à desistência e ao insucesso estudantil. Também é importante considerar a influência exercida pelas instituições de ensino responsáveis pela oferta de cursos a distância e as políticas sociais mal implementadas, que frequentemente não satisfazem as necessidades dos discentes, muitas vezes deixando-os evadir e não demonstram interesse em conhecer os fatores causadores da problemática e desenvolver planos de ação que os contenham (Siqueira, 2009).

Albertin e Brauer (2012) estudaram as principais causas de resistência à EAD no contexto de Educação Corporativa. Este estudo focou no indivíduo, independentemente do tipo de organização na qual ele trabalhava, englobando as áreas públicas e privada e verificou que as dimensões da autoeficácia e expectativa de desempenho influenciam a resistência em EAD, tornando-se barreiras para que o aluno continue no curso. Neste estudo, a autoeficácia foi conceituada como o grau de habilidade do aluno em aprender sozinho e em realizar o que planeja. Quanto maior a necessidade de interação presencial nas aulas ou no estudo, quanto maiores a indisciplina e as dificuldades com o gerenciamento do tempo, e quanto maior o grau de procrastinação, demonstraram maior resistência do aluno em relação aos sistemas de EAD.

Em sua definição sobre expectativa de desempenho, Albertin \& Brauer (2012) buscaram identificar o grau em que um funcionário acredita que o uso da EAD vai ajudá-lo a atingir ganhos no trabalho. Concluíram que se o empregado não acredita que a EAD lhe trará benefícios, terá grandes chances da resistência ser maior. Aponta-se que a expectativa de desempenho é influenciada positivamente por três dimensões: Expectativa de esforço, que buscou medir a facilidade de uso percebida pelo aluno do sistema de EAD; Interatividade, que buscou mensurar o grau de interatividade entre o funcionário, aluno e o tutor ou outros alunos; e Condições facilitadoras, que buscou mensurar o grau em que um funcionário acredita que existe uma infraestrutura organizacional e técnica que suporte o uso do sistema.

Segundo Brauer (2009) barreiras pessoais à conclusão do curso referem-se às dificuldades percebidas pelo aluno a distância para que consiga concluir o curso. Os conceitos de barreiras pessoais à conclusão do curso e evasão possuem correlação. Entretanto, o conceito de barreiras se atrela ao processo, ou seja, o aluno ainda não se evadiu. Já o conceito de evasão se refere ao abandono do curso, já determinado, por parte do aluno. Ao estudar barreiras pessoais à conclusão do curso estuda-se também o fenômeno da evasão, como efeito esperado diante de grandes dificuldades, ou barreiras, enfrentadas ou não pelo aluno para que este possa ir até o final de um curso a distância, concluindo-o. Vargas (2004) define o termo 
persistência como o comportamento do aluno que estuda a distância, com relação a concluir ou não concluir o curso.

Algumas das variáveis ligadas ao abandono discente em iniciativas de EaD podem ser classificadas em três grandes grupos (Abbad, 2007; Sales, 2009; Xenos, Pierrakeas, \& Pintelas, 2002): (1) fatores relativos ao evento instrucional; (2) fatores relacionados a características pessoais dos estudantes; e (3) fatores ligados ao contexto que cerca o aluno a distância. Em relação às variáveis do curso ligadas à evasão, a literatura aponta que problemas relacionados ao desempenho do tutor, como questões do exercício profissional, falta de apoio ao aluno, falta de conhecimentos ou falta de habilidade para transmiti-los, são apontados como uma das causas para o abandono discente (Abreu-e-Lima \& Alves, 2011; Lee \& Anderson, 2013).

Segundo Vargas (2004), o termo "barreiras” geralmente é utilizado para dar menção a diferentes fatores que dificultam a implantação de programas de educação e treinamento a distância nos contextos acadêmico e corporativo. Em seu estudo, a autora propõe duas classes de barreiras à implantação de programas de educação e treinamentos a distância: barreiras institucionais e barreiras pessoais. A primeira se refere às limitações ao domínio macro da organização e se relaciona à tomada de decisões e gestão de recursos; a segunda refere-se a algumas características que os indivíduos possuem e/ou a situações enfrentadas por eles, que podem interferir na eficácia de um evento instrucional. A autora também classifica barreiras pessoais nas seguintes categorias: (1) barreiras demográficas, (2) barreiras motivacionais e (3) barreiras tecnológicas. A primeira refere-se aos dados pessoais da clientela; a segunda diz respeito às atitudes do treinando com relação ao evento instrucional, e a terceira refere-se à atitude do aluno diante do uso das novas tecnologias de informação e comunicação. Vargas (2004) afirma que o estudo de barreiras pessoais e persistência em cursos a distância faz parte de um quadro teórico em construção.

Em seu estudo, Mendonça (2015) realizou uma síntese de estudos sobre de barreiras na educação a distância em organizações, nele contemplou diversos estudiosos da área, que possibilita observar que o tema tem sido pesquisado com maior frequência a partir do ano de 2004, conforme quadro reproduzido abaixo: 
Tabela 9. Barreiras à EAD nas Organizações Mendonça (2015)

\begin{tabular}{|c|c|c|c|}
\hline & Barreiras/dificuldades & Autor(es) referenciado(s) \\
\hline \multirow{13}{*}{ 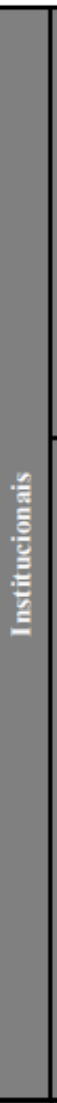 } & \multirow{5}{*}{ 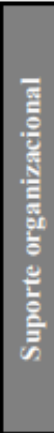 } & $\begin{array}{l}\text { Falta de apoio dos dirigentes e gestores na implantação e } \\
\text { aplicação do projeto }\end{array}$ & $\begin{array}{l}\text { (Vargas \& Lima, 2004; Abreu, } \\
\text { Gonçalves, \& Pagnozzi, 2003; } \\
\text { Bastos, 2003; Abbad et al., 2010) } \\
\end{array}$ \\
\hline & & Falta de de recursos materiais e equipamentos & $\begin{array}{l}\text { (Vargas \& Lima, 2004; Ghedini et } \\
\text { al., 2008) }\end{array}$ \\
\hline & & Falta de planejamento do custo de investimento no projeto & (Ghedini et al., 2008; Maia, 2007) \\
\hline & & $\begin{array}{l}\text { Inexistência de um plano de comunicação eficiente sobre a } \\
\text { ferramenta }\end{array}$ & $\begin{array}{l}\text { (Cavalheiro, 2007; Ghedini et al., } \\
\text { 2008) }\end{array}$ \\
\hline & & $\begin{array}{l}\text { Baixo alinhamento entre as iniciativas de Educação a } \\
\text { Distância e as estratégias do negócio }\end{array}$ & (Ghedini et al., 2008) \\
\hline & \multirow{8}{*}{ 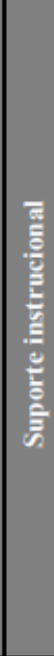 } & $\begin{array}{l}\text { Ausência ou inadequação de um sistema de tecnologia da } \\
\text { educação }\end{array}$ & (Vargas \& Lima, 2004) \\
\hline & & $\begin{array}{l}\text { Desconhecimento das necessidades, expectativas, } \\
\text { características e dificuldades do público interno }\end{array}$ & $\begin{array}{l}\text { (Brauer \& Albertin, 2012; Saraiva } \\
\text { et al., 2006; Abreu et al., 2003) }\end{array}$ \\
\hline & & Utilização das ferramentas de forma repetitiva e limitante & $\begin{array}{l}\text { (Saraiva, Pernigotti, \& } \\
\text { Barcia.,2006) } \\
\end{array}$ \\
\hline & & Baixa interatividade do conteúdo & (Bastos, 2003; Almeida, 2003) \\
\hline & & $\begin{array}{l}\text { Ausência de possibilidade de comunicação e trocas } \\
\text { colaborativas }\end{array}$ & $\begin{array}{l}\text { (Abreu et al., 2003; Ikeda \& } \\
\text { Cavalheiro, 2005; Almeida, 2003) }\end{array}$ \\
\hline & & $\begin{array}{l}\text { Falta de preparo dos tutores para dar feedback e prestar } \\
\text { suporte }\end{array}$ & $\begin{array}{l}\text { (Ikeda \& Cavalheiro, 2005; Maia, } \\
\text { 2007) }\end{array}$ \\
\hline & & $\begin{array}{l}\text { Estabilidade da rede e velocidade de acesso à internet } \\
\text { diferentes em diversas localidades da empresa }\end{array}$ & $\begin{array}{l}\text { (Vargas \& Lima, 2004; Saraiva et } \\
\text { al., 2006) }\end{array}$ \\
\hline & & $\begin{array}{l}\text { Falta de ferramentas adequadas para mensuração do retorno } \\
\text { das práticas }\end{array}$ & $\begin{array}{l}\text { (Ghedini et al., 2008; Ikeda \& } \\
\text { Cavalheiro, 2005) }\end{array}$ \\
\hline \multirow{10}{*}{ है } & \multirow{6}{*}{$\begin{array}{l}\text { है } \\
\text { है } \\
\text { है } \\
\text { है } \\
\text { है } \\
\text { है }\end{array}$} & Acomodação à capacitação presencial & $\begin{array}{l}\text { (Bastos, 2003; Ikeda \& Cavalheiro, } \\
\text { 2005) }\end{array}$ \\
\hline & & $\begin{array}{l}\text { Pressão e dificuldade de conciliar as ações de educação e } \\
\text { demais exigência do cargo }\end{array}$ & (Abbad et al., 2010) \\
\hline & & $\begin{array}{l}\text { Crenças de que as ferramentas não agregarão valor à } \\
\text { aprendizagem }\end{array}$ & $\begin{array}{l}\text { (Vargas \& Lima, 2004; Brauer \& } \\
\text { Albertin, 2012; Vasconcellos \& } \\
\text { Fleury, 2008) }\end{array}$ \\
\hline & & $\begin{array}{l}\text { Medo e estresse relacionados ao desconhecimento das } \\
\text { ferramentas }\end{array}$ & (Brauer \& Albertin, 2012) \\
\hline & & Incapacidade de aprender sozinho e falta de disciplina & $\begin{array}{l}\text { (Brauer \& Albertin, 2012; Ikeda \& } \\
\text { Cavalheiro, 2005) }\end{array}$ \\
\hline & & Excesso de expectativa & (Ikeda \& Cavalheiro, 2005) \\
\hline & \multirow{4}{*}{ 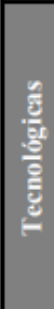 } & $\begin{array}{l}\text { Aversão ao uso do computador e demais recursos } \\
\text { tecnológicos }\end{array}$ & $\begin{array}{l}\text { (Vargas \& Lima, 2004; Saraiva et } \\
\text { al., 2006; Cavalheiro, 2007) }\end{array}$ \\
\hline & & $\begin{array}{l}\text { Desconfiança em relação a processos de mudança e } \\
\text { inovação }\end{array}$ & (Vasconcellos \& Fleury, 2008) \\
\hline & & Dificuldades ao utilizar a plataforma de ensino & (Cavalheiro, 2007) \\
\hline & & $\begin{array}{l}\text { Impessoalidade do método e falta de sentimento de } \\
\text { acolhimento e pertença }\end{array}$ & (Saraiva et al., 2006; Maia, 2007) \\
\hline
\end{tabular}

Os estudos abarcam variáveis que podem atuar como barreiras para a evasão de alunos a distância, ampliar os estudos sobre as barreiras que impedem a conclusão dos cursos se faz necessário para que as instituições possam aprimorar o planejamento instrucional dos cursos de acordo com o perfil da clientela, ressalta-se que é papel da instituição buscar a 
compreensão das estratégias adotadas por elas que podem atuar como barreiras nos cursos a distância. Esta não é uma preocupação recente, porém se estudada com profundidade permite grandes avanços para a área de TD\&E. 


\section{CAPÍTULO 4. CARACTERÍSTICAS METODOLÓGICAS DA PESQUISA}

\section{Objetivo do capítulo 4}

O presente capítulo visa apresentar a delimitação do problema, a justificativa e os objetivos da pesquisa no Estudo 1 e objetivos da pesquisa no Estudo 2, retratar o modelo de investigação, e apresentar as características da instituição de ensino superior participante, características da amostra, instrumentos de medida, assim como dos procedimentos de coleta e análise quantitativa e qualitativa dos dados.

\subsection{Delimitação do problema, objetivos de pesquisa e modelo de investigação}

A partir da revisão da literatura, percebe-se um crescente aumento pela procura de cursos EAD, isto se deve ao fato dos profissionais buscarem maneiras de aprendizagem flexíveis, ao mesmo tempo em que suprem as lacunas de competências, garantindo assim a o crescimento sustentável do indivíduo e das organizações onde atuam. Ainda há poucos estudos que se dedicam a investigar de forma sistemática as barreiras relacionadas aos cursos de pós-graduação a distância. Percebe-se uma necessidade de aperfeiçoamento na modalidade a distância em relação ao aprimoramento dos procedimentos instrucionais, formação de tutores e hábitos de estudo do aprendiz.

Nesse sentido, o Estudo 1 pretende fornecer informações que compreendam as barreiras relacionadas aos cursos de pós-graduação a distância. Para tanto, serão analisadas as possíveis relações existentes entre a variável critério Barreiras (Suporte Oferecido pela Instituição, Contexto Externo ao Curso, Desenho do Curso, Características do Aluno, Questões de Saúde e Financeiras) e a variáveis relacionadas às Estratégias de Aprendizagem (Estratégias Cognitivas, Estratégias Autorregulatórias, Reflexão e Aplicação Prática, Busca por ajuda Interpessoal) e Perfil da Clientela (Dados Sociodemográficos), conforme figura 7. 


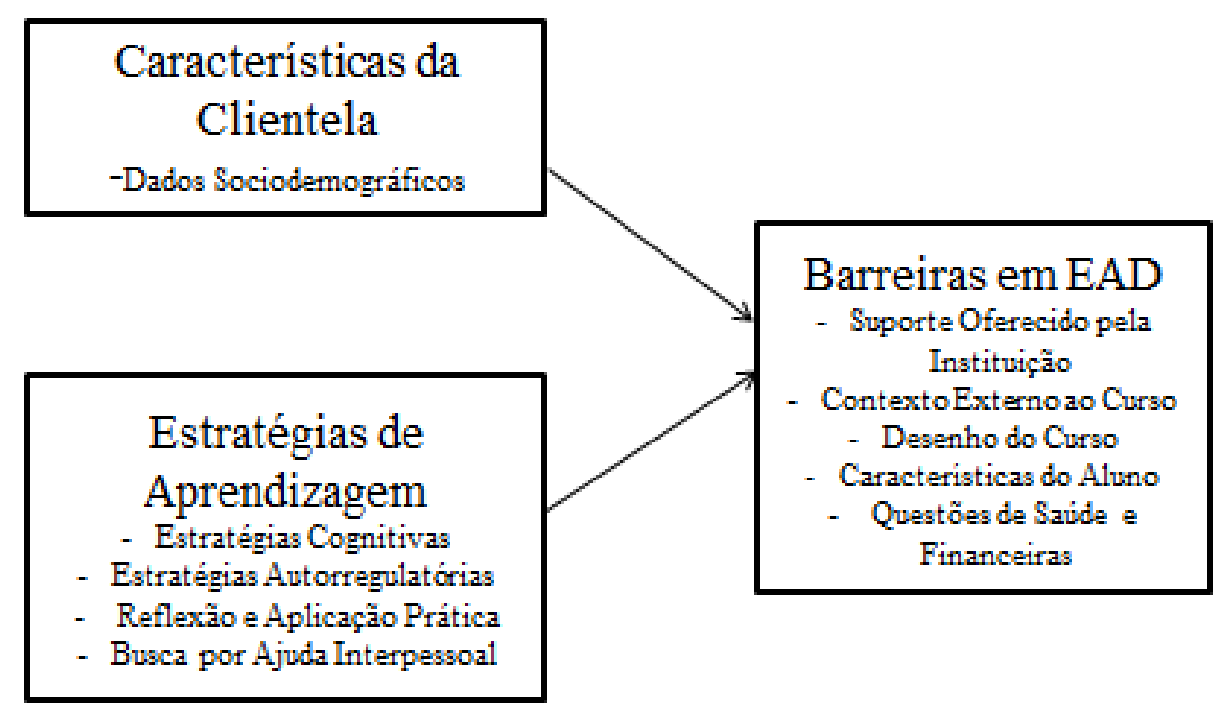

Figura 7. Modelo das variáveis do Estudo 1

Elaboração da autora

A fim de aprofundar a análise sobre as barreiras em EAD, o Estudo 2 pretende analisar quais foram as barreiras que influenciaram os alunos a evadirem-se dos curso, na abordagem qualitativa. Segundo os autores Creswell e Clark (2011), o uso de abordagens quantitativas e qualitativas combinadas oferece uma melhor compreensão dos problemas de pesquisa do que qualquer abordagem sozinha.

Em função disso, propõem-se os seguintes problemas de pesquisa:

1. Qual é o perfil da clientela em EAD quanto aos dados sociodemográficos?

2. Quais são as estratégias de aprendizagem utilizadas pelos alunos em cursos desta natureza?

3. Como eventuais barreiras encontradas pelo aluno ao longo do curso referentes ao contexto de estudo do aluno, desenho do curso e perfil do estudante podem influenciar na sua desistência no curso?

Com a finalidade de responder às questões acima descritas, foram traçados os objetivos da pesquisa, apresentados a seguir. 


\section{Objetivo Geral Estudo 1}

O objetivo deste estudo é identificar preditores de barreiras na modalidade EAD, em cursos de pós-graduação ofertados a distância em uma Instituição de Ensino, situada em Ribeirão Preto/SP.

\section{Objetivos Específicos do Estudo 1}

- Verificar evidências de validade na Escala de Barreiras em EAD de Martins, Zerbini e Medina (2018), submetido.

- Verificar evidências de validade na Escala de Estratégias de Aprendizagem de Martins, Zerbini e Medina (2018).

- Identificar as estratégias de aprendizagem utilizadas pelos alunos ao longo da ação educacional de pós-graduação.

- Identificar as barreiras referentes ao contexto de estudo do aluno, desenho do curso e perfil do estudante podem influenciar na sua desistência no curso.

- Analisar o perfil da clientela de ações educacionais a distância no curso de pósgraduação.

\section{Objetivo Geral Estudo 2}

O objetivo deste estudo é avaliar fatores que levam os estudantes de pós-graduação a se evadirem dos cursos EAD por meio de um roteiro semiestruturado sobre barreiras de conclusão de cursos de pós-graduação em EAD.

\section{Objetivos Específicos do Estudo 2}

- Construir um roteiro semiestruturado sobre barreiras que podem influenciar na evasão de cursos de pós-graduação a distância; 
- Realizar uma análise temática das entrevistas realizadas com alunos que se evadiram dos cursos.

\subsection{Características da instituição-alvo}

Para a realização desta pesquisa, foi estabelecida uma parceria com o INEPAD Instituto de Ensino e Pesquisa em Administração situado em Ribeirão Preto, São Paulo, é um instituto sem fins lucrativos que foi instituído em 2003 a partir da união de profissionais, professores e pesquisadores da área de Administração. Contam com a colaboração de aproximadamente 250 professores doutores ligados a renomadas instituições de Educação nacionais e internacionais. Oferecem cursos na área de Educação Corporativa, todos os cursos oferecidos na modalidade de ensino EAD (Ensino à Distância). Nas modalidades EAD oferecemos opencourses (MBA's e Cursos de Curta Duração) e cursos In Company, em parceria com empresas.

O Instituto manteve parceira com as instituições de ensino a seguir: Faculdade de Filosofia, Ciências e Letras de Ribeirão Preto da Universidade de São Paulo, que oferece o ensino de graduação, a formação de pesquisadores e serviços de extensão, atualmente contam com dez cursos de Graduação: Ciências Biológicas, Ciências da Informação e da Documentação, Física Médica, Informática Biomédica, Matemática Aplicada a Negócios, Licenciatura em Química, Pedagogia, Psicologia e Química, sendo 445 vagas no vestibular da FUVEST, sete Programas de Pós-Graduação, todos avaliados pela CAPES, em: Biologia Comparada, Entomologia, Física Aplicada à Medicina e Biologia, Psicobiologia, Psicologia, Química e Educação, e uma ampla gama de projetos de pesquisa e de serviços de extensão. Escola de Enfermagem de Ribeirão Preto da Universidade de São Paulo, na graduação, oferece os cursos de Bacharelado em Enfermagem e Bacharelado e Licenciatura em Enfermagem, reconhecidos pelo Conselho Estadual de Educação, para a formação de mestres e doutores, a EERP mantém quatro programas de pós-graduação: Enfermagem Fundamental, Enfermagem Psiquiátrica, Enfermagem em Saúde Pública e Mestrado Profissional em Tecnologia e Inovação em Enfermagem. Em parceria com Escola de Enfermagem da USP, sediada em São Paulo, oferece o Programa Interunidades de Doutoramento em Enfermagem. 
O Programa de Pós-Doutoramento apresenta-se como uma opção ao pesquisador que pretende consolidar e atualizar seus conhecimentos ou redirecionar sua linha de pesquisa, desenvolvendo um projeto de investigação científica em um dos grupos de pesquisa da EERP. Fundação para Pesquisa e Desenvolvimento da Administração - Fundace é uma instituição sem fins lucrativos criada em 1995 pelos docentes da FEA-RP/USP para facilitar o processo de integração entre universidade e comunidade. Exerce a importante tarefa de ser um mecanismo de fomento à produção e disseminação de conhecimento nas áreas de Administração, Contabilidade e Economia, proporcionando que docentes e alunos avancem em conhecimento e experiências. Contabilidade e Economia. Sescoop - Serviço Nacional de Aprendizagem do Cooperativismo do Estado de São Paulo, surgiu em 1999 com o objetivo de contribuir para a revitalização das cooperativas paulistas, funcionando como um grande aliado cultural, econômico e social. Nesse primeiro momento, o maior desafio era aprimorar a gestão dos empreendimentos cooperativistas, tornando-os mais competitivos em um mercado em constante transformação.

Desde sua criação, o Sescoop/SP vem atuando, principalmente, em três diferentes frentes: formação profissional, promoção social e monitoramento das cooperativas. Ao longo de mais de 13 anos, o Sescoop/SP tem desenvolvido diversos programas e projetos que refletem diretamente na capacitação de pessoas ligadas às cooperativas, além de programas de caráter social que promovem integração, lazer e cultura do público cooperativista e das comunidades. Nesse período, também foram empreendidas diversas ações de monitoramento para apoiar a gestão das cooperativas, com consultorias especializadas, programas de capacitação de dirigentes e promoção de intercâmbios para troca de experiências, entre outras iniciativas. Ajudando as cooperativas, o Sescoop/SP incentiva também o movimento cooperativista, modelo econômico que apresenta soluções para as mais diversas atividades econômicas, ligadas principalmente a relações de consumo, produção e prestação de serviços, Sicoob - Sistema de Cooperativas de Crédito do Brasil é o maior sistema financeiro cooperativo do país com mais de 3,6 milhões de associados, 2,5 mil pontos de atendimento, distribuídos em todo Brasil. É composto por cooperativas financeiras e empresas de apoio, que em conjunto oferecem aos associados serviços de conta corrente, crédito, investimento, cartões, previdência, consórcio, seguros, cobrança bancária, adquirência de meios eletrônicos de pagamento, dentre outros. Ou seja, tem todos os produtos e serviços bancários, mas não é 
banco. É uma cooperativa financeira, onde os clientes são os donos e por isso os resultados financeiros são divididos entre os cooperados.

Os depósitos em cooperativas financeiras têm a proteção do Fundo Garantidor do Cooperativismo de Crédito (FGCoop). Esse fundo garante os depósitos e os créditos mantidos nas cooperativas singulares de crédito e nos bancos cooperativos em caso de intervenção ou liquidação extrajudicial dessas instituições. O Centro Universitário Estácio de Ribeirão Preto, é uma das maiores organizações privadas de ensino superior do Brasil em número de alunos matriculados, a Estácio acredita na transformação da sociedade por meio da educação. Trabalham para que os alunos sejam agentes de mudança - em suas comunidades, em seu desempenho profissional e em suas famílias - e atuam no desenvolvimento das comunidades em que estamos presentes por meio, sobretudo, da difusão do conhecimento. A sustentabilidade está presente em todas as atividades e no projeto pedagógico de todos os cursos. Contam com 4.564 colaboradores administrativos e com um corpo docente de 7.719 professores. Oferecem 86 diferentes cursos presenciais e a distância de Graduação e Graduação Tecnológica nas áreas de Ciências Exatas, Ciências Biológicas e Ciências Humanas. Oferecem também 110 cursos de Pós-Graduação latu senso, cinco cursos de Mestrado e três cursos de Doutorado, avaliados pelo MEC/CAPES com elevados conceitos de qualidade, além de cursos livres e cursos voltados para a educação corporativa.

\subsection{Características dos cursos}

Os cursos de pós-graduação analisados por este estudo foram: MBA Gestão em Saúde - USP, Turma I e II, MBA Contabilidade em IFRS - USP, Turma I, MBA Economia Brasileira para Negócios - USP, Turma I, MBA em Gestão em Marketing Estratégico, Turma I e II e MBA em Gestão Estratégica, Turma I, II, III e VI ofertados pelo INEPAD em parceria com a FUNDACE e EERP, todos os cursos referidos acima contam com o corpo docente da USP/Ribeirão Preto e professores externos convidados.

Foram realizadas as análises dos cursos ofertados pela instituição parceira, para isto foi utilizado o Instrumento Roteiro de Análise de Cursos de Graduação - EAD, Mello (2017), (Anexo D). Este instrumento foi adaptado do "Roteiro de Análise do Material Didático EAD” desenvolvido por Zerbini (2003) e Carvalho (2003) utilizado para avaliar a qualidade dos materiais instrucionais de disciplinas e cursos de curta duração. A adaptação foi realizada 
para que fosse possível avaliar cursos de graduação ofertados a distância, que se adequa ao contexto de estudo do presente trabalho.

A partir da análise dos cursos por meio do roteiro de análise de cursos a cima citado, foi possível avaliar os seguintes aspectos no conjunto de disciplinas dos cursos: os objetivos instrucionais, a adequação das estratégias instrucionais, o planejamento do curso, a sequenciação do ensino, as fontes de informações (bibliografia e outros meios) e as informações gerais sobre o curso. Esta avaliação foi realizada sob posse dos PPP's dos cursos e demais documentos disponibilizados pela instituição de ensino. A seguir é apresentada a tabela 10 apresenta algumas com características dos referidos cursos. 
Tabela 10. Características dos cursos de pós-graduação

\begin{tabular}{|c|c|c|c|c|c|c|}
\hline $\begin{array}{c}\text { Instituição } \\
\text { Parceira }\end{array}$ & Curso & Modalidade & Objetivo & Duração & Estrutura & Público-Alvo \\
\hline $\begin{array}{c}\text { Fundação para } \\
\text { Pesquisa e } \\
\text { Desenvolvimento } \\
\text { da } \\
\text { Administração }\end{array}$ & $\begin{array}{l}\text { MBA em } \\
\text { Gestão de } \\
\text { Marketing } \\
\text { Estratégico }\end{array}$ & EAD & $\begin{array}{l}\text { Capacitar gestores } \\
\text { modernos para } \\
\text { uma atuação } \\
\text { efetiva na gestão } \\
\text { do marketing } \\
\text { estratégico de suas } \\
\text { organizações, } \\
\text { ampliando seus } \\
\text { conhecimentos nos } \\
\text { seguintes } \\
\text { contextos: } \\
\text { Ampliação dos } \\
\text { conceitos de } \\
\text { marketing, } \\
\text { estruturação das } \\
\text { estratégias } \\
\text { completas para } \\
\text { marketing } \\
\text { organizacional, } \\
\text { gerenciamento do } \\
\text { marketing mix, } \\
\text { tendência em } \\
\text { marketing e gestão } \\
\text { de vendas. }\end{array}$ & $\begin{array}{c}1 \text { ano e } \\
\text { dez meses } \\
420 \text { horas }\end{array}$ & 6 módulos & $\begin{array}{c}\text { Graduados em } \\
\text { diversas áreas, } \\
\text { em franca } \\
\text { ascensão } \\
\text { gerencial. } \\
\text { Profissionais } \\
\text { que atuam em } \\
\text { áreas como } \\
\text { estratégia, } \\
\text { finanças ou } \\
\text { gestão de } \\
\text { pessoas, que } \\
\text { possuam } \\
\text { experiência } \\
\text { gerencial. }\end{array}$ \\
\hline $\begin{array}{c}\text { Fundação para } \\
\text { Pesquisa e } \\
\text { Desenvolvimento } \\
\text { da } \\
\text { Administração }\end{array}$ & & EAD & $\begin{array}{l}\text { Com uma grade } \\
\text { estruturada para } \\
\text { focar os tópicos } \\
\text { das normas } \\
\text { contábeis } \\
\text { internacionais, o } \\
\text { programa tem o } \\
\text { objetivo de fazer } \\
\text { com que o } \\
\text { participante } \\
\text { conheça desde os } \\
\text { fundamentos da } \\
\text { contabilidade até } \\
\text { pronunciamentos } \\
\text { técnicos mais } \\
\text { avançados. }\end{array}$ & $\begin{array}{c}2 \text { anos e } \\
\text { seis } \\
\text { meses } \\
420 \text { horas }\end{array}$ & 6 módulos & $\begin{array}{c}\text { Graduados em } \\
\text { diversas áreas, } \\
\text { em franca } \\
\text { ascensão } \\
\text { gerencial. } \\
\text { Profissionais } \\
\text { que atuam em } \\
\text { áreas como } \\
\text { Contabilidade, } \\
\text { Auditoria, } \\
\text { Finanças, } \\
\text { Tributária e } \\
\text { Controladoria. }\end{array}$ \\
\hline
\end{tabular}


Tabela 10. Características dos cursos de pós-graduação a distância(Continuação)

\begin{tabular}{|c|c|c|c|c|c|c|}
\hline $\begin{array}{c}\text { Instituição } \\
\text { Parceira }\end{array}$ & Curso & Modalidade & Objetivo & Duração & Estrutura & Público-Alvo \\
\hline $\begin{array}{c}\text { Fundação para } \\
\text { Pesquisa e } \\
\text { Desenvolvimento } \\
\text { da } \\
\text { Administração }\end{array}$ & $\begin{array}{c}\text { MBA } \\
\text { Economia } \\
\text { Brasileira para } \\
\text { Negócios }\end{array}$ & EAD & $\begin{array}{l}\text { Capacitar os } \\
\text { participantes para } \\
\text { melhor analisar, } \\
\text { compreender e } \\
\text { avaliar as } \\
\text { oportunidades e } \\
\text { o ambiente de } \\
\text { negócios, } \\
\text { preparando-os } \\
\text { para atuar em um } \\
\text { contexto de } \\
\text { constantes } \\
\text { transformações. } \\
\text { Pretende-se } \\
\text { fornecer um } \\
\text { referencial } \\
\text { adequado e um } \\
\text { amplo } \\
\text { instrumental para } \\
\text { capacitá-los a } \\
\text { tomada } \\
\text { estratégica de } \\
\text { decisões dentro } \\
\text { do contexto da } \\
\text { Economia } \\
\text { Brasileira. }\end{array}$ & $\begin{array}{c}2 \text { anos } \\
444 \text { horas }\end{array}$ & 4 módulos & $\begin{array}{c} \\
\\
\text { Graduados em } \\
\text { diversas áreas, } \\
\text { em franca } \\
\text { ascensão } \\
\text { gerencial. } \\
\text { Profissionais } \\
\text { que atuam em } \\
\text { áreas com a } \\
\text { estratégia, } \\
\text { finanças ou } \\
\text { gestão, que } \\
\text { possuam } \\
\text { experiência } \\
\text { gerencial. }\end{array}$ \\
\hline $\begin{array}{c}\text { Escola de } \\
\text { Enfermagem de } \\
\text { Ribeirão Preto - } \\
\text { USP }\end{array}$ & $\begin{array}{l}\text { MBA Gestão } \\
\text { em Saúde }\end{array}$ & EAD & $\begin{array}{c}\text { Capacitar } \\
\text { profissionais para } \\
\text { atuarem de forma } \\
\text { crítica e } \\
\text { competente na } \\
\text { gestão dos } \\
\text { serviços de saúde } \\
\text { em diferentes } \\
\text { cenários do } \\
\text { sistema de saúde } \\
\text { brasileiro. }\end{array}$ & $\begin{array}{c}2 \text { anos } \\
\text { 438horas }\end{array}$ & 6 módulos & $\begin{array}{c}\text { Profissionais } \\
\text { graduados } \\
\text { atuando direta } \\
\text { ou } \\
\text { indiretamente } \\
\text { em atividades } \\
\text { operacionais ou } \\
\text { gerenciais na } \\
\text { Ârea da Saúde } \\
\text { (médicos, } \\
\text { enfermeiros, } \\
\text { nutricionistas, } \\
\text { psicólogos, } \\
\text { farmacêuticos, } \\
\text { fisioterapeutas, } \\
\text { assistentes } \\
\text { sociais, } \\
\text { terapeutas } \\
\text { ocupacionais e } \\
\text { outros } \\
\text { profissionais da } \\
\text { saúde; gestores, } \\
\text { administradore } \\
\text { s, pessoal da } \\
\text { tecnologia da } \\
\text { informação). }\end{array}$ \\
\hline
\end{tabular}


Tabela 10. Características dos cursos de pós-graduação (Continuação)

\begin{tabular}{|c|c|c|c|c|c|c|}
\hline $\begin{array}{c}\text { Instituição } \\
\text { Parceira }\end{array}$ & Curso & Modalidade & Objetivo & Duração & Estrutura & Público-Alvo \\
\hline $\begin{array}{c}\text { Fundação para } \\
\text { Pesquisa e } \\
\text { Desenvolvimento } \\
\text { da Administração }\end{array}$ & $\begin{array}{c}\text { MBA Gestão } \\
\text { Estratégica }\end{array}$ & EAD & $\begin{array}{l}\text { O objetivo geral } \\
\text { é desenvolver } \\
\text { competências } \\
\text { estratégico } \\
\text { financeiras e } \\
\text { oferecer } \\
\text { repertório } \\
\text { qualificado de } \\
\text { conhecimentos } \\
\text { para profissionais } \\
\text { que atuam como } \\
\text { gestores em } \\
\text { organizações } \\
\text { públicas ou } \\
\text { privadas. }\end{array}$ & $\begin{array}{c}2 \text { anos e } \\
\text { seis meses } \\
420 \text { horas }\end{array}$ & 6 módulos & $\begin{array}{c}\text { Graduados em } \\
\text { diversas áreas, } \\
\text { em franca } \\
\text { ascensão } \\
\text { gerencial. } \\
\text { Profissionais } \\
\text { que atuam em } \\
\text { áreas como } \\
\text { estratégia, } \\
\text { finanças ou } \\
\text { gestão de } \\
\text { pessoas com } \\
\text { experiência } \\
\text { gerencial de } \\
\text { aproximadame } \\
\text { nte cinco anos. }\end{array}$ \\
\hline
\end{tabular}

\subsubsection{Descrição curso Gestão em Marketing Estratégico}

A seguir está descrito o evento instrucional titulado MBA Gestão em Marketing Estratégico, ministrado pelo INEPAD em parceria com a FUNDACE concentrou sua entrega por meio da educação à distância (EAD) e presencial.

A Tabela 11 apresenta disciplinas específicas do curso de pós-graduação Gestão em Marketing Estratégico:

Tabela 11. Disciplinas do curso de pós-graduação Gestão em Marketing Estratégico

\begin{tabular}{ccc} 
Disciplina & Tema & Carga Horária \\
\hline 1 & Fundamentos para o Marketing & 108 \\
2 & Marketing Estratégico & 96 \\
3 & Gerenciamento do Marketing Mix & 84 \\
4 & Gestão de Vendas & 24 \\
5 & Tendências em Marketing & 48 \\
6 & Trabalho de Conclusão de Curso & 60 \\
\hline
\end{tabular}

\subsubsection{Descrição curso Contabilidade em IFRS}

Na sequência está descrito o evento instrucional titulado Contabilidade em IFRS, ministrado pelo INEPAD em parceria com a FUNDACE, concentrou sua entrega por meio da educação à distância (EAD) e presencial.

A Tabela 12 apresenta as disciplinas do curso de pós-graduação Contabilidade em 
IFRS:

Tabela 12. Disciplinas do curso de pós-graduação Contabilidade em IFRS

\begin{tabular}{ccc} 
Disciplina & Tema & Carga Horária \\
\hline 1 & Tributação e Instrumentos Financeiros & 48 \\
2 & Ativos, Passivos, Receitas e Despesas & 84 \\
3 & Apresentação de Demonstrações Financeiras & 48 \\
4 & Contabilidade de Grupos Empresariais & 48 \\
5 & Tributação e Instrumentos Financeiros & 72 \\
6 & Outras Normas Contábeis Relevantes & 60 \\
7 & Trabalho de Conclusão de Curso & 60 \\
\hline
\end{tabular}

\subsubsection{Descrição curso Economia Brasileira para Negócios}

A seguir está descrito o evento instrucional titulado MBA Economia Brasileira para Negócios, ministrado pelo INEPAD em parceria com a FUNDACE concentrou sua entrega por meio da educação à distância (EAD) e presencial.

A Tabela 13 apresenta disciplinas específicas do curso de pós-graduação Economia Brasileira para Negócios:

Tabela 13. Disciplinas do curso de pós-graduação Economia Brasileira para Negócios

\begin{tabular}{clc} 
Disciplina & \multicolumn{1}{c}{ Tema } & Carga Horária \\
\hline 1 & Teoria Econômica & 96 \\
2 & $\begin{array}{l}\text { Dados e Estudos Estatísticos, Mercados de Capitais e } \\
\text { Avaliação de Projetos }\end{array}$ & 84 \\
3 & Macroeconomia Brasileira & 72 \\
4 & Análise Setorial da Economia Brasileira & 132 \\
5 & Trabalho de Conclusão de Curso & 60 \\
\hline
\end{tabular}

\subsubsection{Descrição Curso Gestão em Saúde}

Tal como já foi explicitado, o evento instrucional titulado Gestão em Saúde, ministrado pelo INEPAD em parceria com a EERP, concentra sua entrega por meio da educação à distância (EAD), além de encontros presenciais para realização de avaliações e apresentação do TCC. 
A Tabela 14 apresenta as disciplinas do curso de pós-graduação Gestão em Saúde:

Tabela 14. Disciplinas do curso de pós-graduação Gestão em Saúde

Disciplina

\begin{tabular}{lcc}
\hline 1 & Políticas de Saúde e o Sistema Único de Saúde & 72 \\
2 & Paradigmas da Gestão e Gerência em Saúde & 60 \\
3 & Metodologia da Pesquisa e Educação em Saúde & 72 \\
4 & Planejamento, Custos e Insumos em Saúde & 72 \\
5 & Liderança, Empreendedorismo, Inovação e Projetos & 48 \\
6 & Gestão de Pessoas & 60 \\
7 & Trabalho de Conclusão de Curso & 54 \\
\hline
\end{tabular}

\subsubsection{Descrição curso Gestão Estratégica}

A seguir está descrito o evento instrucional titulado MBA Gestão Estratégica, ministrado pelo INEPAD em parceria com a FUNDACE concentrou sua entrega por meio da educação à distância (EAD) e presencial.

A Tabela 15 apresenta disciplinas específicas do curso de pós-graduação Gestão em Marketing Estratégico:

Tabela 15. Disciplinas do curso de pós-graduação Gestão em Marketing Estratégico

\begin{tabular}{clc} 
Disciplina & Tema & Carga Horária \\
\hline 1 & Administração e Contemporaneidade & 84 \\
2 & Gestão de Pessoas & 60 \\
3 & Controladoria & 36 \\
4 & Finanças de Curto e Longo Prazo & 60 \\
5 & Finanças Estratégicas & 60 \\
6 & Estratégias & 60 \\
7 & Trabalho de Conclusão de Curso & 60 \\
\hline
\end{tabular}

Todos os cursos apresentam atividades em cada ciclo de aprendizagem, bem como atividades de avaliação conforme descrição abaixo:

Fórum: Os fóruns são ferramentas de interação, mediados pelo tutor sob a supervisão do Professor responsável pelo Ciclo de Aprendizagem, Supervisor de Conteúdo e Coordenação, sendo o principal canal de reflexão coletivo do curso. Nos fóruns que grande parte das dúvidas é dirimida e onde as opiniões podem ser mais elaboradas por serem frutos de mais profundas reflexões 
Pergunta Dissertativa - PBL (Problem Based Learning): é uma pergunta dissertativa elaborada de modo a embasar a reflexão sobre o conteúdo do Ciclo de Aprendizagem. A instituição de ensino utiliza dos estudos de caso, para esta atividade, pois entende que este método tem grande utilidade, pois demonstra situações potencialmente reais (em muitas circunstâncias os casos são reais de fato). A situação dada é analisada e debatida por diversos pontos de vista tendo como objetivo chegar a múltiplas possibilidades de encaminhamento para o caso. O caso é oferecido no início do Ciclo de Aprendizagem e debatido, com a mediação de um tutor, durante os 15 dias de sua duração. Esta atividade apresenta um importante nível de dificuldade, para que o aluno se prepare para as Provas a Distância e Presencial, e a sua resposta pode estar contida na Aula ao Vivo e/ou no Material didático principal.

Mensagem da Tutoria: Ferramenta utilizada pelos tutores para postagem de comentários ao final de cada ciclo de aprendizagem, onde comenta o desempenho dos alunos naquele ciclo, pontos fortes e fracos observados ao longo da mesma, comentários sobre as melhores e as mais fracas respostas dos alunos nas atividades on-line. Em razão de sua importância no contexto da metodologia do curso, os alunos podem avaliar a qualidade da mensagem de seu tutor, que tem nessa avaliação um dos mais importantes elementos de avaliação de seu desenvolvimento. Atividade Preparatória: Esta atividade exige a reflexão do aluno sobre o tema que será apresentado e sobre as suas implicações práticas, elevando o nível da aula e estimulando o interesse dos alunos, no referido curso, esta atividade não é obrigatória. A Atividade Preparatória será utilizada pelo professor da Aula ao Vivo na $2^{\mathrm{a}}$ parte da aula, para que assim, seja apresentada e discutida durante a transmissão. Além destas atividades, ao final da disciplina (conjunto de 4 a 6 ciclos de aprendizagem) os alunos realizam uma atividade avaliativa a distância que contempla o conteúdo de todos os ciclos de aprendizagem de forma interdisciplinar e prepara os alunos para a realização das Provas Presenciais. Esta atividade pode ser ofertada em dois formatos: Prova a Distância: São 4 questões abertas por Disciplina, em formato dissertativo, que têm como objetivo mensurar a compreensão que cada estudante teve quanto ao conteúdo da Disciplina. Seguindo a linha pedagógica do curso, habitualmente as questões são elaboradas a partir de estudos de casos. Essa atividade é acompanhada pelos Professores, Supervisão de Conteúdo e Coordenação;

Trabalho em Grupo: Alternativamente à Prova a Distância, poderá ser disponibilizado o Trabalho em Grupo, que será composto de 2 a 3 questões. Os alunos são distribuídos de forma aleatória em grupos e serão responsáveis quanto à organização para resolverem o caso proposto. O Trabalho em Grupo conta com menos questões e mais tempo, 
pois se entende que o esforço da construção coletiva demanda mais tempo e organização dos participantes, além de se revelar mais efetivo do ponto de vista de aprendizado. Todas estas atividades são supervisionadas pelos Professores responsáveis dos ciclos de aprendizagem em parceira com os Tutores, Supervisores de Conteúdo e Coordenação.

Atividades presenciais: nos encontros presenciais os alunos devem realizar uma prova presencial individual e dissertativa, que contemple todos os Ciclos de Aprendizagem. A Prova Presencial tem como objetivo avaliar a capacidade do aluno em articular os diversos conceitos apresentados nas disciplinas, bem como sua capacidade de adequação prática desses conteúdos. A elaboração das provas e correção é supervisionada pelos Professores responsáveis dos ciclos de aprendizagem em parceira com os Tutores, Supervisores de Conteúdo e Coordenação

Trabalho de Conclusão do Curso (TCC): O trabalho de conclusão do curso contempla carga horária total estimada de 54 horas, sendo 12 horas referentes a um ciclo de aprendizagem de Metodologia de Pesquisa. Neste este ciclo de aprendizagem não há atividade avaliativa à distância, pois a partir deste momento passa-se ao processo de Desenvolvimento do TCC. Após o encerramento do ciclo de aprendizagem de Metodologia de Pesquisa, o aluno deverá desenvolver o TCC com a orientação de professor indicado pela Coordenação.

De acordo com o PPP dos cursos, que ficam sob posse da IES, podendo ser disponibilizados aos alunos por meio de solicitação dos mesmos, devido ao fato de conter informações de custos operacionais dos cursos. Sobre as disciplinas são divididas em 32 ciclos de aprendizagem de 12 horas que duram 15 dias cada. Estas 12 horas são divididas em atividades agrupadas, atividades a distância ministradas, 4 horas por ciclo de aprendizagem, atividades a distância supervisionadas, 7 horas e 30 minutos por ciclo de aprendizagem, atividades presenciais, 30 minutos por ciclo de aprendizagem

Ainda no que se refere aos ciclos de aprendizagem, são realizadas 2 aulas ao vivo, por meio da internet (voz e vídeo), de 2 horas cada uma, ministradas pelo professor responsável do ciclo de aprendizagem. As aulas são realizadas ao vivo, sendo que os alunos são divididos em salas de chat on-line com até 50 alunos. Há um tutor que acompanha a discussão da turma e estimula os alunos para o envio de dúvidas acerca do conteúdo que serão respondidas pelo professor responsável. 


\subsubsection{Resultados das análises dos cursos}

A partir da análise dos cursos é possível verificar uma grande homogeneidade entre os cursos MBA Gestão de Marketing Estratégico, MBA em Contabilidade e IFRS e Economia Brasileira para Negócios, MBA Gestão em Saúde e MBA em Gestão Estratégica, no que tange às características dos mesmos, como: tempo de duração, número de módulos, e atividades previstas nas grades dos cursos.

Os resultados apontaram que, com exceção ao MBA Contabilidade em IFRS, os objetivos instrucionais estão descritos em termos de desempenhos observáveis e há clareza na descrição e precisão do verbo de ação; Quanto às estratégias instrucionais, observou-se que estimulam situações cotidianas e práticas diárias, este fator pode contribuir para a aprendizagem dos alunos; As estratégias instrucionais se encontram adequadas ao perfil da clientela e objetivos dos cursos; Sobre os planejamento do curso, a carga horária se apresentou adequada ao volume de disciplinas oferecidas, no programa contém informações sobre os meios de interação e avaliação dos alunos; A sequenciação do ensino se apresentou de forma adequada em todos os cursos; $\mathrm{Na}$ maior parte dos casos as fontes bibliográficas são dos últimos cinco anos; De um modo geral, os cursos apresentaram características que contribuem para a aprendizagem dos alunos que participaram do curso.

\subsection{Características da Amostra do Estudo 1}

A amostra do Estudo 1 é composta dos alunos e ex-alunos do programa de EAD, da instituição de ensino parceira. Foram convidados a compor a amostra 1.603 alunos que concluíram o curso. Foram convidados também 333 alunos evadidos, ou seja, que não concluíram o curso. Ao total participaram 142 pessoas, sendo 3 evadidos e 139 não evadidos. Sobre a região predominante da amostra, se caracteriza pela região Sudeste, $71 \%$ da amostra é composta por esta região, seguida pela região Sul com $12 \%$, Centro- Oeste com $8 \%$, Nordeste $7 \%$ e Norte com 2\%, todos os alunos possuem Ensino Superior Completo, já possuíam experiências anteriores ao uso da internet. Ainda sobre as características dos participantes, $64 \%$ da amostra encontram-se casados, $23 \%$ solteiros, $7 \%$ divorciados e $6 \%$ com união estável, $54 \%$ da amostra possuem filhos e $46 \%$ da amostra não possuem filhos.

\subsection{Características da Amostra do Estudo 2}


A amostra do Estudo 2 é composta por ex-alunos do programa de EAD, da instituição de ensino parceira. Ao total foram convidados 3 alunos que evadiram-se do curso, mas apenas 2 alunos aceitaram participar da etapa qualitativa da pesquisa. Ambos são casados e possuem filhos, residem na região Sudeste, O participante A participante possui superior completo e o participante B possui Pós-Graduação completa Lato Sensu e Strictu Senso.

\subsubsection{Instrumentos de medida do Estudo 1}

Os instrumentos de medida empregados na investigação são: 1) Estratégias de Aprendizagem (Martins, Zerbini e Medina, 2018) (Anexo C); 2) Barreiras EAD (Martins, Zerbini e Medina, 2018), submetido. Tais instrumentos foram desenvolvidos e validados em pesquisas precedentes. A seguir, são apresentadas as informações referentes às estruturas empíricas de cada uma dessas escalas obtidas nos estudos correspondentes (Tabela 16).

Tabela 26. Resumo das informações sobre os instrumentos utilizados no Estudo 1

\begin{tabular}{|c|c|c|c|c|c|}
\hline \multirow{2}{*}{ Instrumento } & \multirow{2}{*}{ Escalas obtidas } & \multirow{2}{*}{$\begin{array}{l}N^{0} \text { de } \\
\text { itens }\end{array}$} & \multirow{2}{*}{ Alfa } & \multicolumn{2}{|c|}{ Cargas fatoriais } \\
\hline & & & & Min. & Max. \\
\hline \multirow{4}{*}{$\begin{array}{l}\text { Estratégias de } \\
\text { Aprendizagem } \\
\text { (Martins, Zerbini } \\
\text { e Medina, 2018). }\end{array}$} & Monitoramento da compreensão & 14 & 0,87 & 0,30 & 0,70 \\
\hline & Estratégias autorregulatórias & 9 & 0,80 & 0,35 & 0,81 \\
\hline & Busca de ajuda interpessoal & 4 & 0,82 & 0,63 & 0,72 \\
\hline & $\begin{array}{l}\text { Estratégias cognitivo- } \\
\text { comportamentais }\end{array}$ & 10 & 0,78 & 0,38 & 0,80 \\
\hline \multirow{3}{*}{$\begin{array}{c}\text { Barreiras em } \\
\text { EAD (Martins, } \\
\text { Zerbini e Medina, } \\
\text { 2018), } \\
\text { submetido. }\end{array}$} & $\begin{array}{l}\text { Desenho do curso e Interação } \\
\text { Social/Tutoria }\end{array}$ & 9 & 0,77 & 0,41 & 0,56 \\
\hline & $\begin{array}{l}\text { Condições pessoais e tempo } \\
\text { disponíveis }\end{array}$ & 8 & 0,64 & $-0,33$ & $-0,50$ \\
\hline & Características do aluno & 4 & 0,72 & $-0,39$ & $-0,49$ \\
\hline
\end{tabular}

\subsubsection{Instrumentos de medida do Estudo 2}

Para a realização do Estudo 2, foi construído um roteiro semiestruturado de Barreiras a Conclusão do Curso em EAD. Tal instrumento foi desenvolvido e validado por dois juízes, sendo um mestre e um doutor em TD\&E. O detalhamento do instrumento segue abaixo: 
Tabela 17. Resumo das informações sobre os instrumentos utilizados no Estudo 2

\begin{tabular}{ccc}
\hline Instrumento & Origem & Objetivo \\
\hline Roteiro & & Identificar as barreiras que \\
semiestruturado de & Instrumento elaborado pela autora, & influenciaram a evasão do \\
curreiras a Conclusão & submetido a validação por juízes & EAduação em \\
do Curso em EAD & & EAD.
\end{tabular}

Tabela 18. Número de questões referente a cada tema do roteiro de Barreiras a Conclusão do Curso em EAD

\begin{tabular}{lc}
\hline Temas abordados & $\mathbf{N}^{\mathbf{0}}$ de questões \\
\hline Contexto de Estudo & 4 \\
Desenho do Curso & 10 \\
Perfil do Estudante & 7 \\
\hline
\end{tabular}

\subsubsection{Procedimentos de coleta de dados do Estudo 1}

Os dados do Estudo 1 foram coletados por meio de um questionário que foi enviado por email aos alunos e ex-alunos do programa de EAD, da instituição de ensino parceira. A coleta de dados foi realizada a distância, pela internet, por meio da qual os instrumentos foram enviados via e-mail, em formato de questionário no google drive, para serem respondidos e enviados pelos estudantes do programa de EAD da instituição de ensino superior parceira contatada. Os questionários foram enviados para 1.936 pessoas, destas 1.603 concluíram o curso e 333 evadiram-se, ao total tiveram142 respondentes, sendo 3 evadidos e 139 não evadidos, devido a baixa participação dos estudantes foram enviados à eles diversas vezes aos um e-mail abordando sobre a importância da participação deles, mas a participação mesmo assim foi pequena.

\subsubsection{Procedimentos de coleta de dados do Estudo 2}

Os dados do Estudo 2 foram coletados por meio de um roteiro semiestruturado de Barreiras à Conclusão do curso de Pós-Graduação em EAD. Para a coleta dos dados foi feito o contato com três alunos que se evadiram dos cursos, mas apenas dois de mostraram dispostos a colaborar. As entrevistas foram realizadas via Skype com dois alunos que se evadiram dos cursos de MBA em Gestão Estratégica Turma II e MBA em Gestão em Saúde 
Turma I, da instituição de ensino superior parceira contatada. Estes alunos participaram da do Estudo 1 respondendo os questionários, por isso, foram convidados a participar do Estudo 2.

\subsection{Considerações Éticas}

No que tange aos aspectos éticos para a realização de pesquisa, o estudo foi submetido à aprovação do Comitê de Ética em Pesquisa da Faculdade de Filosofia, Ciências e Letras de Ribeirão Preto (FFCLRP-USP). No Estudo 1, o Termo de Consentimento Livre e Esclarecido (Apêndice A), era o primeiro item composto pelo questionário, tendo o participante a opção de aceitar ou não fazer parte do estudo, nele também continha os objetivos da pesquisa e seus procedimentos. Conforme as diretrizes da Resolução 196/96, do Conselho Nacional de Saúde, cada participante tem garantido a manutenção de sigilo e anonimato acerca de sua identidade, o caráter voluntário de sua participação, o direito de recusa/interrupção em sua participação na pesquisa há qualquer momento, bem como, foi requerida a autorização do uso de suas informações no estudo. Já no Estudo 2 os termos foram enviados por e-mail, antes da realização das entrevistas, sob posse dos aceites, as entrevistas foram agendadas.

\subsection{Procedimentos de Análise de Dados Estudo 1}

Para aplicação dos procedimentos de análise de dados, foram consultadas as orientações de Hair et al. (2005), Pasquali (2004) e Tabachnick e Fidell (2007). Foram realizadas as análises descritivas (média, desvio-padrão, moda, mínimo e máximo) e exploratórias para investigar a exatidão da entrada dos dados, a presença de casos extremos, a distribuição dos casos omissos, a distribuição de frequência das variáveis e o tamanho das amostras. Para a verificação de evidências de validade dos instrumentos de medida, foram realizadas análises fatoriais exploratórias, utilizando os métodos dos componentes principais (Principal Components- PC) e de fatoração dos eixos principais (Principal AxisFactoring PAF); e de consistência interna (Alfa de Cronbach). As análises descritivas, exploratórias e fatoriais foram feitas no SPSS (StatisticalPackage for the Social Science) versão 19.0. Na AFE, o método e os dados estatísticos definem a natureza das relações e a matriz de correlações procura os fatores. 


\subsubsection{Procedimentos de análises exploratórias das estruturas empíricas dos questionários}

As análises do estudo 1 que consistiram na validação dos instrumentos foram realizadas no SPSS versão 19.0. Para a realização das análises exploratórias foram identificados os casos omissos, casos extremos univariados e multivariados, multicolinearidade, singularidade e linearidade, de acordo com a teoria de Tabachnick e Fidell (2001). Nesta etapa não foram realizados os testes de normalidade das distribuições de frequência, esta decisão foi tomada, pois segundo Pasquali (2004), a normalidade não é um problema grave na análise fatorial exploratória, pois essa técnica é robusta e suporta desvios de normalidade.

Em caso de identificação de casos omissos, é possível prosseguir de três formas: substituí-los pela média, eliminá-los em uma ou duas variáveis, quando os mesmos são tomados aos pares (parwise), considerar apenas os dados que contêm dados válidos em todos os indicadores/variáveis (listwise). É necessário verificar a quantidade bem como a aleatoriedade de dados ausentes antes de optar por um dos procedimentos, devido a possível identificação de subgrupos amostrais. Porém esta análise não é essencial quando o percentual de dados omissos for inferior a 5\% dos casos. Ao longo na análise observou-se que nenhuma variável apresentava mais do que 5\% dos casos omissos, foi escolhido o método pairwise. Para que fossem identificados os casos extremos univariados todas as variáveis foram transformadas em escores $\mathrm{Z}$. Todas as respostas que continham escores iguais ou superiores a 3.29 ( $\mathrm{p}=0,001$, two-tailed). Os casos extremos multivariados foram identificados a partir da distância Mahalanobis $(\alpha=0,001)$ e na sequência foram excluídos.

Posteriormente foram realizadas as análises fatoriais dos dois instrumentos, seguindo as orientações de Pasquali (2004), é necessário seguir alguns passos como: coleta da informação através da pesquisa empírica, elaboração da matriz de covariância, análise da matriz de covariância em termos de fatorabilidade e do número de fatores, extração inicial dos fatores, rotação dos fatores para uma estrutura final, interpretação dos fatores, construção dos escores fatoriais para uso em análises futuras. Para que fosse elaborada a matriz de covariância, algumas características apontadas por Pasquali (2004), foram utilizadas e serão apresentadas a seguir:

i. Para a análise fatorial foi utilizado o tipo mais adequado de matriz de covariâncias, baseado nas correlações bivariadas paramétricas de Pearson; 
ii. Sobre o tamanho da amostra é recomendável cerca de 10 casos para cada variável observável, no estudo tiveram 8 casos para cada variável;

iii. Para a análise fatorial exploratória a normalidade não é um problema grave, pois é uma análise robusta e por isso suporta os desvios de normalidade. A linearidade afeta a análise fatorial, pois as correlações consistem em medidas de relações lineares. Para a análise da linearidade foram realizadas correlações bivariadas e o parâmetro avaliado foi o coeficiente de correlação produto-momento de Pearson , ou seja, valores diferentes de zero e significativos indicam a presença de uma relação linear, considerada forte quanto mais próxima for o coeficiente obtido.

iv. As variáveis com multicolinearidade se definem pela por terem uma correlação tão grande ao ponto de parecerem sinônimos. Sendo assim é necessário que uma das variáveis seja excluída da análise. Já as variáveis que apresentam singularidade são redundantes, uma variável é a combinação de duas ou mais variáveis. Para a análise das multicolinearidade e singularidade, foi preciso verificar a existência de correlações superiores a 0,90, seguindo a sugestão de Pasquali (2004), também foram analisadas as correlações superiores a 0,80, seguindo as sugestões de Tabachnick e Fidell (2001).

Para a realização análise de fatorabilidade da matriz de covariância, ou seja, verificar se a matriz possui covariâncias e qual o número de fatores, foram realizados os passos a seguir:

i. Para a análise do tamanho das correlações, a correlação considerada importante quando o valor apresentado estava acima de 0,30, positivo ou negativo. Se os valores de correlações acima de 0,30 ultrapassavam 50\% dos casos, significava que a matriz podia ser fatorável;

ii. Para a análise das correlações parciais das variáveis foi utilizado o teste de adequação da amostra de Kaiser-Meyer-Olkin (KMO). Quanto mais próximo do valor 1 estiver o índice, mais a matriz é fatorável, porque isto indica que as variáveis têm muita variância em comum.

i. Foi realizada uma análise para obter a extração inicial dos fatores dos componentes principais (Principal Components), ela busca reduzir o número de variáveis em componentes que expliquem a maior parte da variância original das variáveis. É uma técnica que analisa os componentes mais importantes, também é considerada uma técnica de simplificação e ortogonalização. Sobre a análise fatorial (AF) pode-se defini-la como 
técnica que analisa as covariâncias e possui um modelo teórico que subsidia as suas análises, assumindo que a covariância entre as variáveis é produto de uma causa comum entre elas que são os fatores comuns. Já a PC tem o papel de reduzir apenas o tamanho de uma matriz (rank reduction). $\mathrm{Na}$ análise PC foram utilizados os seguintes critérios: Sobre os critérios convencionais, foram considerados apenas os valores próprios (eigenvalues) superiores a 1 (um), foi analisada a distribuição visual dos valores próprios definida como o scree plot (os pontos que representam os componentes passam de uma inclinação acentuada para uma inclinação quase horizontal, retendo-se os componentes que se encontram à esquerda desse ponto);

ii. Já os critérios estatísticos denominados testes de significância, foi realizada a análise paralela de Horn. Segundo Laros (2004), apresenta índice de precisão de $92 \%$ de indicação correta do número de fatores, sendo melhor método para definição do número de fatores de uma matriz de respostas a questionários. Essa análise compara valores próprios aleatórios, obtidos com o auxílo do software RanEign, devido a quantidade de variáveis e tamanho da amostra. Os fatores são retirados da estrutura quando apresentam valor próprio empírico igual ou menor que os valores aleatórios;

iii. Sobre os critérios de relevância do fator, forma feitas análises de interpretabilidade, importância e consistência dos fatores logo após a rotação dos fatores. A importância do fator é definida pela variância que consegue explicar após a rotação da matriz fatorial. O critério de Harman considera um fator irrelevante aquele que explica menos que $3 \%$ da variância total das variáveis. A validade do fator é expressa pelo tamanho das cargas fatoriais, sendo assim, quanto maiores elas forem, mais a variável é representativa do fator. Porém, um fator pode ser válido e ao mesmo tempo não ser consistente, devido a isso foram feitas análises de consistência dos fatores, por meio da análise de Alfa de Cronbach.

Seguindo as análises o passo seguinte foi obter e confirmar as estruturas fatoriais, através das análises fatoriais, utilizando o método de fatoração dos eixos principais (Principal Axis Factoring $-P A F)$, que utiliza os mesmos métodos da PC, porém na diagonal da matriz, 
substituindo o valor 1 da PC por uma estimativa de comunalidades, pois a variabilidade interessante na PAF é a variabilidade que as variáveis têm em comum, ou seja, a covariância entre elas (modelo causal). Existe uma vantagem em se utilizar a PC antes da PAF, com todos os seus critérios, é definir os números mínimos de fatores a serem extraídos inicialmente.

Foi utilizado o método de rotação oblíqua (direct oblimin), pois ele permite que apareçam fatores ortogonais quando existirem, e também não força a dependência entre os fatores, ao passo que a rotação ortogonal só permite fatores independentes. Após a extração dos fatores, para que os mesmos possam ser usados nas próximas análises e futuras pesquisas, foram verificadas a estabilidade e interpretabilidade dos mesmos, também foram produzidos escores fatoriais.

Para a análise de estabilidade, foi verificado o quanto os itens eram bons representantes do fator, pelo tamanho da carga fatorial, que é correlação entre o item com o conjunto dos outros itens do fator (quanto mais próxima de 1 for esta carga, melhor representa o fator). Por fim, para analisar a interpretabilidade identificou-se o traço latente que é considerado a causa do agrupamento das variáveis, por meio da análise da literatura da área. Os escores fatoriais foram produzidos pela média dos escores das variáveis originais que pertencem ao fator.

\subsubsection{Procedimentos de análises dos testes de regressão múltipla}

Realizadas as análises fatoriais exploratórias, na sequência foram produzidos os escores fatoriais a partir da média das variáveis originais dos fatores. Foram realizadas análises de regressão múltipla padrão, com o objetivo de investigar quais foram os principais preditores da variável Barreiras em EAD. Conforme os critérios definidos por Tabachnick e Fidell (2001), as análises de regressão precisam respeitar os seguintes critérios de inclusão para análise: a amostra deve ser maior ou igual a 50 casos mais oito vezes o número de variáveis antecedentes $(\mathrm{N}>50+8 \mathrm{~m})$ para testar correlações múltiplas e $\mathrm{N}>104+\mathrm{m}$, para testar preditores individuais. No capítulo de resultados será apresentado mais detalhes sobre a amostra. Foi decidido utilizar os dados originais nas regressões múltiplas, não foram identificados casos de assimetria e curtose.

Sobre a assimetria e curtose Miles e Shelvlin (2001) sugerem que se o valor da assimetria ou curtose (o sinal de menos é ignorado) é menor do que 1.0, então o problema é tão pequeno que não chega a ser preocupante, se é maior que 1.0 e menor que 2.0, é um pouco 
preocupante, mas provavelmente a distribuição está bem próxima da normalidade, se é maior que 2.0, o caso é preocupante. Cada um dos valores citados depende do tamanho da amostra, ou seja, quanto maior a amostra, menor deve será preocupação com a normalidade.

A seguir serão apresentados os valores de assimetria e curtose, associados aos desviospadrão dos escores fatoriais das escalas Estratégias de Aprendizagem e Barreiras em EAD.

Tabela 19. Valores de assimetria e curtose e os desvios-padrão associados às Estratégias de Aprendizagem

\begin{tabular}{ccccc}
\hline & $\begin{array}{c}\text { Estrat_Cog- } \\
\text { nitivas }\end{array}$ & $\begin{array}{c}\text { Estrat_Autorregulatória } \\
\text { s }\end{array}$ & Aplicação_Prática & Busca_Aju-da_Inter \\
\hline $\mathrm{N}^{\mathbf{0}}$ de Casos & 138 & 142 & 140 & 138 \\
\hline Assimetria & $-0,408$ & $-0,472$ & $-0,212$ & 0,018 \\
DP assimetria & 0,206 & 0,203 & 0,205 & 0,206 \\
\hline Curtose & 0,13 & $-0,165$ & $-0,348$ & $-0,666$ \\
DP curtose & 0,41 & 0,404 & 0,407 & 0,41 \\
\hline
\end{tabular}

Na tabela 19, apresentaram uma assimetria e curtose diferentes de uma distribuição normal, porém todos os valores são abaixo de 1.0, não sendo preocupantes, além de mostrar que estão bem próximos da normalidade. Na sequência será apresentada a tabela 20, com os escores fatoriais de Barreiras em EAD.

Tabela 20. Valores de assimetria e curtose e os desvios-padrão associados às Barreiras em EAD

$$
\text { Suporte_Inst Context_Ext_Cur-so } \begin{gathered}
\text { Desenho_Cu- } \\
\text { rso }
\end{gathered} \underset{\begin{array}{c}
\text { Caract_Alu- } \\
\text { no }
\end{array}}{\begin{array}{c}
\text { Quest_Saú- } \\
\text { de_Financ }
\end{array}}
$$

\begin{tabular}{cccccc}
\hline $\mathrm{N}^{\mathrm{o}}$ de Casos & 140 & 140 & 137 & 140 & 139 \\
\hline Assimetria & $-0,916$ & $-0,208$ & $-0,933$ & $-0,975$ & $-1,129$ \\
DP assimetria & 0,205 & 0,205 & 0,207 & 0,205 & 0,206 \\
\hline Curtose & 0,069 & $-1,013$ & $-0,302$ & $-0,273$ & $-0,99$ \\
DP curtose & 0,407 & 0,407 & 0,411 & 0,407 & 0,408 \\
\hline
\end{tabular}

Na tabela 20, apresentaram uma assimetria diferente de uma distribuição normal, porém a maioria dos valores são abaixo de 1.0, não sendo preocupantes, além de mostrar que estão bem próximos da normalidade. A assimetria da variável Context_Ext_Curso, possui um valor acima de 1.0 e abaixo de 2.0, ou seja, não é tão alto ao ponto de ser preocupante. A curtose da variável Quest_Saúde_Financ, possui um valor acima de 1.0 e abaixo de 2.0, também não é tão alto ao ponto de ser preocupante. 
Para a análise da linearidade foram feitas correlações bivariadas e o parâmetro considerado foi o coeficiente de correlação produto-momento de Pearson, segundo ele, os valores diferentes de zero e significativos sugerem a presença de uma relação linear, ela é considerada forte quanto mais próximo de 1 for o coeficiente obtido. Neste trabalho foram encontradas relações lineares entre as variáveis utilizadas das regressões.

$\mathrm{Na}$ análise de singularidade a maioria das correlações estão com valores acima de 0,30, quando a correlação entre as variáveis é abaixo de 0,30 , os instrumentos não são válidos. A análise de multicolinearidade não apontou a existência de correlações acima de 0,80 e 0,90, se os itens apresentam correlação acima de 0,80 , significa que os itens são tão correlacionados que representam a mesma variável. Para esta análise foram utilizadas as literaturas de Tabachnick e Fidell (2001) e por Pasquali (2004), portanto, não foram identificados casos de singularidade e multicolinearidade. Após as análises exploratórias foram realizadas as regressões múltiplas que serão apresentados no capítulo 5.

\subsubsection{Procedimentos de Análise de Dados Estudo 2}

Para a realização da análise dos dados qualitativos foi escolhido como método a análise temática, ela pode ser definida como um processo utilizado para codificar as informações qualitativas, a partir de uma sequência: identificação, análise e informação dos padrões temáticos relacionados à questão de pesquisa, a partir do conjunto de dados coletados pelo pesquisador (Braun \& Clarke, 2006). A análise temática é utilizada em diversas áreas de estudo, pois possibilita que as informações coletadas sejam analisadas sistematicamente, o que resulta na evidência dos temas mais relevantes para a compreensão do fenômeno estudado (Joffe, 2012).

Segundo Bardin (1977), a análise temática é uma das formas que melhor se adequou a investigações qualitativas. $\mathrm{O}$ autor propõe que três etapas constituem a aplicação desta técnica de análise: (1) Pré-análise; (2) Exploração do material; (3) Tratamento dos resultados e interpretação.

Um tema pode ser definido como um padrão identificado que descreve e organiza informações a partir dos dados coletados na pesquisa. Esses temas podem ser identificados em dois níveis: manifesto a partir das informações explícitas presentes nos dados, ou nível latente, que envolve a intepretação dos dados coletados. Neste estudo, os temas foram 
identificados em nível manifesto e foi utilizada a abordagem dedutiva para a elaboração dos temas (Boyatzis,1998).

Braun e Clarke (2006) elaboraram um o guia de diretrizes para a análise temática que foi escolhido para a utilização da análise deste estudo. As fases que compõem estas diretrizes estão apresentadas na Tabela 21.

Tabela 21. Diretrizes da análise temática

\begin{tabular}{|c|c|}
\hline Fase & Descrição do processo \\
\hline $\begin{array}{l}\text { 1. Familiarizar-se com os } \\
\text { dados }\end{array}$ & Transcrever os dados, ler e reler os dados, tomar nota das ideias iniciais \\
\hline 2. Gerar códigos iniciais & $\begin{array}{l}\text { Codificar recursos interessantes dos dados de forma sistemática em todo o } \\
\text { conjunto de dados, agrupar dados relevantes para cada código }\end{array}$ \\
\hline 3. Procurar por temas & $\begin{array}{l}\text { Transformar códigos em temas potenciais, reunir todos os dados relevantes } \\
\text { para cada tema potencial }\end{array}$ \\
\hline 4. Revisar os temas & $\begin{array}{l}\text { Checar se os temas trabalham em relação com os extratos codificados e } \\
\text { com todo o conjunto de dados, gerar um "mapa" temático de análise }\end{array}$ \\
\hline $\begin{array}{l}\text { 5. Definir e nomear os } \\
\text { temas }\end{array}$ & $\begin{array}{l}\text { Analisar os temas para refinar as especificidades de cada tema e a história } \\
\text { geral que a análise conta, gerar definições e nomes claros para cada tema }\end{array}$ \\
\hline 6. Relatar & $\begin{array}{l}\text { Selecionar exemplos de extratos vívidos e convincentes, analisar os } \\
\text { extratos selecionados, relacionar a análise com as questões de pesquisa e } \\
\text { dados da literatura }\end{array}$ \\
\hline
\end{tabular}

Fonte: Braun e Clarke (2006).

\subsubsection{Validação Semântica do Instrumento do Estudo 2}

O roteiro semiestruturado de Barreiras à Conclusão em Cursos de Pós-Graduação em EAD, foi construído com base nas teorias sobre barreiras em educação a distância, posteriormente foi analisado por dois juízes, afim de apontarem possíveis falhas presentes no instrumento, após os apontamentos, as alterações foram feitas e foram realizadas as entrevistas. 


\section{CAPÍTULO 5. RESULTADOS}

\section{Objetivo do capítulo 5}

O objetivo deste capítulo é apresentar os resultados obtidos no Estudo 1 e Estudo 2, desta pesquisa, relacionando estes com os objetivos propostos inicialmente.

\subsection{Análises Descritivas}

A seguir são apresentados os resultados descritivos de cada variável do modelo de investigação. São discutidos os valores das médias, desvios-padrão, modas, mínimo, máximo e concentração das respostas dos participantes.

\subsection{Estratégias de Aprendizagem}

Abaixo, na tabela 22 são apontados os resultados descritivos dos itens do questionário de Estratégias de Aprendizagem, que mensura a frequência de comportamentos utilizados pelo aluno durante o curso. O instrumento possui 18 itens associados a uma escala Likert que varia de 1 (Nunca) a 5 (Sempre).

Tabela 22. Estratégias Descritivas

\begin{tabular}{|l|c|c|c|c|c|c|c|c|}
\hline \multicolumn{1}{|c|}{ Itens } & $\begin{array}{c}\text { Casos } \\
\text { Omissos }\end{array}$ & $\mathbf{N}$ & Média & $\begin{array}{c}\text { Desvio } \\
\text { Padrão }\end{array}$ & Moda & \multicolumn{2}{c|}{$\begin{array}{c}\text { Concentração de } \\
\text { Respostas (\%) }\end{array}$} \\
\hline & & & & & & $1 \_2$ & 3 & $4 \_5$ \\
\hline $\begin{array}{l}\text { 18. Associei os conteúdos do curso aos } \\
\text { meus conhecimentos anteriores. }\end{array}$ & 0 & 142 & 4,32 & 0,634 & 4 & 0,7 & 7 & 92,2 \\
\hline $\begin{array}{l}\text { 1. Mantive a calma quando tive } \\
\text { dificuldades durante o curso. }\end{array}$ & 0 & 142 & 4,3 & 0,753 & 5 & 2,8 & 9,2 & 88,1 \\
\hline $\begin{array}{l}\text { 3. Mantive a calma diante dos erros que } \\
\text { cometi ao realizar atividades do curso. }\end{array}$ & 0 & 142 & 4,12 & 0,821 & 4 & 4,9 & 13,4 & 81,7 \\
\hline $\begin{array}{l}\text { 14. Realizei os exercícios práticos } \\
\text { propostos ao longo do curso para me } \\
\text { ajudar a aprender. }\end{array}$ & 1 & 141 & 4,1 & 1,002 & 5 & 7 & 13,5 & 79,4 \\
\hline $\begin{array}{l}\text { 6. Esforcei-me para verificar minha } \\
\text { compreensão sobre o que estava sendo } \\
\text { ensinado. }\end{array}$ & 1 & 142 & 4,04 & 0,841 & 4 & 3,5 & 20,4 & 76,1 \\
\hline $\begin{array}{l}\text { 8. Busquei compreender melhor os } \\
\text { conteúdos ao estudá-los nos materiais } \\
\text { didáticos do curso. }\end{array}$ & 0 & 142 & 4,04 & 0,829 & 4 & 4,2 & 17,6 & 78,2 \\
\hline
\end{tabular}

Tabela 22. Estratégias Descritivas (Continuação) 


\begin{tabular}{|l|c|c|c|c|c|c|c|c|}
\hline $\begin{array}{l}\text { 15. Refleti sobre as implicações que os } \\
\text { conteúdos aprendidos poderiam ter. }\end{array}$ & 1 & 141 & 4,04 & 0,769 & 4 & 3,5 & 14.9 & 81,5 \\
\hline $\begin{array}{l}\text { 17. Busquei desenvolver uma ideia } \\
\text { global sobre como os conteúdos do curso } \\
\text { se relacionavam entre si. }\end{array}$ & 1 & 141 & 3,99 & 0,671 & 4 & 2,1 & 16,3 & 81.6 \\
\hline $\begin{array}{l}\text { 4. Esforcei-me mais quando percebi que } \\
\text { estava perdendo a concentração. }\end{array}$ & 1 & 141 & 3,94 & 0,904 & 4 & 4,9 & 24,8 & 70,2 \\
\hline $\begin{array}{l}\text { 16. Identifiquei situações diárias em que } \\
\text { eu pudesse aplicar os conteúdos do } \\
\text { curso. }\end{array}$ & 2 & 140 & 3,91 & 0,821 & 4 & 5,7 & 21,4 & 72,9 \\
\hline $\begin{array}{l}\text { 2. Mantive a calma com a possibilidade } \\
\text { de ter um rendimento abaixo do } \\
\text { esperado. }\end{array}$ & 0 & 142 & 3,73 & 1,005 & 4 & 10,5 & 27,5 & 61,9 \\
\hline $\begin{array}{l}\text { 9. Busquei outras fontes de pesquisa } \\
\text { relacionadas ao curso para me ajudar a } \\
\text { aprender. }\end{array}$ & 4 & 138 & 3,72 & 1,119 & 5 & 15,2 & 25,4 & 59,5 \\
\hline $\begin{array}{l}\text { 5. Esforcei-me mais quando percebi que } \\
\text { estava perdendo o interesse no assunto. }\end{array}$ & 0 & 142 & 3,65 & 1,011 & 4 & 12 & 31,7 & 56,3 \\
\hline $\begin{array}{l}\text { 12. Fiz anotações, resumos e/ou } \\
\text { esquemas dos conteúdos do curso como } \\
\text { método para aprender. }\end{array}$ & 2 & 140 & 3,44 & 1,152 & 4 & 22,8 & 24,3 & 52,9 \\
\hline $\begin{array}{l}\text { 10. Li o conteúdo do curso várias vezes } \\
\text { como método para aprender. }\end{array}$ & 1 & 141 & 3,29 & 1,039 & 4 & 23,4 & 31,2 & 45,3 \\
\hline $\begin{array}{l}\text { 13. Revisei os conteúdos relativos aos } \\
\text { exercícios em que cometi erros. }\end{array}$ & 2 & 140 & 3,29 & 0,963 & 3 & 18,6 & 40 & 41,4 \\
\hline $\begin{array}{l}\text { 11. Repeti mentalmente os conteúdos do } \\
\text { curso que gostaria de aprender até } \\
\text { perceber que havia entendido. }\end{array}$ & 2 & 140 & 3,1 & 1,041 & 3 & 27,1 & 38,6 & 34,3 \\
\hline $\begin{array}{l}\text { 7. Busquei auxílio de colegas para } \\
\text { esclarecer minhas dúvidas sobre os } \\
\text { conteúdos do curso. }\end{array}$ & 0 & 142 & 2,61 & 1,203 & 2 & 54,2 & 21,1 & 24,7 \\
\hline
\end{tabular}

Sobre a análise da tabela 22, dos 18 itens do questionário, 16 apresentaram maior concentração das respostas nos pontos mais altos da escala (4 e 5), entre 41,4 e 92,2\%, o item 7 item se concentrou nos pontos mais baixos da escala ( 1 e 2), com 54,2\% e o item 11 se concentrou no ponto médio da escala (3), com 38,6\%. Pode-se verificar na tabela que a variação média do uso das estratégias de aprendizagem foi de 2,61 a 4,32. Os valores da moda variaram entre 2,3,4 e 5. É possível verificar que os alunos utilizaram com mais frequência as estratégias cognitivas, controle da emoção e motivação, reflexão para aplicação prática e utilizaram menos a busca por ajuda interpessoal. Analisando de forma mais profunda pode se afirmar que os alunos foram estimulados a utilizar as estratégias cognitivas, e as autorregulatórias que são o controle da emoção e motivação, reflexão para aplicação prática. O uso destas estratégias é importante para que os alunos mantenham a atenção no curso, controlem a ansiedade no decorrer da ação instrucional e mantenha-se motivados, também é importante ressaltar a reflexão para a aplicação prática, ou seja, o que vai levar o aluno a 
transferência do conhecimento em situações cotidianas e de trabalho. As estratégias menos utilizadas foram a de busca por ajuda interpessoal, isso pode refletir em uma necessidade maior do EAD em promover ações de integração entre os alunos, que podem trocar experiências e enriquecer a aprendizagem ao longo do curso.

\subsubsection{Barreiras em EAD}

Na tabela 23 são apontados os resultados descritivos dos itens do questionário Barreiras em EAD, que mensura a frequência das características relacionadas ao curso e perfil do aluno que podem ter atuado como barreiras durante o curso. O instrumento possui 22 itens associados a uma escala Likert que varia de 1 (Dificultou totalmente o desempenho) a 5 (Não dificultou o desempenho).

Tabela 23. Barreiras Descritivas

\begin{tabular}{|c|c|c|c|c|c|c|c|c|}
\hline \multirow[t]{2}{*}{ Itens } & \multirow[t]{2}{*}{$\begin{array}{c}\text { Casos } \\
\text { Omissos }\end{array}$} & \multirow[t]{2}{*}{$\mathbf{N}$} & \multirow[t]{2}{*}{ Média } & \multirow[t]{2}{*}{$\begin{array}{l}\text { Desvio } \\
\text { Padrão }\end{array}$} & \multirow[t]{2}{*}{ Moda } & \multicolumn{3}{|c|}{$\begin{array}{l}\text { Concentração de } \\
\text { Respostas }(\%)\end{array}$} \\
\hline & & & & & & $1 \_2$ & 3 & $4 \_5$ \\
\hline $\begin{array}{l}\text { 22. Habilidades pessoais para uso das } \\
\text { ferramentas web (chats, e-mails, } \\
\text { fóruns, etc.). }\end{array}$ & 1 & 141 & 4,7 & 0,707 & 5 & 2,8 & 5,7 & 91,5 \\
\hline $\begin{array}{l}\text { 9. Custos financeiros associados às } \\
\text { tecnologias e materiais necessários } \\
\text { durante o curso (acesso à internet, } \\
\text { manutenção do computador, etc.). }\end{array}$ & 3 & 139 & 4,49 & 0,863 & 5 & 5 & 9,4 & 85,6 \\
\hline $\begin{array}{l}\text { 19. Condições de saúde no período de } \\
\text { realização do curso. }\end{array}$ & 2 & 140 & 4,38 & 1,028 & 5 & 8,6 & 10,7 & 80,7 \\
\hline $\begin{array}{l}\text { 7. Acesso ao ambiente virtual do curso } \\
\text { com a regularidade proposta. }\end{array}$ & 2 & 140 & 4,36 & 0,961 & 5 & 7,8 & 6,4 & 85,7 \\
\hline $\begin{array}{l}\text { 12. Recursos de ensino utilizados } \\
\text { (figuras, vídeos, slides, etc). }\end{array}$ & 2 & 140 & 4,26 & 1,034 & 5 & 9,2 & 9,3 & 81,4 \\
\hline 8. Materiais didáticos do curso. & 3 & 139 & 4,24 & 1,026 & 5 & 7,9 & 15,1 & 77 \\
\hline 4. Orientações prestadas pelo tutor. & 1 & 141 & 4,21 & 1,066 & 5 & 9,2 & 16,3 & 74,4 \\
\hline 10. Duração do curso. & 4 & 138 & 4,21 & 0,932 & 5 & 7,2 & 10,9 & 81,9 \\
\hline $\begin{array}{l}\text { 18. Condições do ambiente de estudo } \\
\text { em casa. }\end{array}$ & 2 & 140 & 4,2 & 1,012 & 5 & 9,3 & 15 & 75,7 \\
\hline 6. Conexão à internet. & 2 & 140 & 4,19 & 0,971 & 5 & 8,6 & 11,4 & 80 \\
\hline $\begin{array}{l}\text { 2. Utilização das ferramentas web } \\
\text { (chats, e-mails, fóruns, etc.) para } \\
\text { comunicação com tutores e colegas. }\end{array}$ & 1 & 141 & 4,17 & 1,069 & 5 & 10,6 & 13,5 & 75,9 \\
\hline 11. Conteúdo do curso. & 2 & 140 & 4,17 & 1,052 & 5 & 10 & 15,7 & 74,3 \\
\hline $\begin{array}{l}\text { 5. Suporte técnico oferecido pela } \\
\text { instituição. }\end{array}$ & 2 & 140 & 4,01 & 1,122 & 5 & 15 & 10,7 & 74,3 \\
\hline
\end{tabular}

Tabela 23. Barreiras Descritivas (Continuação) 


\begin{tabular}{|l|c|c|c|c|c|c|c|c|}
\hline $\begin{array}{l}\text { 3. Relação entre alunos e tutores } \\
\text { quanto ao processo de aprendizagem } \\
\text { ao longo do curso. }\end{array}$ & 1 & 141 & 4 & 1,177 & 5 & 12,8 & 17,7 & 69,5 \\
\hline $\begin{array}{l}\text { 21. Habilidades pessoais de } \\
\text { organização e planejamento de } \\
\text { atividades de estudo. }\end{array}$ & 1 & 141 & 3,96 & 1,152 & 5 & 14,9 & 17 & 68,1 \\
\hline $\begin{array}{l}\text { 1. Promoção da interação social entre } \\
\text { os participantes do curso por parte do } \\
\text { tutor. }\end{array}$ & 1 & 141 & 3,91 & 1,18 & 5 & 10,6 & 31,2 & 57,8 \\
\hline $\begin{array}{l}\text { 13. Quantidade das atividades } \\
\text { propostas durante o curso. }\end{array}$ & 3 & 139 & 3,91 & 1,126 & 5 & 15,9 & 13,7 & 70,5 \\
\hline $\begin{array}{l}\text { 20. Correspondência do curso às } \\
\text { expectativas pessoais. }\end{array}$ & 2 & 140 & 3,76 & 1,328 & 5 & 21,4 & 16,4 & 62,2 \\
\hline $\begin{array}{l}\text { 15. Conciliação do curso com os } \\
\text { compromissos familiares. }\end{array}$ & 2 & 140 & 3,69 & 1,08 & 4 & 17,1 & 22,9 & 60 \\
\hline $\begin{array}{l}\text { 17. Conciliação do curso com outras } \\
\text { atividades de estudo. }\end{array}$ & 2 & 140 & 3,65 & 1,15 & 4 & 20,7 & 20,7 & 58,6 \\
\hline $\begin{array}{l}\text { 14. Conciliação do curso com as } \\
\text { taividades profissionais. }\end{array}$ & 2 & 140 & 3,44 & 1,164 & 4 & 24,3 & 21,4 & 54,3 \\
\hline 16. Tempo disponível para estudar. & 2 & 140 & 3,39 & 1,179 & 4 & 27,1 & 22,1 & 50,7 \\
\hline
\end{tabular}

Sobre a análise da tabela 23 , dos 22 itens do questionário, todos os itens apresentaram maior concentração das respostas nos pontos mais altos da escala (4 e 5), entre 50,7 e 91,5. Pode-se verificar na tabela que a variação média dos itens do questionário foi de 3,39 a 4,70. Os valores da moda variaram entre 4 e 5. Pode-se verificar que o suporte oferecido pela instituição de ensino, contexto externo ao curso, desenho do curso, características do aluno e questões financeiras e de saúde não foram apontados como barreiras ou dificultadores em relação ao curso. Ao analisar os itens que tiveram menor frequência de respostas nos pontos mais baixos da escala é possível verificar que os itens relacionados ao contexto externo ao curso, mantiveram índices não tão baixos como os demais itens da escala, sendo estes itens que se referem a conciliação das atividades do curso com compromissos familiares, outras atividades de estudo e de trabalho. Este ponto apesar de baixo, se comparado a literatura pode ser fator alarmante para próximos cursos. 


\subsubsection{Análises fatoriais exploratórias}

\subsection{Análises Fatoriais Exploratórias Estudo 1}

\subsubsection{Estratégias de aprendizagem}

Foram realizadas as análises fatoriais exploratórias, no instrumento de Estratégias de Aprendizagem a $P C$ indicou uma estrutura empírica de 4 componentes, em conjunto, estes componentes explicam 59,06\% da variância total das respostas dos participantes nos itens que compõe o questionário, que foi validada pela análise dos valores próprios e variância explicada e scree plot. Nas análises, a PAF também indicou 4 fatores do instrumento, os fatores foram configurados da seguinte forma: Cognitivas (9 itens sendo 4, 5,6,8,10,11,12, 13 e 14; $\alpha=0,83$; cargas fatoriais de 0,46 a 0,8), Controle da Emoção e Motivação (3 itens sendo, 1,2 e 3; $\alpha=0,78$; cargas fatoriais de 0,54 a 0,74), Reflexão e Aplicação Prática (4 itens, sendo 15,16,17 e 18; $\alpha=0,80$; cargas fatoriais de 0,52 a 0,59) e por fim, Busca de Ajuda (2 itens sendo, 7 e 9; $\alpha=0,74$; cargas fatoriais de 0,56 a 0,61). O teste de Kaiser-Meyer-Olkin (KMO), obteve um valor de 0,85, que é considerado por Pasquali (2004) um excelente índice de adequação da amostra. O fator 1, denominado Cognitivas possui as características de memorização, organização e repetição dos conteúdos apresentados. $\mathrm{O}$ fator 2 , denominado Controle da Emoção e Motivação possui as características de controle da emoção e motivação ao longo de dificuldades encontradas no curso. O fator 3, denominado Reflexão e Aplicação Prática possui as características de reflexão do conteúdo apresentado para a aplicação na prática e associação a experiências anteriores. O fator 4, denominado Busca por Ajuda, possui características de busca por ajuda em outras fontes de pesquisa e colegas do curso. Em seu estudo, (Martins, Zerbini e Medina, 2018), encontraram um agrupamento de 4 fatores, porém o agrupamento das estratégias de aprendizagem foi distinto ao agrupamento deste estudo.

A tabela 24 mostra a estrutura empírica da escala, as cargas fatoriais, as comunalidades (h2) dos itens, as médias e desvios-padrão, os índices de consistência interna da escala e os valores próprios e percentuais de variância explicada de cada fator. Para realizar a análise da estabilidade, verificou-se o quanto os itens eram bons representantes do fator, pelo tamanho das cargas fatoriais, estas apresentaram um valor acima de 0,40. Nenhum item foi excluído nas estruturas propostas. 
Tabela 24. Estrutura Empírica do Questionário Estratégias de Aprendizagem

\begin{tabular}{|c|c|c|c|c|c|c|c|}
\hline & \multicolumn{4}{|c|}{ Cargas Fatoriais } & \multirow[b]{2}{*}{ h2 } & \multirow[b]{2}{*}{ Média } & \multirow[b]{2}{*}{$\begin{array}{l}\text { Desvio } \\
\text { Padrão }\end{array}$} \\
\hline Itens & 1 & 2 & 3 & 4 & & & \\
\hline $\begin{array}{l}\text { 1. Mantive a calma quando tive dificuldades } \\
\text { durante o curso. }\end{array}$ & & 0,54 & & & 0,55 & 4,3 & 0,75 \\
\hline $\begin{array}{l}\text { 2. Mantive a calma com a possibilidade de ter } \\
\text { um rendimento abaixo do esperado. }\end{array}$ & & 0,69 & & & 0,71 & 3,73 & 1,01 \\
\hline $\begin{array}{l}\text { 3. Mantive a calma diante dos erros que } \\
\text { cometi ao realizar atividades do curso. }\end{array}$ & & 0,74 & & & 0,67 & 4,12 & 0,82 \\
\hline $\begin{array}{l}\text { 4. Esforcei-me mais quando percebi que } \\
\text { estava perdendo a concentração. }\end{array}$ & 0,74 & & & & 0,59 & 3,94 & 0,90 \\
\hline $\begin{array}{l}\text { 5. Esforcei-me mais quando percebi que } \\
\text { estava perdendo o interesse no assunto. }\end{array}$ & 0,75 & & & & 0,56 & 3,65 & 1,01 \\
\hline $\begin{array}{l}\text { 6. Esforcei-me para verificar } \\
\text { compreensão sobre o que estava } \\
\text { ensinado. }\end{array}$ & 0,80 & & & & 0,65 & 4,04 & 0,84 \\
\hline $\begin{array}{l}\text { 7. Busquei auxílio de colegas para esclarecer } \\
\text { minhas dúvidas sobre os conteúdos do curso. }\end{array}$ & & & & 0,61 & 0,65 & 2,61 & 1,20 \\
\hline $\begin{array}{l}\text { 8. Busquei compreender melhor os conteúdos } \\
\text { ao estudá-los nos materiais didáticos do curso. }\end{array}$ & 0,72 & & & & 0,54 & 4,04 & 0,83 \\
\hline $\begin{array}{l}\text { 9. Busquei outras fontes de pesquisa } \\
\text { relacionadas ao curso para me ajudar a } \\
\text { aprender. }\end{array}$ & & & & 0,56 & 0,62 & 3,72 & 1,12 \\
\hline $\begin{array}{l}\text { 10. Li o conteúdo do curso várias vezes como } \\
\text { método para aprender. }\end{array}$ & 0,66 & & & & 0,56 & 3,29 & 1,04 \\
\hline $\begin{array}{l}\text { 11. Repeti mentalmente os conteúdos do curso } \\
\text { que gostaria de aprender até perceber que } \\
\text { havia entendido. }\end{array}$ & 0,67 & & & & 0,55 & 3,1 & 1,04 \\
\hline $\begin{array}{l}\text { 12. Fiz anotações, resumos e/ou esquemas dos } \\
\text { conteúdos do curso como método para } \\
\text { aprender. }\end{array}$ & 0,52 & & & & 0,50 & 3,44 & 1,15 \\
\hline $\begin{array}{l}\text { 13. Revisei os conteúdos relativos aos } \\
\text { exercícios em que cometi erros. }\end{array}$ & 0,66 & & & & 0,52 & 3,29 & 0,96 \\
\hline $\begin{array}{l}\text { 14. Realizei os exercícios práticos propostos } \\
\text { ao longo do curso para me ajudar a aprender. }\end{array}$ & 0,46 & & & & 0,43 & 4,10 & 1,00 \\
\hline $\begin{array}{l}\text { 15. Refleti sobre as implicações que os } \\
\text { conteúdos aprendidos poderiam ter. }\end{array}$ & & & 0,59 & & 0,55 & 4,04 & 0,77 \\
\hline $\begin{array}{l}\text { 16. Identifiquei situações diárias em que eu } \\
\text { pudesse aplicar os conteúdos do curso. }\end{array}$ & & & 0,57 & & 0,62 & 3,91 & 0,82 \\
\hline $\begin{array}{l}\text { 17. Busquei desenvolver uma ideia global sobre } \\
\text { como os conteúdos do curso se relacionavam } \\
\text { entre si. }\end{array}$ & & & 0,52 & & 0,60 & 3,99 & 0,67 \\
\hline $\begin{array}{l}\text { 18. Associei os conteúdos do curso aos meus } \\
\text { conhecimentos anteriores. }\end{array}$ & & & 0,54 & & 0,69 & 4,32 & 0,63 \\
\hline Eigenvalue (Valor Próprio) & & & & 5,89 & 1,91 & 1,72 & 1,1 \\
\hline \% da Variância Explicada $(P A F)$ & & & & 45,8 & 24,61 & 19,27 & 10,31 \\
\hline $\mathrm{N}^{0}$ de Itens & & & & 9 & 3 & 4 & 2 \\
\hline $\operatorname{Alfa}(\alpha)$ & & & & 0,83 & 0,8 & 0,78 & 0,74 \\
\hline Índice de KMO & & & & 0,85 & & & \\
\hline \% da Variância Total Explicada $(P C)$ & & & & 32,72 & 10,61 & 9,58 & 6,15 \\
\hline
\end{tabular}




\subsubsection{Barreiras em EAD}

Foram realizadas as análises fatoriais exploratórias, no instrumento de Barreiras em EAD a $P C$ indicou uma estrutura empírica de 5 componentes, em conjunto, estes componentes explicam $63,92 \%$ da variância total das respostas dos participantes nos itens que compõe o questionário, que foi validada pela análise dos valores próprios e variância explicada e scree plot. Nas análises, a PAF também indicou 5 fatores do instrumento, os fatores foram configurados da seguinte forma: Suporte Oferecido pela Instituição ( 5 itens sendo 1,2,3,4 e 5; $\alpha=0,70$; cargas fatoriais de 0,57 a 0,87), Contexto Externo ao Curso (4 itens sendo, 14,15,16 e 17; $\alpha=0,73$; cargas fatoriais de 0,72 a 0,90), Desenho do Curso (6 itens, sendo 8,10,11,12,13 e 20; $\alpha=0,67$; cargas fatoriais de 0,48 a 0,84), Características do Aluno (3 itens sendo, 18,21 e 22; $\alpha=0,72$; cargas fatoriais de 0,47 a 0,78), por fim, Questões de Saúde e Finanças (4 itens sendo, 6,7,9 e 19; $\alpha=0,74$; cargas fatoriais de 0,40 a 0,77). O teste de KaiserMeyer-Olkin (KMO), obteve um valor de 0,86, que é considerado por Pasquali (2004) um excelente índice de adequação da amostra. O fator 1, denominado Suporte Oferecido pela Instituição possui as características de ferramentas utilizadas ao longo do curso e suporte oferecido ao aluno pela instituição de ensino. O fator 2, denominado Contexto Externo ao Curso possui as características de conciliação do curso com compromissos familiares, profissionais, tempo para estudar e outras atividades de estudo. O fator 3, denominado Desenho do Curso, se refere aos materiais, conteúdo, duração, atividades do curso e a correspondência do mesmo às expectativas pessoais. $\mathrm{O}$ fator 4 , denominado Características do Aluno se refere as habilidades pessoais de organização, planejamento das atividades e utilização das ferramentas web (chats, e-mails, fóruns, etc.) e condições de estudo em casa. $\mathrm{O}$ fator 5 denominado Questões de Saúde e Finanças, se refere às condições de saúde e financeiras durante a realização do curso. Quanto ao questionário, Martins (2016) aplicou a escala de Barreiras e Facilitadores em EAD em seu estudo piloto, e a escala se apresentou como unifatorial, o resultado foi diferente ao agrupamento deste estudo que teve o título Barreiras EAD, porém não foram modificados os itens do questionário.

A tabela 25 mostra a estrutura empírica da escala, as cargas fatoriais, as comunalidades (h2) dos itens, as médias e desvios-padrão, os índices de consistência interna da escala e os valores próprios e percentuais de variância explicada de cada fator. Para realizar a análise da estabilidade, verificou-se o quanto os itens eram bons representantes do fator, pelo tamanho das cargas fatoriais, estas apresentaram um valor acima de 0,40. Nenhum item foi excluído nas estruturas propostas. 
Tabela 25. Estrutura Empírica do Questionário Barreiras em EAD

\begin{tabular}{|c|c|c|c|c|c|c|c|c|}
\hline & & argas & Fatori & & & & & \\
\hline Itens & 1 & 2 & 3 & 4 & 5 & h2 & Média & $\begin{array}{l}\text { Desvio } \\
\text { Padrão }\end{array}$ \\
\hline $\begin{array}{l}\text { 1. Promoção da interação social entre os } \\
\text { participantes do curso por parte do tutor. }\end{array}$ & 0,69 & & & & & 0,59 & 3,91 & 1,18 \\
\hline $\begin{array}{l}\text { 2. Utilização das ferramentas web (chats, e- } \\
\text { mails, fóruns, etc.) para comunicação com } \\
\text { tutores e colegas. }\end{array}$ & 0,62 & & & & & 0,57 & 4,17 & 1,07 \\
\hline $\begin{array}{l}\text { 3. Relação entre alunos e tutores quanto ao } \\
\text { processo de aprendizagem ao longo do } \\
\text { curso. }\end{array}$ & 0,67 & & & & & 0,77 & 4 & 1,18 \\
\hline 4. Orientações prestadas pelo tutor. & 0,58 & & & & & 0,72 & 4,21 & 1,07 \\
\hline 5. Suporte técnico oferecido pela instituição. & 0,64 & & & & & 0,58 & 4,01 & 1,12 \\
\hline 6. Conexão à internet. & & & & & 0,60 & 0,68 & 4,19 & 0,97 \\
\hline $\begin{array}{l}\text { 7. Acesso ao ambiente virtual do curso com } \\
\text { a regularidade proposta. }\end{array}$ & & & & & 0,63 & 0,55 & 4,36 & 0,96 \\
\hline 8. Materiais didáticos do curso. & & & 0,62 & & & 0,68 & 4,24 & 1,03 \\
\hline $\begin{array}{l}\text { 9. Custos financeiros associados às } \\
\text { tecnologias e materiais necessários durante o } \\
\text { curso (acesso à internet, manutenção do } \\
\text { computador, etc.). }\end{array}$ & & & & & 0,59 & 0,60 & 4,49 & 0,86 \\
\hline 10. Duração do curso. & & & 0,50 & & & 0,55 & 4,21 & 0,93 \\
\hline 11. Conteúdo do curso. & & & 0,62 & & & 0,72 & 4,17 & 1,05 \\
\hline $\begin{array}{l}\text { 12. Recursos de ensino utilizados (figuras, } \\
\text { vídeos, slides, etc). }\end{array}$ & & & 0,66 & & & 0,65 & 4,26 & 1,03 \\
\hline $\begin{array}{l}\text { 13. Quantidade das atividades propostas } \\
\text { durante o curso. }\end{array}$ & & & 0,74 & & & 0,62 & 3,91 & 1,13 \\
\hline $\begin{array}{l}\text { 14. Conciliação do curso com as atividades } \\
\text { profissionais. }\end{array}$ & & 0,60 & & & & 0,68 & 3,44 & 1,16 \\
\hline $\begin{array}{l}\text { 15. Conciliação do curso com os } \\
\text { compromissos familiares. }\end{array}$ & & 0,65 & & & & 0,68 & 3,69 & 1,08 \\
\hline 16. Tempo disponível para estudar. & & 0,67 & & & & 0,81 & 3,39 & 1,18 \\
\hline $\begin{array}{l}\text { 17. Conciliação do curso com outras } \\
\text { atividades de estudo. }\end{array}$ & & 0,60 & & & & 0,61 & 3,65 & 1,15 \\
\hline $\begin{array}{l}\text { 18. Condições do ambiente de estudo em } \\
\text { casa. }\end{array}$ & & & & 0,45 & & 0,53 & 4,2 & 1,01 \\
\hline $\begin{array}{l}\text { 19. Condições de saúde no período de } \\
\text { realização do curso. }\end{array}$ & & & & & 0,46 & 0,38 & 4,38 & 1,03 \\
\hline $\begin{array}{lcccc}20 . \quad \text { Correspondência } & \text { do } & \text { curso } & \text { às } \\
\text { expectativas pessoais. }\end{array}$ & & & 0,76 & & & 0,68 & 3,76 & 1,33 \\
\hline $\begin{array}{l}\text { 21. Habilidades pessoais de organização e } \\
\text { planejamento de atividades de estudo. }\end{array}$ & & & & 0,69 & & 0,67 & 3,96 & 1,15 \\
\hline $\begin{array}{l}\text { 22. Habilidades pessoais para uso das } \\
\text { ferramentas web (chats, e-mails, fóruns, } \\
\text { etc.). }\end{array}$ & & & & 0,42 & & 0,65 & 4,7 & 0,71 \\
\hline Eigenvalue (Valor Próprio) & & & & 7,52 & 2,4 & 1,77 & 1,19 & 1,16 \\
\hline \% da Variância Explicada $(P A F)$ & & & & 54,18 & 15,17 & 14,19 & 8,64 & 7,23 \\
\hline $\mathrm{N}^{\circ}$ de Itens & & & & 5 & 4 & 6 & 3 & 4 \\
\hline Alfa $(\alpha)$ & & & & 0,74 & 0,73 & 0,72 & 0,7 & 0,67 \\
\hline Índice de KMO & & & & 0,86 & & & & \\
\hline \% da Variância Total Explicada $(P C)$ & & & & 34,21 & 10,94 & 8,06 & 5,4 & 5,31 \\
\hline
\end{tabular}




\subsection{Análises de Regressão Múltipla}

Foram realizadas as análises de regressão múltipla, estas devem respeitar os seguintes critérios de inclusão: amostra maior ou igual a 50 casos mais oito vezes o número de variáveis antecedentes $(\mathrm{N} \geq 50+8 \mathrm{~m})$ para testagem de correlações múltiplas e $\mathrm{N} \geq 104+\mathrm{m}$ para testagem de preditores individuais (Tabachnick \& Fidell, 2007). Devido ao tamanho da amostra, foi possível a realizar a regressão de 8 variáveis antecendentes $(\mathrm{N} \geq 50+8.8$ $=\mathrm{N} \geq 114)$.

A presente pesquisa buscou identificar as variáveis preditoras de Barreiras em EAD (Suporte Oferecido pela Instituição, Contexto Externo ao Curso, Desenho do Curso, Características do Aluno e Questões de Saúde e Financeiras) relacionadas ao perfil da clientela (Dados Sociodemográficos) e Estratégias de Aprendizagem (Estratégias Cognitivas, Estratégias Autorregulatórias, Reflexão e Aplicação Prática e Busca por Ajuda Interpessoal) a partir de um modelo de avaliação de ações educacionais ofertadas a distância. Para a realização das regressões foram testados modelos com as variáveis independentes Estratégias de Aprendizagem, que foram codificadas da seguinte forma: ESTR 1 - "Estratégias Cognitivas", ESTR 2 - "Estratégias Autorregulatórias", ESTR 3 - "Reflexão e Aplicação Prática" - e ESTR 4 - "Busca da Ajuda Interpessoal”, também foram incluídas as variáveis sociodemográficas Sexo, Estado Civil, Composição Familiar e Experiência anterior ao uso de internet, abaixo serão apresentados os modelos que tiveram correlações significativas, tais fatores são resultados das Análises Fatoriais Exploratórias.

A tabela 27 apresenta as relações entre a variável preditora EST 1 - Estratégias Cognitivas e a variável critério BA 1 - Suporte Institucional, os coeficientes de regressão não padronizados (B), os coeficientes de regressão padronizados $(\beta)$, a contribuição individual de cada variável $\left(\mathrm{Sr}^{2}\right)$, a constante, o $\mathrm{R}^{2}$ (correlação entre todas as variáveis antecedentes com a variável critério - variância individual e compartilhada das variáveis antecedentes em relação à variável critério), o $\mathrm{R}^{2}$ ajustado (estimativa do $\mathrm{R}^{2}$ da população) e o $\mathrm{R}$ (correlação entre a variável critério e as variáveis antecedentes). 
Tabela 27. Regressão Múltipla para a variável dependente Suporte Institucional BA1

\begin{tabular}{|c|c|c|c|}
\hline Variável & $\begin{array}{l}\text { BA1 } \\
(\mathrm{VD})\end{array}$ & EST 1 & \\
\hline EST 1 & $0,31 * *$ & & \\
\hline $\mathrm{B}$ & & $0,23 *$ & \\
\hline$\beta$ & & 0,32 & \\
\hline $\mathrm{Sr}^{2}$ & & 0,03 & \\
\hline $\begin{array}{l}\text { Constante }=6,66 \\
* \mathrm{p}<0,05 \mathrm{e}^{* *} \mathrm{p}<\end{array}$ & $\begin{array}{l}\mathrm{R}^{2}=0,14 * \quad \mathrm{R}^{2}( \\
01\end{array}$ & ust.) $=0,09 *$ & $\mathrm{R}=0,38$ \\
\hline
\end{tabular}

Foi significativamente diferente de zero o coeficiente de regressão múltipla $R, F(2,72)$ $=0,08<0,001$, sendo considerados limites de confiança de $95 \%$. A variável antecedente que contribuiu significativamente para a explicação de Barreiras em EAD - Suporte Institucional, tendo considerado o intervalo de confiança de 95\%, foi: EST 1 ( $\square=0,32$ ). Esta variável, explica 14\% (9\% ajustado) da variabilidade de Barreiras em EAD - Suporte Institucional. Em suma, os alunos que utilizaram as estratégias cognitivas de repetição do conteúdo, reflexão sobre os conteúdos e formulam esquemas mentais que agrupam os conhecimentos aprendidos perceberam o suporte da instituição de ensino como barreira ao longo do curso.

A tabela 28 apresenta as relações entre as variáveis preditoras EST 1 - Estratégias Cognitivas, EST 2 - Estratégias Autorregulatórias e a variável critério BA 2 - Contexto Externo ao Curso, os coeficientes de regressão não padronizados (B), os coeficientes de regressão padronizados $(\beta)$, a contribuição individual de cada variável $\left(\mathrm{Sr}^{2}\right)$, a constante, o $\mathrm{R}^{2}$ (correlação entre todas as variáveis antecedentes com a variável critério - variância individual e compartilhada das variáveis antecedentes em relação à variável critério), o $\mathrm{R}^{2}$ ajustado (estimativa do $\mathrm{R}^{2}$ da população) e o $\mathrm{R}$ (correlação entre a variável critério e as variáveis antecedentes).

Tabela 28. Regressão Múltipla para a variável dependente Contexto Externo ao Curso BA2

\begin{tabular}{lccc}
\hline \multicolumn{1}{c}{ Variável } & $\begin{array}{c}\text { BA2 } \\
(\mathrm{VD})\end{array}$ & EST1 & EST2 \\
\hline EST 1 & $0,29 * *$ & & \\
EST 2 & $0,23 * *$ & & \\
\hline B & $0,15^{*}$ & $0,36 * *$ \\
$\beta$ & 0,24 & 0,19 \\
$\mathrm{Sr}^{2}$ & 0,08 & \\
\hline Constante $=5,53$ & $\mathrm{R}^{2}=0,17^{*}$ & $\mathrm{R}^{2}$ (ajust.) $=0,12^{*}$ & $\mathrm{R}=0,42$ \\
$* \mathrm{p}<0,05 \mathrm{e} * \mathrm{p}<0,01$ & &
\end{tabular}

Foi significativamente diferente de zero o coeficiente de regressão múltipla $R, F(3,39)$ $=0,001<0,001$, sendo considerados limites de confiança de $95 \%$. A variáveis antecedentes 
que contribuíram significativamente para a explicação de Barreiras em EAD - Contexto Externo ao Curso, tendo considerado o intervalo de confiança de 95\%, foram: EST 1 ( $\square=$ 0,24), EST $2(\square=0,19)$. Esta variável, explica 17\% (12\% ajustado) da variabilidade de Barreiras em EAD - Contexto Externo ao Curso. Em suma, os alunos que utilizaram as estratégias cognitivas de repetição do conteúdo, reflexão sobre os conteúdos e controlam a ansiedade, preveem dispersões e avaliam seu processo de aquisição de aprendizagem percebem como uma barreira o contexto externo ao curso, ou seja, o tempo disponível para estudar, a conciliação do curso com os compromissos familiares e profissionais.

A tabela 29 apresenta as relações entre as variáveis preditoras EST 1 - Estratégias Cognitivas, EST 2 - Estratégias Autorregulatórias, EST 3 - Reflexão e Aplicação Prática e a variável critério BA 3 - Desenho do Curso, os coeficientes de regressão não padronizados (B), os coeficientes de regressão padronizados $(\beta)$, a contribuição individual de cada variável $\left(\mathrm{Sr}^{2}\right)$, a constante, o $\mathrm{R}^{2}$ (correlação entre todas as variáveis antecedentes com a variável critério - variância individual e compartilhada das variáveis antecedentes em relação à variável critério), o $R^{2}$ ajustado (estimativa do $R^{2}$ da população) e o $R$ (correlação entre a variável critério e as variáveis antecedentes).

Tabela 29. Regressão Múltipla para a variável dependente Desenho do Curso BA3

\begin{tabular}{llccc}
\hline \multicolumn{1}{c}{ Variável } & $\begin{array}{c}\text { BA3 } \\
(\mathrm{VD})\end{array}$ & EST1 & EST2 & EST 3 \\
\hline EST 1 & $0,39 * *$ & & & \\
EST 2 & $0,26 * *$ & & & \\
EST 3 & $0,31 * *$ & & & \\
\hline B & & $0,30 *$ & $0,41 * *$ & $0,25 * *$ \\
$\beta$ & & 0,37 & 0,17 & 0,11 \\
Sr $^{2}$ & & 0,00 & 0,03 & 0,02 \\
\hline Constante $=6,94$ & $\mathrm{R}^{2}=0,25 *$ & $\mathrm{R}^{2}$ (ajust.) $=0,20 *$ & $\mathrm{R}=0,50$ \\
$* \mathrm{p}<0,05 \mathrm{e} * * \mathrm{p}<0,01$ & & & &
\end{tabular}

Foi significativamente diferente de zero o coeficiente de regressão múltipla $R, F(5,27)$ $=0,000<0,001$, sendo considerados limites de confiança de 95\%. A variáveis antecedentes que contribuíram significativamente para a explicação de Barreiras em EAD - Desenho do Curso, tendo considerado o intervalo de confiança de 95\%, foram: EST $1(\square=0,37)$, EST 2 $(\square=0,17)$, EST $3(\square=0,11)$. Esta variável, explica 25\% (20\% ajustado) da variabilidade de Barreiras em EAD - Desenho do Curso. Em suma, os alunos que utilizaram as estratégias cognitivas de repetição do conteúdo, reflexão sobre os conteúdos e controlam a ansiedade, preveem dispersões e avaliam seu processo de aquisição de aprendizagem, aperfeiçoam o aprendizado através da aplicação prática, percebem como uma barreira o desenho do curso, ou 
seja, o tempo de duração do curso, o conteúdo do curso, os recurso de ensino utilizados ao longo do curso e quantidade de atividades exigidas ao longo do curso.

A tabela 30 apresenta as relações entre as variáveis preditoras EST 1 - Estratégias Cognitivas, EST 3 - Reflexão e Aplicação Prática e a variável critério BA 4 - Características do Aluno, os coeficientes de regressão não padronizados (B), os coeficientes de regressão padronizados $(\beta)$, a contribuição individual de cada variável $\left(\mathrm{Sr}^{2}\right)$, a constante, o $\mathrm{R}^{2}$ (correlação entre todas as variáveis antecedentes com a variável critério - variância individual e compartilhada das variáveis antecedentes em relação à variável critério), o $\mathrm{R}^{2}$ ajustado (estimativa do $\mathrm{R}^{2}$ da população) e o $\mathrm{R}$ (correlação entre a variável critério e as variáveis antecedentes).

Tabela 30. Regressão Múltipla para a variável dependente Características do Aluno BA4

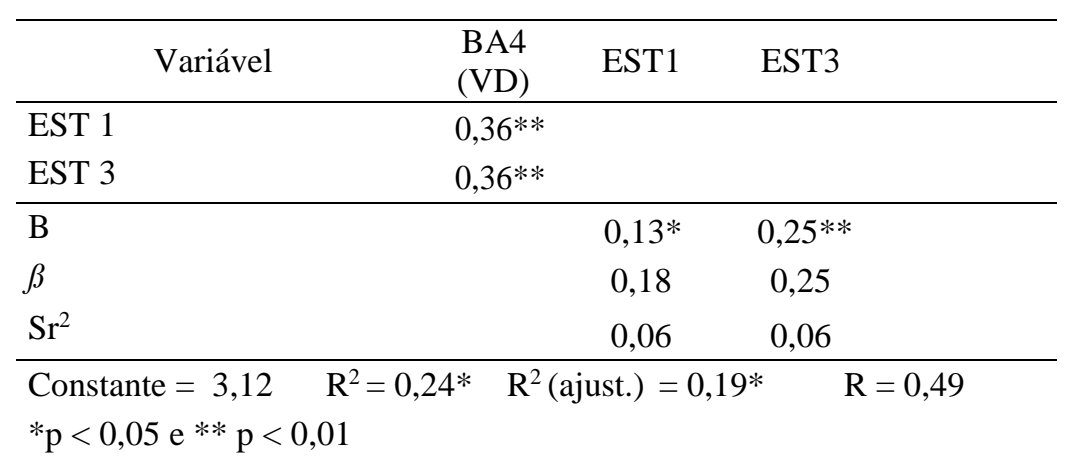

Foi significativamente diferente de zero o coeficiente de regressão múltipla $\mathrm{R}, \mathrm{F}(5,08)$ $=0,000<0,001$, sendo considerados limites de confiança de 95\%. A variáveis antecedentes que contribuíram significativamente para a explicação de Barreiras em EAD - Características do Aluno, tendo considerado o intervalo de confiança de 95\%, foram: EST 1 ( $\square=0,18$ ), EST $3(\square=0,25)$. Esta variável, explica 24\% (19\% ajustado) da variabilidade de Barreiras em EAD - Características do Aluno. Em suma, os alunos que utilizaram as estratégias cognitivas de repetição do conteúdo, reflexão sobre os conteúdos e aperfeiçoam o aprendizado através da aplicação prática, percebem como uma barreira às características do aluno, ou seja, as habilidades de organização para a realização das atividades propostas pelo curso e as habilidades para o uso das ferramentas web (chats, e-mails, fóruns, etc.).

A variável preditora EST 4 - Busca por ajuda interpessoal e a variável critério BA 5 Questões Financeiras e de Saúde, não apresentaram correlações significativas em nenhuma das análises realizadas. É importante ressaltar que a EST 1 - Estratégias Cognitivas teve correlações significativas em 4 dos 5 fatores de Barreiras em EAD, pode-se concluir que os 
alunos que utilizam mais estas estratégias percebem mais as barreiras encontradas ao longo do curso.

\subsection{Análise Qualitativa do Estudo 2}

Foram realizadas as análises temáticas das entrevistas, com elas foram criados 4 agrupamentos de temas conforme tabela 31 :

Tabela 31. Categorização por Temas Roteiro de Barreiras em EAD

\begin{tabular}{|c|c|}
\hline \multicolumn{2}{|c|}{ Categorização por Temas Roteiro de Barreiras } \\
\hline Contexto de Estudo & $\begin{array}{r}\text { Se refere ao tempo disponível para estudar, conciliação do curso com outros } \\
\text { compromissos sociais, de família e outras atividades de estudo, recursos } \\
\text { disponíveis para estudar }\end{array}$ \\
\hline Desenho do Curso & $\begin{array}{r}\text { Se refere ao conteúdo do curso, carga horária, atividades de interação dos alunos, } \\
\text { interação com o tutor e suporte da instituição }\end{array}$ \\
\hline Perfil do Aluno & $\begin{array}{r}\text { Se refere a motivação do aluno para estudar, ao conhecimento dos objetivos do } \\
\text { curso e expectativas pessoais em relação ao curso }\end{array}$ \\
\hline Influenciadores de Evasão & Se refere aos principais motivos que levaram o aluno a evadir-se do curso \\
\hline
\end{tabular}

A seguir serão apresentadas 4 seções com relatos dos participantes, estas seções foram elaboradas com base nos agrupamentos apresentados na tabela acima.

\subsubsection{Contexto de Estudo}

Segundo os alunos, sobre a conciliação das atividades pessoais, profissionais e de estudo, um aluno cursava além do MBA, o mestrado, afirmou que era difícil a conciliação com a outra atividade de estudo e em relação à atenção dada a família, por assistir as aulas em casa tinha interrupções do filho que queria atenção, mas não foi o fator decisório para abandonar o curso, pois ao desistir do curo a distância se inscreveu e concluiu uma pósgraduação presencial.

Entrevistador: Você conseguia conciliar os compromissos de trabalho, família e estudos? 
Entrevistado 1: "Olha, tava bem dificil, eu acho que até por isso eu optei por esperar um pouquinho, eu tava no mestrado quase defendendo, não sei, a gente dá um jeito, é tudo uma questão de prioridade, eu acho que se a gente for pensar no momento, eu acho que não, filho, casa, normal”.

Entrevistado 2: "Isso é ruim, se você não tem um ambiente, no presencial você saiu de casa, lógico, mas se você não tem um ambiente e disciplina disso, de você sentar e saber que aquele momento é para aquilo, as pessoas em casa acham que você esta em casa, e meu filho chamava, ele era pequeno, ele chamava, mãe”!

“Como eu era freelancer, eu tinha na verdade bastante flexibilidade, como tenho até hoje, nessa cultura nossa aqui, ela não se interessa por quantas horas você trabalha, ela se interessa por quanto você entrega de fato, se você tá entregando o que foi solicitado, não interessa se eu vou ficar aqui a noite, a noite inteira, vai vim entendeu”?

Ainda sobre o contexto vivenciado pelos alunos durante o curso, apontaram que tiveram alguns percalços em relação às finanças, e outras atividades de estudo paralelas ao curso, porém não citaram que foram motivos decisórios para evadirem-se do curso, mas outras questões que envolviam conteúdo do curso foram importantes para a decisão.

Entrevistador: Como estava sua condição (física, mental, espiritual, financeira, relacionamentos, trabalho) durante a realização do curso?

Entrevistado 1: "Tava tudo bem, estava numa época um pouco agitada, é difícil lembrar mais, eu sei que estava fazendo, eu era meio maluca, sempre estava fazendo trabalho, dou aula, enfim o filho, terminando o mestrado, ai eu sentia falta, por mais que eu não trabalho como gestora eu acho que você conhecer o sistema de saúde é importante, mas realmente eu até escrevi na justificativa da carta que era por causa do mestrado, mas se for falar bem a verdade, eu fui fazer a GV três vezes por semana a noite, defendi o mestrado no meio e assim vai, agora no doutorado e a gente vai continuando, mas isso a gente tem que se policiar, é bem estressante essa parte da nossa geração, que acha que tudo tem que estudar, mas enfim, tava tudo bem, mas na hora que eu senti que não tava dedicando eu falei, há, não vai rolar, eu achei que por 
ser primeira turma, em relação a GV que estava mega conceituada no mercado, do curso de pós graduação em administração e saúde, falei há, não tem comparação, vou pra lá”.

Entrevistado 2: "Acredito que a parte mais complicada na época era de trabalho, porque ser freelancer, você já trabalhou por conta? Você sabe como é ne? Arrumar cliente, poxa, no fim do mês as contas tem que bater né? Então acredito que essa foi a fase mais tensa de grana, porque enfim o Brasil estava passando por uma fase maluca, e eu acredito também que por um comportamento, você vê que comportamento é tudo né"?

Em relação à estrutura adequada para assistir as aulas e realizar as atividades do curso, ambos afirmaram que sim, tinham boas condições para a realização do curso (Internet, computador e local para estudo).

Entrevistador: Você possuía a estrutura necessária para a realização do curso (Internet, Computador, Local adequado para estudo)?

Entrevistado 1: "Sim, tinha sim".

Entrevistado 2: "Sim, como e da minha área profissional, eu sempre tive equipamentos legais e internet boa".

\subsubsection{Desenho do Curso}

O curso continha aulas ao vivo semanais, contendo duas horas de duração, o aluno assistia de qualquer local desde que tivesse acesso à internet. A aula gravada era disponibilizada no dia seguinte à aula ao vivo. Além disso, incluíam fóruns semanais para discussão, mediados pelo tutor, estudos de caso semanais, mensagem do tutor ao final da disciplina e as avaliações, sendo uma prova a distância ou trabalho em grupo e uma prova presencial no polo mais próximo da residência do aluno.

Entrevistador: Como você avalia o conteúdo ministrado ao longo curso, considera adequado ao seu perfil como aluno que trabalha? 
Entrevistado 1: "Eu acho que, bom, eu desisti logo, mas era um curso muito bom, o conteúdo era bem legal, bem focado em segurança do paciente pelo menos até a parte que eu fiquei tinha alguns módulos, e acho que, até ali era bem focado com evidência, bem característico mesmo da USP, o que eu tava sentindo um pouco de falta, não sei, também não terminei né?, Mas que fosse algo mais prático para mercado, por isso que dai eu optei por fazer na GV, porque ali focava mais isso, do que na pesquisa em si, tanto que eu estava indo super bem nos módulos, tudo, mas tem essas dificuldades ainda né? Sou de 84, enfrentava essas barreiras ainda, eu me via ligando o negócio e filho chamando para as coisas, eu falava gente eu preciso ir presencial, e olha que eu fazia com bolsa, foi dificil desistir um que tinha bolsa, por outro que para pagar era 1500 por mês, realmente eu fiz uma troca de cursos, na verdade”.

Entrevistado 2: “Eu acredito até que os conteúdos eram relevantes sim, importantes, o conteúdo ser relevante, deixa eu me explicar melhor, o tema ser relevante, não quer dizer que o conteúdo desenvolvido era relevante, eu posso falar que um tema era super importante pra você e só ficar blá, blá, blá... artigos de revista pra vc, artigos de jornal entende"?

Entrevistador: Como você avalia as ferramentas disponibilizadas para a interação dos alunos?

Entrevistado 1: "Acho que, isso tem dois lados, como eu acho que ficava como uma tarefa, você não sentia que realmente tinha que propor uma discussão ativa ali no fórum, isso variava muito do tutor, tinha tutor que numa determinada matéria comentava junto, tinha gente que deixava mais perto do prazo final, e as vezes no calor da discussão, quando, eu não participei muito, mas tinha várias respostas e a pessoa entra só no outro dia, isso que eu te falei que pode ser uma coisa que dificulta, a pessoa não tem como estar disponível 24 horas, então às vezes naquele momento vocês estão com uma dúvida, alguém que pudesse fazer uma mediação, então essas são as dificuldades gerais do EAD né? Estar em tempo real, mas ao mesmo tempo tem a facilidade de você poder fazer em um outro momento, também te os seus prós e contras, mas acho que sim, os tutores ajudavam na medida, do que fora as barreiras de presença”. 
Entrevistado 2: "Nas poucas interações que eu tive com a plataforma, se eu não me engano a plataforma usada era o moodle, então, isso dai pra mim já chateou, porque o moodle é uma plataforma que funciona, mas ela é pré-histórica de velha, não sei se você já fez outro curso, por exemplo, na Bildme, na poxa tantos outros lugares, o moodle é bem chatinho de trabalhar, eu achava que o tutor, na minha impressão, posso ta enganado, mas eu achava que o tutor só tava ali pra cumprir papel de tutor, entendeu? Receber trabalho, esse tipo de coisa, resolver problema de aluno, a poxa atrasei meu trabalho, não percebia assim, não tive o sentimento, se é que eu podia esperar esse tipo de coisa, mas eu não tive o sentimento que eu estava sendo tutoriado e amparado academicamente, esse foi o meu sentimento pelo menos".

Entrevistado 2: “Eu não me recordo não, mas essas ferramentas são muito impessoais né? Muito diferentes do que a gente está fazendo aqui agora, você podia ter me mandado um questionário, ou dado uma entrada num fórum, eu responderia, então é muito diferente do que a gente tá fazendo agora, então eu acho que são ferramentas de interação de uma década passada, entendeu? Então essa, eu acredito que essa impessoalidade provoque bastante gente desistir ou pensar em desistir do curso, a única coisa que segura é o investimento que o cara tá fazendo, eu me arrisquei na verdade em relação a isso, eu falei não aguento mais isso, entrei em contato com alguém lá da administração, falei olha, desculpa eu tava errado, não aguento acabar isso".

Entrevistador: O tutor ofereceu o apoio necessário para sanar as dúvidas? O tutor promoveu a interação entre os alunos?

Entrevistado 1: “Eu acho que isso faltou, precisava de mais coisas para interação dos alunos, estimular sub grupos eu acho que seria legal, tipo assim, faça grupos com seus alunos de discussão a parte e ai depois traga uma síntese pra colocar no fórum, eles estimulavam, mas isso é muito individual, é legal o EAD, mas isso eu senti falta, não é só no texto um professor, e fora do que ele postou naquele momento, se tivessem estes outros momentos de encontrar essas pessoas, não precisa ser pessoalmente, mas se tivesse uma atividade obrigatória, porque o aluno funciona assim, você deixa uma atividade, vocês tem que fazer uma síntese em grupo, então eu faço um subgrupo e discuto, pode ser alguma coisa, ná, não sei, pode ser algo, uma vez a cada não sei quantos meses presencial entendeu, algumas coisas diferentes assim, acho que seria legal isso eu acho que faltou um pouquinho a gente não fazia tanta amizade, eu até 
tentei adicionar um outro no facebook, olha lá hein? Só via a carinha ali, é diferente de pessoalmente. Eram legais, mas acho que ficava muito também do tutor tinha gente que falava que tinha tutor, fazer o que, é assim, ninguém consegue corrigir todos uns falavam que o tutor cobrava mais uma coisa, outro que cobrou mais outro na prova, e assim vai".

Entrevistado 1: "Fora as barreiras da informática era legal sim, acho que podia criar uma forma do aluno buscar algumas coisas assim, igual eu te falei da troca, tinha gente de todas as profissões ali, é lógico que fico na minha zona de conforto ali, sabia de enfermagem essa parte de segurança do paciente, então eu queria saber das outras trocas de outras pessoas quem era um chefe de outro serviço que era da área de gestão, até mesmo no Ava podia ter uma aba pro aluno colocar, olha isso é interessante, não em fórum, mas será que eu quero disponibilizar algo, não sei, ter uma página própria, agora com esses grupos eu eu te falei da USP, podemos usar várias coisas que aluno usa, então você pode colocar no seu perfil, parece até de faceboook você vai adicionando aula, tudo que contribui, acho que fica legal”.

Entrevistado 2: "Essa era a parte que eu achava mais legal na verdade, e o fato de você ter que estar lá fazendo a aula, se bem que o pessoal dá o chapéu de qualquer jeito, vai la oito horas da noite tem aula, vai lá, liga o computador e vai ver novela, Mas só quem tá perdendo é quem ta fazendo isso. Mas eu achava aquele momento interessante sim, só gostaria que ele tivesse uma interação mais eficiente. Tinha um chat lá, só que para um curso dessa natureza ser lucrativo, você precisa, usando a ferramenta né? E pelo fato de ser online, você precisa ter um monte de gente pendurada, então o que acontece, você fala lá, ou você pergunta, e tal, o cara não tem tempo de ler nada, porque ele tem que cumprir aquele horário que ele tem que falar, entendeu, ele até olhava la, e falava não sei quem ta perguntando se, ele ia pinçando algumas coisas que ele conseguia ver no chat, e comentava, era bem superficialmente”.

Entrevistador: As atividades oferecidas no curso possuíam relação entre a teoria e a prática?

Entrevistado 1: “OH, eu ainda acho, que senti falta, olhando no geral, eu não terminei, mas eu acho que comparado com o outro que eu fiz, eu sou bem acadêmica, 
tenho doutorado, tudo, eu acho que é comum em universidade pública ir muito por esse lado acadêmico, quando você fala em gestão em saúde, infelizmente você tem que sair um pouco disso, e ir atrás do que o mercado quer, então o que eu tive na GV, eu tive contabilidade, matemática financeira, para entender mesmo o que era essas contas de saúde, não era focado em enfermagem no geral ou na parte médica, explicar o que é um convênio, então eu acho que a gente fica muito nas evidências de artigo".

Entrevistado 2: "As vezes sim, as vezes não, as vezes era um caso estapafúrdio e as vezes não, era um caso real ou muito parecido com o real. Esse é um modelo didático mundial, onde você for fazer um MBA, principalmente um MBA voltado pra negócios ne? Pra business você vai achar esse tipo de atividade e de estudo de caso, na verdade vários MBA's aí fora são baseados em estudos de caso, na verdade os MBAS todos são vários estudos de caso importantes, não que você faz, você de fato estuda o caso, então acho que é uma iniciativa boa, um tanto quanto desajeitada, nesse caso mas boa".

\subsubsection{Perfil do Aluno}

Em relação ao perfil dos alunos, motivação para a realização do curso e o atendimento do mesmo às expectativas pessoais de cada um, foram apontadas a dificuldades em relação ao perfil dos alunos e barreiras em EAD, o que influenciou a falta de motivação ao longo do curso.

Entrevistador: $\mathrm{O}$ curso atendeu às suas expectativas pessoais?

Entrevistado 1: “Atendeu, eu só acho que senti um pouco de falta dessa interação do presencial, eu acho que é isso, por mais que você esteja ali no fórum, eu sentia que as pessoas postavam porque tinham uma atividade assim, obrigatória. Ah eu tenho que buscar uma pergunta, ou uma resposta para postar no fórum, mas não no sentido de falar, eu to ali pra tirar dúvidas, eu tenho que fazer como uma tarefa, terminei ali e acabou, então isso que tem em uma aula presencial que você pode discutir tudo ao mesmo tempo e talvez um vídeo ao vivo, não sei, não tinha tido ao vivo até o momento, 
o dia que foi ao vivo caia muito, que é o começo dessas partes mais EAD assim, então caia bastante, você acabava perdendo um pouco da discussão".

Entrevistado 2: "Eu queria me tornar um executivo melhor, queria obter as competências que normalmente um cara da área de exatas como eu na área de TI não tem, a gente costuma falar mais com as máquinas do que com as pessoas, entendeu? Na verdade eu precisava de, agente tem um jargão, que talvez seja o mesmo jargão do pessoal de RH, softskills eu precisava ter mais jeito de falar com as pessoas, precisava ter liderança, resolução de conflitos, eu precisava de uma série de softskills que são importantes pra um cara que, chega uma hora no mundo técnico que a sua carreira se divide Né?"

Entrevistado 2: "Na minha opinião, teria que ter uma coisa para me preparar melhor para o mercado, ele é uma pós graduação profissional, quando é um negócio muito acadêmico, é chatão demais, é o que eu falei pra você, teve uma hora que eu não suportava. Isso acontece quando você faz um curso e coloca um monte de acadêmicos, só, né? Se você não traz profissionais de mercado, caras mais velhos que tiveram já uma vivência no mercado e aí estão dando aula agora de você traz só gente da academia é muito complicado, eu acho né? Fica fora da realidade, a maioria das pessoas não desiste pelo investimento e porque elas querem aquele papel, pra mim, na minha área por algum motivo que eu desconheço, o papel não é tão importante quanto o seu portfólio, o que você tem pra mostrar, e a sua competência naquela área, por isso uma pessoa dessa área busca aprender de verdade, ele não vai ficar dois anos só ouvindo, ouvindo, ouvindo, só pra dizer no final que tem um MBA".

Entrevistado 1: "No começo sim, mas depois que eu te falei, virava uma tarefa obrigatória, você tem que postar até às nove da noite e isso não te estimula, vira obrigatório, então ai eu percebi que eu não ia fazer, eu estava dando aula em uma palestra, eu até estou assumindo, estava aqui na USP mesmo, eu liguei a aula, comecei a assistir e fui dar a palestra, porque eu tinha que estar presente, eu podia assistir aquela aula depois, mas não você tinha que estar presente no dia lá que era ao vivo, então eu me vi fazendo isso, eu disse, não vai rolar. Meu marido quase me matou, disse que o negócio era caro, eu falei, não eu vou fazer o da GV, não vai ter jeito”. 


\subsubsection{Influenciadores de Evasão}

Em relação aos fatores determinantes para a decisão de evadirem-se do curso, os alunos citaram o conteúdo ministrado no curso, não tão aplicado à prática. A forma que o curso foi desenhado em termos de Ambiente Virtual de Aprendizagem e interação também foi citada pelos alunos.

Entrevistador: Quais foram os principais fatores que influenciaram a sua decisão de evadir-se do curso?

Entrevistado 1: "O principal acho que eu te falei, quando eu vi que eu prestei o outro e achei que era mais conceituado no mercado, não tenho como dizer que não foi importante pra mim, é, a parte de interação com outros alunos, a troca, acho faltou, e realmente eu olhar pro programa e sentir falta dessa parte do mercado o que é essa parte financeira fora os custos, um pregão como que é? Ou no particular como funciona a medicina de grupo, mudei e senti que isso faltava um pouquinho, eu não sei, não cursei até o final pode ser que tenham tido essas aulas até o momento que tinha uma coisa mais acadêmica mesmo que os dois, mas isso eu estava sentindo um pouco de falta de formar para um mercado, aqui é diferente, fui fazer uma entrevista e me falaram, nossa esse curso é o mais fera, um dos melhores, então você tem outra inserção, foi difícil escolher, eu não pagava nada no da USP, consegui a bolsa entre os primeiros fiz uma prova, fiquei mega feliz, mas, não teve jeito”.

Entrevistado 2: "Os motivos foram o conteúdo e a forma como ele foi exposto né? A ferramenta, o moodle é muito ruizinho, talvez de você não tenha contato com ferramentas melhores como eu tenho, você usa o moodle de boa, mas pra mim aquilo era muito chato, muito desconfortável e pra mim ineficiente, e eu também comecei a achar que a relação de custo e beneficio começou a ficar muito ruim, entendeu, na verdade foi isso, é custo, conteúdo, o ambiente educacional eletrônico, é tudo, você junta preço, junta onde você vai estudar e o conteúdo, acabou o curso. E a falta de interação né? Eu acho que a coisa mais significativa mesmo foi a forma da exposição do conteúdo mesmo, muito expositiva, que vocês da área de humanas estão muito mais acostumados, aquele monte de textos que vocês fazem me deixam louco, um pouco maçante, bastante maçante, muito texto. Trabalhava 18 horas por dia, mas trabalhava por conta, não atrapalhava”. 


\subsection{Discussão do Estudo 1 e Estudo 2}

Sobre os resultados das análises descritivas dos dados, e atendendo aos objetivos específicos deste estudo, foi possível observar que os alunos utilizaram com mais frequência as estratégias cognitivas, controle da emoção e motivação, reflexão para aplicação prática e utilizaram menos a busca por ajuda interpessoal.

Analisando de forma mais profunda pode se afirmar que os alunos foram estimulados a utilizar as estratégias cognitivas, e as autorregulatórias que são o controle da emoção e motivação, reflexão para aplicação prática. O uso destas estratégias é importante para que os alunos mantenham a atenção no curso, controlem a ansiedade no decorrer da ação instrucional e mantenha-se motivados, também é importante ressaltar a reflexão para a aplicação prática, ou seja, o que vai levar o aluno a transferência do conhecimento em situações cotidianas e de trabalho.

As estratégias menos utilizadas foram a de busca por ajuda interpessoal, isso pode refletir em uma necessidade maior do EAD em promover ações de integração entre os alunos, que podem trocar experiências e enriquecer a aprendizagem ao longo do curso, o que vai de encontro com os achados de Umekawa e Zerbini (2015), testaram modelos de predição que proveram evidências de que quanto mais forem aplicadas específicas estratégias de aprendizagem, maiores serão as chances do corpo discente perceber um conjunto específico de variáveis como muito influentes sobre a permanência ou saída dos mesmos de seus cursos. Os alunos que solicitam ajuda de outras pessoas e atentam-se para os processos de aquisição de conhecimento perceberão como altamente importantes as condições tecnológicas e de suporte a eles ofertadas. Os para indivíduos cujas estratégias de monitoramento da compreensão, busca de ajuda interpessoal e cognitivo - comportamentais são as mais empregadas, os eventos provenientes do entorno social (como compromissos sociais e doenças) prejudicarão em maior intensidade a estadia do discente no curso.

Pode-se observar que as estratégias cognitivas de aprendizagem tiveram relação com todas as variáveis de barreiras relacionadas ao curso, sendo estas: Contexto Externo ao Curso, Suporte Institucional, Contexto Externo ao Curso, Desenho do Curso e Características do Aluno. 
Pode-se verificar também que o suporte oferecido pela instituição de ensino, contexto externo ao curso, desenho do curso, características do aluno e questões financeiras e de saúde não foram apontados como barreiras ou dificultadores em relação ao curso. Ao analisar os itens que tiveram menor frequência de respostas nos pontos mais baixos da escala é possível verificar que os itens relacionados ao contexto externo ao curso, mantiveram índices não tão baixos como os demais itens da escala, sendo estes itens que se referem a conciliação das atividades do curso com compromissos familiares, outras atividades de estudo e de trabalho. Este ponto, se comparado a literatura pode ser fator alarmante, já que em outros estudos os fatores ligados ao contexto que cerca o aluno a distância, são apontados como variáveis historicamente ligadas ao abandono discente em iniciativas de EaD (Abbad, 2007; Sales, 2009; Xenos, Pierrakeas, \& Pintelas, 2002). No estudo 2 o contexto externo do aluno foi apontado como barreira ao longo do curso, devido à conciliação com outros cursos e questões financeiras, também foi citado o fato de estudar EAD em casa, o que pode ocasionar interrupções pela família, por estar presencialmente em casa.

Tanto o instrumento de Estratégias de Aprendizagem quanto o Instrumento de Barreiras em EAD apresentaram um bom índice de consistência interna, ambos instrumentos foram adaptados por Martins (2016), em seu estudo, também apresentaram bons índices.

Pode-se afirmar que os alunos que utilizaram as estratégias cognitivas de repetição do conteúdo, reflexão sobre os conteúdos e formulam esquemas mentais que agrupam os conhecimentos aprendidos perceberam o suporte da instituição de ensino como barreira ao longo do curso. Em relação ao suporte institucional, no Estudo 2 tiveram pontuações em relação à interação com o tutor, que assumia um papel de responder dúvidas apenas, não estimulando a interação dos alunos durante os fóruns.

Já os alunos que utilizaram as estratégias cognitivas de repetição do conteúdo, reflexão sobre os conteúdos e controlam a ansiedade, preveem dispersões e avaliam seu processo de aquisição de aprendizagem percebem como uma barreira o contexto externo ao curso, ou seja, o tempo disponível para estudar, a conciliação do curso com os compromissos familiares e profissionais, para a definição desta barreira pode-se utilizar a barreira motivacional utilizada por Vargas (2004), que diz respeito às atitudes do treinando com relação ao evento instrucional. Conforme apontado anteriormente, os alunos apontaram que esta foi uma barreira ao longo da ação educacional a distância.

Em suma, os alunos que utilizaram as estratégias cognitivas de repetição do conteúdo, reflexão sobre os conteúdos e controlam a ansiedade, preveem dispersões e avaliam seu processo de aquisição de aprendizagem, aperfeiçoam o aprendizado através da aplicação 
prática, percebem como uma barreira o desenho do curso, ou seja, o tempo de duração do curso, o conteúdo do curso, os recurso de ensino utilizados ao longo do curso e quantidade de atividades exigidas ao longo do curso, (Abbad, 2007; Sales, 2009; Xenos, Pierrakeas, \& Pintelas, 2002) apontam também a barreira de fatores relativos ao evento instrucional, que se relacionam ao que foi encontrado no presente estudo. No estudo 2, foram apontadas falhas no que se refere aos conteúdos dos cursos serem muito teóricos e pouco aplicados à prática, com professores muito acadêmicos e com pouca experiência prática, isto foi um fator que segundo os alunos teve impacto na decisão por evadirem-se do curso.

Em suma, os alunos que utilizaram as estratégias cognitivas de repetição do conteúdo, reflexão sobre os conteúdos e aperfeiçoam o aprendizado através da aplicação prática, percebem como uma barreira às características do aluno, ou seja, as habilidades de organização para a realização das atividades propostas pelo curso e as habilidades para o uso das ferramentas web (chats, e-mails, fóruns, etc.), o que corrobora com o estudo de Meneses et al. (2006), que categorizou as variáveis de características da clientela, sendo a primeira o repertório de entrada, que são conhecimentos, habilidades, atitudes, expectativas e experiências adquiridas pelo aprendiz previamente ao início do evento instrucional. No estudo 2 , foram apontadas falhas na conexão durante as aulas ao vivo, e a ferramenta de acesso ao aluno que segundo afirmações, eram muito atrasadas, também citaram a falta de interação nos forúns com o tutor e demais alunos.

\subsection{Conclusões}

Pode-se concluir que os objetivos deste estudo foram alcançados, os achados contribuem para a área de planejamento instrucional das ações educacionais a distância, em especial as IES, já que fornece informações sobre os desafios do perfil da clientela, bem como às estratégias mais utilizadas pelos alunos. Com estas informações as IES, podem buscar meios de conhecer melhor a clientela de seus cursos e com isso personalizá-los de acordo com o perfil dos alunos, também é possível refletir se os meios de interação são suficientes para promover uma integração dos alunos, e planejar outras formas de aproximá-los. Desta forma, enriquecerá as trocas de experiências favorecendo a aplicação prática do conteúdo aprendido. Os elementos ligados mais intimamente ao desenho instrucional, como os procedimentos adotados pelas IES, também são apontados como fatores que contribuem para a desistência estudantil (Umekawa, 2014; Umekawa \& Zerbini, 2018). 
Pode-se concluir também que o planejamento instrucional dos cursos aqui analisados não focou na interação dos alunos, por isto é necessário que as IES criem estratégias que promovam esta interação entre alunos e tutores.

O estudo também contribui metodologicamente com a elaboração do "Roteiro de Barreiras à Conclusão de Cursos de Pós-Graduação Lato Senso a Distância”, que poderá ser utilizado em pesquisas futuras no contexto educacional e adaptado a outros contextos. Ressalta-se a problemática deste estudo e demais tentativas anteriores por outros pesquisadores de conseguir contatar os alunos evadidos, o contato foi feito por diversas vezes, e mesmo assim, obteve-se um índice mínimo de participação. A dificuldade de participação dos evadidos impede o acesso a informações extremamente relevantes para a área de psicologia mais especificamente TD\&E. Apesar do baixo índice de participação dos evadidos, a opção de contatá-los via Skipe foi vista como uma oportunidade de ter acesso a novas informações que contribuíram para o estudo.

A literatura aponta para um intervalo médio no país de 25 a $50 \%$ de alunos evadidos Censo EAD (2015). Neste estudo tivemos um índice de 17\%, que se mostra abaixo das médias de evasão em Instituição de Ensino Superior no Brasil.

A seguir, outras limitações podem ser listadas neste estudo:

1- Necessidade de uma amostra significativa de alunos que se evadiram dos cursos EAD;

2 - De uma amostra de 1936 alunos, apenas 142 responderam, sendo 3 evadidos e 139 não evadidos, destes 3 evadidos, somente 2 aceitaram participar do estudo qualitativo;

3- Poucas informações relevantes sobre o perfil sociodemográfico dos alunos e o quanto este fator pode influenciar na evasão;

4- Devido ao tamanho da amostra de evadidos não é possível generalizar os dados;

5 - Necessidade de estudos que busquem identificar como o planejamento instrucional pode se desenvolver para atender as demandas da clientela dos cursos EAD;

6 - Necessidade de mais estudos na área de Ensino Superior em EAD, buscando aprimorar os recursos teóricos para as Instituições de Ensino.

Diante dos resultados e discussões promovidas no presente estudo, a seguinte agenda de pesquisa é proposta:

1) Realização de investigações com a amostra composta somente por alunos evadidos;

2) Inserção de outras variáveis relacionadas ao perfil do aluno;

3) Realização de investigações com a temática envolvendo uma amostra em cursos corporativos; 
4) Realização de investigações com o "Roteiro de Barreiras à Conclusão de Cursos de Pós-Graduação Lato Senso a Distância" no contexto de ensino superior, treinamentos e cursos corporativos;

5) Construção de modelos de predição envolvendo as variáveis deste estudo e outras relevantes no contexto de TD\&E.

Pode-se concluir que mesmo com as limitações deste estudo, o tema abordado é relevante e contribui para os avanços da área de TD\&E. Espera-se que os achados desta pesquisa possam complementar os estudos anteriores e despertar para novos estudos relacionados da área. 


\section{REFERÊNCIAS BIBLIOGRÁFICAS}

Abbad, G. (1999). Um modelo integrado de avaliação de impacto de treinamento no trabalho. Tese Doutorado, Instituto de Psicologia, Universidade de Brasília.

Abbad, G. S., Carvalho, R. S., \& Zerbini, T. (2006). Evasão em curso via internet: explorando variáveis explicativas. Revista de administração de empresas (5)2, Art. 17, jul./dez.

Abbad, G., \& Borges-Andrade, J. E. (2004). Aprendizagem humana em organizações de trabalho. In J. C. Zanelli, J. E. Borges-Andrade \& A.V. B. Bastos (Orgs.), Psicologia, Organizações e Trabalho no Brasil (pp. 237-275). Porto Alegre, RS: Artmed.

Abbad, G., Côrrea, V. P., \& Meneses, P. P. M. (2010). Avaliação de treinamentos a distância: Relações entre estratégias de aprendizagem e satisfação com o treinamento. RAM Revista de Administração Mackenzie, 11(2), 43-67.

Abbad, G., Pilati, R., \& Pantoja, M. J. (2003). Avaliação de treinamento: Análise da literatura e agenda de pesquisa. Revista de Administração da USP, 38(3), 205-218.

Abbad, G., Zerbini, T., \& Souza, D. B. L.(2010). Panorama das pesquisas em Educação a Distância no Brasil. Estudos de Psicologia 15(3), 291-298.

Abbad, G., Zerbini, T., Carvalho, R. S., \& Meneses, P. P. M. (2006). Planejamento instrucional em TD\&E. In J. E. Borges-Andrade, G. Abbad, L. Mourão (Orgs.), Treinamento, desenvolvimento e educação em organizações e trabalho: fundamentos para a gestão de pessoas (pp. 289-321). Porto Alegre, RS: Artmed.

Abbad, G.S. (2007). Educação a Distância: O Estado da Arte e o Futuro Necessário. Revista do Serviço Público Brasília 58 (3), 351-374.

ABED. Associação Brasileira de Educação a Distância. Censo EaD.br: relatório analítico da aprendizagem a distância no Brasil. São Paulo: Pearson Education do Brasil, 2017.

ABED. Associação Brasileira de Educação a Distância. Censo EaD.br: relatório analítico da aprendizagem a distância no Brasil. São Paulo: Pearson Education do Brasil, 2015.

ABED. Associação Brasileira de Educação a Distância. Censo EaD.br: relatório analítico da aprendizagem a distância no Brasil. São Paulo: Pearson Education do Brasil, 2010.

Abreu-e-Lima, D. M., \& Alves, M. N. (2011). O feedback e sua importância no processo de tutoria a distância. Pro-Posições, 22(2), 189-205.

Aguinis, H., \&Kraiger, K. (2009). Benefitis of training and development for individuals and teams, organizations, and society. Annual Reviewof Psychology, 60, 451-474.

Almeida, O. (2007). Evasão em cursos a distância: validação de instrumento, fatores influenciadores e cronologia da desistência. Dissertação de Mestrado, Instituto de Psicologia, Universidade de Brasília, Brasília. 
Alonso, K. M. (2010). A expansão do ensino superior no Brasil e a EaD: dinâmicas e lugares. Educação e Sociedade, 31(113),1319-1335.

Alvarez, K., Salas, E., \& Garofano, C.M. (2004). An integrated model of training evaluation and effectiveness. Human Resource Development Review, 3(4), 385-416.

Amidani, C. (2004). Evasão no ensino superior a distância: o curso de licenciatura em matemática a distância da Universidade Federal Fluminense/CEDERJ - RJ. Dissertação de Mestrado. Faculdade de Educação, Universidade de Brasília, Brasília.

Anderson, T. (2005) Distance learning - Social software's killer ap? The Open \& Distance Learning Association of Australia.

Anuário Brasileiro Estatístico de Educação Aberta e a Distância. Instituto Monitor. São Paulo: Autor, 2007.

Anuário Brasileiro Estatístico de Educação Aberta e a Distância. Instituto Monitor. São Paulo: Autor, 2008.

Appana, S. (2008). A Review of Benefits and Limitations of Online Learning in the Context of the Student, the Instructor and the Tenured Faculty. International Journalon E-Learning, $7(1), 5-22$.

Associação Brasileira de Educação a Distância (2012).

Bardin, L. (1977). Análise de conteúdo. Lisboa, Portugal: Edições 70.

Bell, B. S. Tanneunbaum, S.i, Ford, J. K., Noe, R.A., \& Kraiger, K. (2017). 100 years of training and development research: What we know and where we should go. Journal of Applied Psychology, 102(3),305-323.

Belloni, M. L. (1999). Educação a distância. Campinas: Autores Associados.

Bentes, M. C. B.; Kato. M. (2014). Fatores que afetam a evasão na educação a distância: Curso de administração - Psicologia. da Educação, São Paulo, v.39 (1), n4 jan/abril 13

Biazus, C. A. (2004) Sistema de fatores que influenciam o aluno a evadir-se dos cursos de graduação na UFSM e na UFSC: um estudo no curso de Ciências Contábeis. Tese de Doutorado,Programa em Engenharia de Produção, Universidade Federal de Santa Catarina.

Bittencourt, I. M. \& Mercado, L. P. L. Evasão nos cursos na modalidade de educação a distância: estudo de caso do Curso Piloto de Administração da UFAL/UAB. Ensaio: aval. pol. públ. Educ., Rio de Janeiro, v.22 (83), p. 465-504, abr./jun. 2014

Bjork, R. A.; Dunlosky, J.; \& Kornell, N. (2013). Self-Regulated Learning: Beliefs, Techniques, and Illusions. Annu. Rev. Psychol., 64, 417-44. 
Bohadana, E., \& Valle, L. (2009). O quem da educação a distância. Revista Brasileira de Educação. 14(42), 551-564.

Borges-Andrade, J. E. (1982). Avaliação somativa de sistemas instrucionais: integração de três propostas. Tecnologia Educacional, 11(46), 29-39.

Borges-Andrade, J. E. (2006). Avaliação integrada e somativa em TD\&E. In J. E. BorgesAndrade, G. Abbad, L. Mourão (Orgs.). Treinamento, desenvolvimento e educação em organizações e trabalho: fundamentos para a gestão de pessoas (pp. 343-358). Porto Alegre, RS: Artmed.

Borges-Andrade, J. E.; Zerbini, T.; Abbad, G. S. \& Mourão, L. (2013). Treinamento, desenvolvimento e educação: Um modelo para sua gestão. In Borges, L., Mourão, L. (Org). O Trabalho e as Organizações. Atuações a partir da Psicologia (pp. 465-498). Porto Alegre: Editora Artmed.

Brandão, H. P., \& Borges-Andrade, J. E. (2011). Desenvolvimento e validação de uma escala de estratégias de aprendizagem no trabalho. Psicologia: Reflexão e Crítica, 24(3), 448457.

Brant, S. R. C. (2014). Estudo multinível de antecedentes do impacto no trabalho e da persistência/Evasão em treinamentos a distância. Tese de doutorado, Instituto de Psicologia, Universidade de Brasília.

Brasil. Decreto n. 2.494, de 10 de fevereiro de 1998. Regulamento da Educação a Distância no País. Diário Oficial da Republica Federativa do Brasil. Disponível em <http://www.mec.gov.br. Acesso em 12/12/2016.

Brauer, S., Abbad, G., \& Zerbini, T. (2009). Características da clientela e barreiras à conclusão de um curso a distância. Psico-USF, 14, 317-328.

Brauer, S. (2005). Avaliação de um Curso a Distância: Valor Instrumental do Treinamento, Barreiras Pessoais à Conclusão e Evasão. Dissertação de Mestrado, Instituto de Psicologia, Universidade de Brasília, Brasília.

Brusilovsky, P., \& Peylo, C. (2003). Adaptative ansinteligente Web-based educational systems [Special Issue]. International Journal of Artificial Intelligence in Education, 13, 159-172.

Burke, L. A., \& Hutchins, H. M. (2007). Training transfer: an integrative literature review. HumanResourceDevelopmentReview, 6(3), 263-297.

Carswell, A. D., \& Venkatesh, V. (2002). Learner outcomes in an asynchronous distance education environment. International Journal of Human-Computer Studies, 56, 475-494.

Carvalho, R. S., \&Abbad, G. (2006). Avaliação de treinamento a distância: reação, suporte à transferência e impactos no trabalho. Revista de Administração Contemporânea, 10(1), 95-116.

Castro, M. N. M., \& Ferreira, L. D. V. (2006). TD\&E a distância: múltiplas mídias e clientelas. In J. E. Borges-Andrade, G. Abbad, L. Mourão (Orgs.). Treinamento, 
desenvolvimento e educação em organizações e trabalho: fundamentos para a gestão de pessoas (pp. 322-339). Porto Alegre, RS: Artmed.

Cheung, D. (2000). Evidence of a single second-order factor in student ratings of teaching effectiveness. StructuralEquationModeling, 7(3), 442-460.

Codes, A. L. M. (2005). Modelagem de equações estruturais: um método para a análise de fenômenos complexos. Caderno CRH, 18(45), 471-484.

Coelho Jr., F. A., \& Borges-Andrade, J. E. (2008). Uso do conceito de aprendizagem em estudos relacionados ao trabalho e organizações. Paidéia, 18(40), 221-234.

Coelho, M. L. A. (2003). Formação continuada do docente universitário em cursos a distância via Internet: um estudo de caso. Monografia de Conclusão de Curso. Belo Horizonte: ABED.

Coelho, Maria. L. A formação continuada do docente universitário em cursos a distância via internet: Um estudo de caso. Recuperado de http://www.abed.org.br/seminario2003/texto06.htm Acesso em: 12 de Dezembro 2016.

Cookson, P. (1990). Persistence in distance education. In M. G. Moore, P. Cookson, J. Donaldson, \& B. A. Quigley (Eds.), Contemporary issues in American distance education (pp. 192-204). Oxford, England: Pergamon Press.

Creswell, J. W.; Clark, V. L.. (2011). Designing and conducting mixed methods research. 2nd. Los Angeles: SAGE Publications

Deimann, M. \& Bastiaens, T. (2010). The Role of Volition in Distance Education: An Exploration of its Capacities. International Review of Research in Open and Distance Learning Volume 11, Number 1. 1-16.

Döös, M., \&Wilhelmson, L. (2011). Collective learning: interaction and a shared action arena, Journal of Workplace Learning, 23(8), 487-500.

Freeze, R. D., Alshare, K. A., Lane, P. L., \& Wen, H. J. (2010). IS success model in elearning context based on students' perceptions.Journal of Information Systems Education, 21(2), 173-184.

Fritsch, R., Rocha, C, S., \&Vitelli, R, F. (2015). A evasão nos cursos de graduaçãoem uma instituição de ensino superior privada. Revista Educação em Questão, 52,81-108.

Gondin, S. M. G. \& Silva, N. (2004). Motivação no Trabalho. In J. C. Zanellie, J. E. BorgesAndrade \& A. V. B. Bastos (Orgs.), Psicologia, organizações e trabalho no Brasil (pp. 145-176). Porto Alegre: Artmed.

Hair, J. F., Anderson, R. L., Tatham, R. L., \& Black, W. C. (2005).Análise Multivariada de dados (5a ed.). Porto Alegre, RS: Bookman. 
Hayes, H., Scott, V., Abraczinskas, M., Scaccia, J., Stout, S., \& Wanderman, A. (2016). A formative multimethod approach to evaluating training. Evaluation and Program Planning, 58, 199-207.

Hamblin, A. C. (1978). Avaliação e controle do treinamento. São Paulo: McGraw-Hill do Brasil.

Henderson, B.D. (1998). As origens da Estratégia. Em Montgnomery, C. A, Porter, M. P. Estratégia: a busca da vantagem competitiva. $15^{\text {a }}$ ed. Rio de Janeiro. Elsevier.

Henke, H., \&Russum, J. (2000). Factors Influencing Attrition Rates in a Corporate Distance Education Program. Education at a Distance Journal, 14(11), 2-16.

Holman, D., Epitropaki, O., \& Fernie, S. (2001). Understanding learning strategies in the workplace: A factor analytic investigation. Journal of Occupational and Organizational Psychology, 74, 675-681.

Iglesias, M., \& Salgado, J. F. (2012). Effectiveness of Occupational Training Through Videoconferencing: Comparison with Classroom Training and Individual Differences. Revista de PsicologíadelTrabajo y de lasOrganizaciones, 28(3), 183-188

INEP -Instituto Nacional de Estudos e Pesquisas Educacionais Anísio Teixeira (2015).

Kirkpatrick, D. L. (1976). Evaluation of training. In R. L. Craig (Org.), Training and Development Handbook (pp. 18.1-18.27). New York: McGraw-Hill.

Lacerda, E. R. M., \& Abbad, G. (2003). Impacto do Treinamento no Trabalho: Investigando Variáveis Motivacionais e Organizacionais como suas Preditoras. Revista de Administração Contemporânea, 7(4), 77-96.

Lee, H. S. \& Anderson, J. R. (2013). Student Learning: What Has Instruction Got to Do With It?. Annu. Rev. Psychol.,64(3),1-25.

Lee, Y., \& Choi, J. (2011). A review of online course dropout research: Implications for practice and future research. Education Tech Research, 59, 593-618.

Lee, Y., Tseng, S., Liu, F., \& Liu, S. (2007). Antecedents of learner satisfaction toward elearning.Journal of American Academy of Business, 11(2), 161-168.

Lu, H. P., \&Chiou, M. J. (2010). The impact of individual differences on e-learning system satisfaction: a contingency approach. British JournalofEducational Technology, 41(2), 307-323.

Martins, L. B. (2012). Aprendizagem em ações educacionais a distância: fatores influentes no desempenho acadêmico de universitário. Dissertação de Mestrado, Faculdade de Filosofia, Ciências e Letras de Ribeirão Preto, Universidade de São Paulo, São Paulo.

Martins, L. B., \& Zerbini, T. (2014). Educação a distância em instituições de ensino superior: uma revisão de pesquisas. Revista Psicologia: Organizações e Trabalho, 14(3), 271-282. 
Martins, L.B. \& Zerbini, T. (2015). Evidências de validade de instrumentos de reações no ensino superior a distancia. Estudos e Pesquisas em Psicologia, 15(1), 116-134.

Martins, L. B. (2016). Impacto do treinamento no trabalho: determinantes individuais e contextuais em cursos a distância. Tese de doutorado, Faculdade de Filosofia, Ciências e Letras de Ribeirão Preto, Universidade de São Paulo, São Paulo.

Martins, L. B., Zerbini, T., \& Medina, F. J. (2018). Learning strategies scale: adaptation to

Portuguese and factor structure. Revista Psicologia: Reflexão e Crítica, 31.

Mello, C. G. (2017). Estratégias de aprendizagem em ações educacionais a distância: Relação com características da clientela e reações ao curso. Dissertação de Mestrado, Faculdade de Filosofia, Ciências e Letras de Ribeirão Preto, Universidade de São Paulo, São Paulo.

Mendonça, C. G. P. (2015) Fatores críticos de sucesso da educação a distância no ambiente corporativo. Trabalho de Conclusão de Curso, Universidade Federal do Rio Grande do Sul, Instituto de Psicologia, Rio Grande do Sul.

Meneses, P. P. M., Zerbini, T., \& Martins, L. B. (2012). Determinantes situacionais e individuais da aprendizagem em ensino a distância: desenvolvimento de escala. PSICOPUCRS, 43(2), 208-218.

Meneses, P. P. M., Zerbini, T., \&Abbad, G. (2010). Manual de Treinamento Organizacional. Porto Alegre, RS: Artmed.

Meneses, P. P. M., Abbad, G, Zerbini, T., \& Lacerda, E. (2006). Medidas de características da clientela em avaliação de TD\&E. In: J. E. Borges-Andrade, G. Abbad, L. Mourão (Orgs.). Treinamento, desenvolvimento e educação em organizações e trabalho: Fundamentos para a gestão de pessoas (pp. 422-442). Porto Alegre: Artmed.

Mintzberg, H., \& Quinn, J. B (2001). O processo da Estratégia. $3^{\text {a }}$ ed. Porto Alegre. Bookman.

Moore, M. G; Kearsley, G. (2007) Educação a distância: uma visão integrada. São Paulo: Thomson Learning.

Moore, G. \& Kearley, G. (2011) Educação a distância: uma visão integrada. Tradução de Roberto Galman. São Paulo: Cengage Learning.

Moraes, R. B. N. \& Zerbini, T. (2018). Estilos de aprendizagem em EaD: construção e evidências de validade de instrumento. Estudos e Pesquisas em Psicologia, 18 (1), 149-168.

Moraes, R.B.N. (2016). Estilos de Aprendizagem em ações educacionais ofertadas a distância: Evidências de Validade, Validade Convergente e Análise Conceitual. Dissertação de Mestrado, Faculdade de Filosofia, Ciências e Letras de Ribeirão Preto, Universidade de São Paulo, São Paulo. 
Mugnol, M. (2009). A educação a distância no Brasil: Conceitos e fundamentos. Revista Diálogo Educacional, 9(27),335-349.

Ngoma, P. S., Simwanza, A., \& Makukna, C. K. (2004). Investigating the Drop Out Problem Amongst University Extension Studies Learners in Zambia. Third Pan- Commonwealth Forum on Open Learning, Dunedin, New Zealand. Acessado em 15 de dezembrombro de 2016 em: http://www.col.org/pcf3/Papers/PDFs/Ngoma_Simwanza_Makunka.pdf.

Oliveira, K. L., Boruchovitch, E., \& Santos, A. A. A. (2009). Estratégias de aprendizagem e desempenho acadêmico: evidências de validade. Psicologia: teoria e pesquisa, 25(4), 531536.

Pacheco, A. S; Melo, P. A.; Moretto Neto L.(2007). Evasão na modalidade a distância. Disponível em: <http://www.inpeau.ufsc.br/wp/wpcontent/ BD_documentos/2138.pdf>. Acesso em: 102de dezembro de 2017.

Palloff, R. M., \& Pratt, K. (2004). O aluno virtual: um guia para trabalhar com alunos online. Porto Alegre, RS: Artmed.

Pantoja, M. J. (2004). Estratégias de aprendizagem no trabalho e percepções de suporte à aprendizagem - uma análise multinível. Tese de Doutorado, Instituto de Psicologia, Universidade de Brasília.

Pantoja, M. J., \& Borges-Andrade, J. E. (2009). Estratégias de aprendizagem no trabalho em diferentes ocupações profissionais. RAC-Eletrônica, 3(1), 41-62.

Parker, A. (2003). Identifying predictors of academic persistence in distance education. Usdla Journal, v.17, n1.

Pasquali, L. (2004). Análise fatorial para pesquisadores. Petrópolis, RJ: Vozes.

Pedroso, C., Maracci, F., Kunze, W., \& Rizo, C. (2013). Hipermídia Adaptativa e a Evasão na Educação a Distância. Colloquium Exactarum.5(2),01-11.

Petters, O. (2006) Didática do ensino a distância: experiências e estágio da discussão numa visão internacional. Tradução de Ilson Kayser. São Leopoldo: Unisinos

Pilati, R. (2004). Modelo de efetividade do treinamento no trabalho: aspectos dos treinandos e moderação do tipo de treinamento. Tese de Doutorado, Instituto de Psicologia, Universidade de Brasília.

Pilati, R., \& Borges-Andrade, J. E. (2006). Construção de medidas e delineamentos em avaliação de TD\&E. In J. E. Borges-Andrade, G. Abbad, L. Mourão (Orgs.), Treinamento, desenvolvimento e educação em organizações e trabalho: fundamentos para a gestão de pessoas (pp. 359-384). Porto Alegre, RS: Artmed.

Prado, Maria. E. B.; Valente, José. A. A. (2002). Educação a distância possibilitando a formação do professor com base no ciclo da prática pedagógica. In M. C. Moraes (Org.). Educação a Distância: fundamentos e práticas, Campinas, SP:UNICAMP/NIED. 
Praslova, L. (2010). Adaptation of Kirkpatrick's four level model of training criteria to assessment of learning outcomes and program evaluation in higher education. Educational Assessment, Evaluation and Accountability, 22(3), 215-225.

Raymond, A. N., Clarke, A. D. M., \& Klein, H. J. (2014). Learning in the Twenty-FirstCentury Workplace. Annu. Rev. Organ. Psychol. Organ. Behav, 1, 4.1-4.31.

Reis, F.L. (2009). Do ensino presencial ao ensino a distância no contexto universitária na Península Ibérica. Revista Brasileira de Aprendizagem Aberta e a Distância, 8, 1 - 28.

Revista PSICO, 41, 192-200.

Reio, T. G., Rocco, T. S., Smith, D. H. and Chang, E. (2017), A Critique of Kirkpatrick's Evaluation Model. New Horizons in Adult Education and Human Resource Development, 29, 35-53.

Romero, M., \& Barberà, E. (2011). Quality of Learners ${ }^{e e}$ Time and Learning Performance Beyond Quantitative Time-on-Task. The International Review Of Research In Open And Distance Learning, 12(5), 125-137.

Sahin, I., \& Shelley, M. (2008).Considering students' perceptions: the distance education student satisfaction model. Educational Technology \& Society, 11(3), 216-223.

Salas, E., \& Cannon - Bowers, J.A. (2001). The science of training a decade of progress. AnnualReviewofPsychology, 52, $471-499$.

Salas, E., Tannenbaum, S. I., Kraiger, K., \& Smith-Jentsch, K. A. (2012). The Science of Training and Development in Organizations: What Matters in Practice. Psychological Science in the Public Interest, 13(2) 74-101.

Sales P. A. O., Abbad, G., \& RRodrigues, J. L. (2011). Variáveis preditivas de evasão e persistência em treinamentos a distância [CD-Rom]. Associação Nacional dos Programas de Pós-Graduação em Administração (Org.). Anais do XXXV ENANPAD. Rio de Janeiro: ANPAD, 2011

Sales, P. A. O. (2009). Evasão em Cursos a Distância: Motivos Relacionados às Características do Curso, do Aluno e do Contexto de Estudo. Dissertação de Mestrado, Instituto de Psicologia, Universidade de Brasília, Brasília.

Santos, A. A. A., Boruchovitch, E., Primi, R., Zenorini, R. P. C., \& Bueno, J. M. H (2004). Escala de avaliação de estratégias de aprendizagem para universitários (EAP-U): aplicação do Modelo de Rasch de créditos parciais. Braga-PT: Psicologia: Teoria, Investigação e Prática, 9(2), 227-242.

Santos, E. M., Tomotake, M. E., Neto, J. D. O., Cazarini, E. W., Araujo, E. M., \& Oliveira, S. R. M. Evasão na educação a distância: Identificando causas e propondo estratégias de prevenção. Recuperado de: http://www. abed.org.br/congrsso/tc/511200845607PM.pdf Acesso em: 05 de dezembro de 2016.

Santos, J. F. S. (2006). Avaliação no ensino a distância. Revista Iberoamericana de Educación, 38(4), 1-9. 
São Paulo: Thomson Learning, 2007

Shin, N., \& Kim, J. (1999). An exploratory of learner progress and drop-out in Korea National Open University.Distance Education, 20(3), 81-95.

Silva, D. R., \& Tomaz, J. B. C. (2006). Porque a evasão? Escola de Saúde Pública do Ceará. Fevereiro.

Siqueira, K. F. (2009). Alguns estudos sobre evasão e persistência de estudantes. Eccos Revista Científica, 11(1), 247-264.

Sonnentag, S., Niessen, C., \& Ohly, S. (2004). Learning at work: Training and development. In C. L. Cooper \& I. T. Robertson (Orgs.), International Review of Industrial and Organizational Psychology, 19, 249-289.

Tabachnick, B.G., \& Fidell, L.S. (2007). Using multivariate statistics. New York, NY: Harper-Collins College Publishers.

Testa, M. G., \& Luciano, E. M. (2010). A influência da autorregulação dos recursos de aprendizagem na efetividade dos cursos desenvolvidos em ambientes virtuais de aprendizagem na Internet. Revista Eletrônica de Administração, 16(2), 176-208.

Umekawa, E. E. R. \& Zerbini, T. (2018). Fatores relacionados à evasão e à persistência em EAD: validação de uma escala. Cadernos de Educação - UFPel, 15(1), 172-195.

Umekawa, E. E. R. \& Zerbini, T. (2015). Evasão e persistência em ações educacionais a distância: análise do perfil discente. Revista Psicologia: Organizações e Trabalho, (15)2, 188-200.

Umekawa, E. E. R. (2014). Preditores de fatores relacionados à Evasão e à persistência discente em ações educacionais a distância. Dissertação de Mestrado, Faculdade de Filosofia, Ciências e Letras de Ribeirão Preto, Universidade de São Paulo, São Paulo.

Vargas, M. R. M. (2004). Barreiras à implantação de programas de educação e treinamento a distância. Tese de Doutorado. Universidade de Brasília. Brasília.

Vargas, M. R. M., \&Abbad, G. S. (2006). Bases conceituais em treinamento, desenvolvimento e educação - TD\&E. In J.E. Borges-Andrade, G. Abbad, L. Mourão (Orgs.). Treinamento, desenvolvimento e educação em organizações e trabalho: fundamentos para a gestão de pessoas (pp. 137-158). Porto Alegre, RS: Artmed.

Vermunt, J. D. (2005). Relations between student learrning patterns and personal and contextual factors and academic performance.Highereducation, 49 (3), 205-234.

Walter, A. M. (2006). Variáveis Preditoras de Evasão em Cursos a Distância. Dissertação de Mestrado, Universidade de Brasília, Brasília. 
Wang, G., Foucar-Szocki, D., Griffin, O., O’Connor, C., \&Sceiford, E. (2003). Departure, Abandonment, and Dropout of E-learning: Dilemma and Solutions. James Madison University.

Warr, P., \& Allan, C. (1998). Learning strategies and occupational training. International Review of Industrial and Organizational Psychology, 13, 83-121.

Warr, P., \& Downing, J. (2000). Learning strategies, learning anxiety and knowledge acquisition. British Journal Psychology, 91, 311-333.

Xenos, M., Pierrakeas, C., \&Pintelas, P. (2002). A survey on student dropout rates and dropout causes concerning the students in the Course of Informatics of the Hellenic Open University. Computers \& Education, 39, 361-377.

Yukselturk, E., \&Inan, F. A. (2006). Examining the Factors Affecting Student Dropout in an Online Learning Environment. Turkish Online JournalofDistanceEducation, 7(2) 76-88.

Zerbini, T, \& Abbad, G. (2007, Dezembro). Variáveis Preditoras da Transferência de Treinamento em Curso a Distância. Trabalho apresentado no 5th International Conference of the Iberoamerican Academy of Management IAM, Santo Domingo, República Dominicana.

Zerbini, T. \& Abbad, G. (2005). Impacto de treinamento no trabalho via internet. Revista de Administração de Empresas Eletrônica, 4 (2).

Zerbini, T. (2003). Estratégias de aprendizagem, reações aos procedimentos de um curso via internet, reações ao tutor e impacto do treinamento no trabalho. Dissertação de Mestrado, Instituto de Psicologia, Universidade de Brasília, Brasília.

Zerbini, T. (2007). Avaliação da transferência de treinamento em curso a distância. Tese de Doutorado, Instituto de Psicologia, Universidade de Brasília, Brasília.

Zerbini, T., \& Abbad, G. (2008a). Estratégias de aprendizagem em curso a distância: Validação de uma escala. Psico-USF, 13, 177-187.

Zerbini, T., \& Abbad, G. (2008b). Qualificação profissional a distância: Ambiente de estudo e procedimentos de interação - validação de uma escala. Análise, 19(1), 148-172.

Zerbini, T., \& Abbad, G. (2010a). Qualificação profissional a distância: Avaliação da transferência de treinamento. Paideia, 20, 313-323.

Zerbini, T., \& Abbad, G. (2010b). Transferência de treinamento e impacto do treinamento no trabalho: Análise crítica da literatura. Revista Psicologia: Organizações e Trabalho, 10(2), 97-111

Zerbini, T., \& Abbad, G. (2010b). Transferência de treinamento e impacto do treinamento no trabalho: Análise crítica da literatura. Revista Psicologia: Organizações e Trabalho, 10(2), 97-111.

Zerbini, T., \& Abbad, G. (2010c). Reações em cursos a distância: Revisão da literatura. 
Zerbini, T., \&Abbad, G. (2010a). Qualificação profissional a distância: avaliação da transferência de treinamento. Paidéia (Ribeirão Preto), 20, 313-323.

Zerbini, T., Coelho, F. A., Abbad, G. S., Mourão, L., Alvim, S., \& Loiola, E. (2012). Transferência de treinamento e impacto do treinamento em profundidade. In G. S. Abbad, L. Mourão, P. P. M. Meneses, T. Zerbini, J. E. Borges-Andrade, R. Vilas-Boas(Orgs.). Medidas de avaliação em treinamento, desenvolvimento e educação: ferramentas para gestão de pessoas (pp. 127-144). Porto Alegre: Artmed. 


\section{ANEXO A - QUESTIONÁRIO SOCIODEMOGRÁFICO}

Por favor, informe alguns dados pessoais:

\begin{tabular}{|c|c|}
\hline \multicolumn{2}{|c|}{ QUESTIONÁRIO SOCIODEMOGRÁFICO } \\
\hline Sexo & $\begin{array}{l}\square \text { Feminino } \\
\square \text { Masculino }\end{array}$ \\
\hline \multicolumn{2}{|l|}{ Idade } \\
\hline Estado civil & $\begin{array}{l}\square \text { solteiro } \\
\square \text { casado } \\
\square \text { divorciado } \\
\square \text { separado } \\
\square \text { outro }\end{array}$ \\
\hline Composição familiar & $\begin{array}{l}\text { filhos } \\
\square \text { não }\end{array}$ \\
\hline Escolaridade & $\begin{array}{l}\square \text { Ensino Médio Completo } \\
\square \text { Superior Incompleto } \\
\square \text { Superior Completo }\end{array}$ \\
\hline \multicolumn{2}{|l|}{ Profissão/Ocupação atual } \\
\hline Renda (salários mínimos) & $\begin{array}{l}\square \text { até } 1 \\
\square \text { 2-3 } \\
\square \text { 4-5 } \\
\square \text { 6-7 } \\
\square 7 \text { ou mais }\end{array}$ \\
\hline Região geográfica & $\begin{array}{l}\square \text { Norte } \\
\square \text { Nordeste } \\
\square \text { Centro-Oeste } \\
\square \text { Sudeste } \\
\square \text { Sul }\end{array}$ \\
\hline Experiência anterior no uso da internet & $\begin{array}{l}\square \text { Sim } \\
\square \text { Não }\end{array}$ \\
\hline Código do aluno de acesso ao AVA & \\
\hline
\end{tabular}




\section{ANEXO B - QUESTIONÁRIO DE BARREIRAS E FACILITADORES EM EAD}

\begin{tabular}{|c|c|c|c|c|}
\hline \multicolumn{5}{|c|}{ QUESTIONÁRIO DE BARREIRAS E FACILITADORES EM EAD } \\
\hline \multicolumn{5}{|c|}{$\begin{array}{l}\text { Os itens do questionário indicam fatores que podem ter auxiliado ou prejudicado o seu } \\
\text { desempenho durante o treinamento a distância. Leia os itens listados e escolha o ponto da } \\
\text { escala (1,2,3,4 ou 5) que representa o quanto cada fator dificultou o seu desempenho, ou } \\
\text { seja, atuou como uma barreira durante o curso, e registre sua resposta na coluna à direita } \\
\text { (Nota). }\end{array}$} \\
\hline $\begin{array}{c}1 \\
\text { Dificultou } \\
\text { totalmente o } \\
\text { desempenho }\end{array}$ & $\begin{array}{c}2 \\
\text { Dificultou muito }\end{array}$ & $\begin{array}{c}3 \\
\text { Nem muito, nem } \\
\text { pouco }\end{array}$ & $\begin{array}{c}4 \\
\text { Dificultou pouco }\end{array}$ & $\begin{array}{c}5 \\
\text { Não dificultou o } \\
\text { desempenho }\end{array}$ \\
\hline
\end{tabular}

\begin{tabular}{|c|c|}
\hline Itens & Nota \\
\hline 1. Promoção da interação social entre os participantes do curso por parte do tutor. & \\
\hline $\begin{array}{l}\text { 2. Utilização das ferramentas web (chats, e-mails, fóruns, etc.) para comunicação } \\
\text { com tutores e colegas. }\end{array}$ & \\
\hline $\begin{array}{l}\text { 3. Relação entre alunos e tutores quanto ao processo de aprendizagem ao longo } \\
\text { do curso. }\end{array}$ & \\
\hline 4. Orientações prestadas pelo tutor. & \\
\hline 5. Suporte técnico oferecido pela instituição. & \\
\hline 6. Conexão à internet. & \\
\hline 7. Acesso ao ambiente virtual do curso com a regularidade proposta. & \\
\hline 8. Materiais didáticos do curso. & \\
\hline $\begin{array}{l}\text { 9. Custos financeiros associados às tecnologias e materiais necessários durante o } \\
\text { curso (acesso à internet, manutenção do computador, etc.). }\end{array}$ & \\
\hline 10. Duração do curso. & \\
\hline 11. Conteúdo do curso. & \\
\hline 12. Recursos de ensino utilizados (figuras, vídeos, slides, etc). & \\
\hline 13. Quantidade das atividades propostas durante o curso. & \\
\hline 14. Conciliação do curso com as atividades profissionais. & \\
\hline 15. Conciliação do curso com os compromissos familiares. & \\
\hline 16. Tempo disponível para estudar. & \\
\hline 17. Conciliação do curso com outras atividades de estudo. & \\
\hline 18. Condições do ambiente de estudo em casa. & \\
\hline 19. Condições de saúde no período de realização do curso. & \\
\hline 20. Correspondência do curso às expectativas pessoais. & \\
\hline 21. Habilidades pessoais de organização e planejamento de atividades de estudo. & \\
\hline $\begin{array}{l}\text { 22. Habilidades pessoais para uso das ferramentas web (chats, e-mails, fóruns, } \\
\text { etc.). }\end{array}$ & \\
\hline
\end{tabular}




\section{ANEXO C - QUESTIONÁRIO DE ESTRATÉGIAS DE APRENDIZAGEM}

\section{QUESTIONÁRIO DE ESTRATÉGIAS DE APRENDIZAGEM}

Os itens do questionário indicam possíveis comportamentos utilizados por você durante o curso. Leia os itens listados e escolha o ponto da escala $(1,2,3,4$ ou 5) que representa a frequência com que você se comportou da maneira descrita em cada item, registrando sua resposta na coluna à direita (Nota).

\begin{tabular}{|c|c|c|c|c|}
\hline 1 & 2 & 3 & 4 & 5 \\
Nunca & Raramente & Às vezes & Frequentemente & Sempre \\
\hline
\end{tabular}

\begin{tabular}{|c|c|}
\hline Itens & Nota \\
\hline 1. Mantive a calma quando tive dificuldades durante o curso. & \\
\hline 2. Mantive a calma com a possibilidade de ter um rendimento abaixo do esperado. & \\
\hline 3. Mantive a calma diante dos erros que cometi ao realizar atividades do curso. & \\
\hline 4. Esforcei-me mais quando percebi que estava perdendo a concentração. & \\
\hline 5. Esforcei-me mais quando percebi que estava perdendo o interesse no assunto. & \\
\hline 6. Esforcei-me para verificar minha compreensão sobre o que estava sendo ensinado. & \\
\hline 7. Busquei auxílio de colegas para esclarecer minhas dúvidas sobre os conteúdos do curso. & \\
\hline 8. Busquei compreender melhor os conteúdos ao estudá-los nos materiais didáticos do curso. & \\
\hline 9. Busquei outras fontes de pesquisa relacionadas ao curso para me ajudar a aprender. & \\
\hline 10. Li o conteúdo do curso várias vezes como método para aprender. & \\
\hline $\begin{array}{l}\text { 11. Repeti mentalmente os conteúdos do curso que gostaria de aprender até perceber que } \\
\text { havia entendido. }\end{array}$ & \\
\hline 13. Revisei os conteúdos relativos aos exercícios em que cometi erros. & \\
\hline
\end{tabular}


14. Realizei os exercícios práticos propostos ao longo do curso para me ajudar a aprender.

15. Refleti sobre as implicações que os conteúdos aprendidos poderiam ter.

16. Identifiquei situações diárias em que eu pudesse aplicar os conteúdos do curso.

17. Busquei desenvolver uma ideia global sobre como os conteúdos do curso se relacionavam entre si.

18. Associei os conteúdos do curso aos meus conhecimentos anteriores. 


\section{ANEXO D - ROTEIRO DE ANÁLISE DE CURSO- EAD}

\begin{tabular}{|l|l|}
\hline Nome do Curso: & $\begin{array}{l}\text { Carga Horária Mínima Sugerida pela DCN } \\
\text { (Diretriz Curricular Nacional): }\end{array}$ \\
\hline Origem do Curso: & Carga Horária Total do Curso: \\
\hline Público-Alvo: & Data da Análise: \\
\hline Nomes dos Responsáveis pela Análise: & $\begin{array}{l}\text { Disponibilização de Tutoria: } \\
\text { ( ) Sim ( ) Não }\end{array}$ \\
\hline & $\begin{array}{l}\text { Tipo de Tutoria: } \\
\text { ( ) Ativa ( ) Passiva }\end{array}$ \\
\hline
\end{tabular}

\section{ORIENTAÇÃO GERAL}

A análise documental aqui proposta será realizada por dois ou mais avaliadores, que deverão efetuar suas avaliações de forma independente.

\section{INSTRUÇÕES- PARTE 1}

Nesta primeira etapa, leia atentamente o material a ser analisado e julgue os aspectos abaixo relacionados, registrando suas observações nos parêntesis colocados à esquerda de cada afirmativa. Utilize para tanto a escala de 5 pontos apresentada abaixo. Utilize NA (não se aplica) caso o curso não aborde o conteúdo do item.

Caso considere necessário, utilize o espaço destinado a observações e sugestões ou o verso desta folha para justificar seu julgamento e detalhar suas considerações.

\begin{tabular}{|c|c|c|c|c|}
\hline 1 & 2 & 3 & 4 & 5 \\
\hline $\begin{array}{l}\text { Nenhum dos } \\
\text { Casos }\end{array}$ & $\begin{array}{c}\text { Menos da } \\
\text { Metade dos } \\
\text { Casos }\end{array}$ & Metade dos Casos & $\begin{array}{c}\text { Mais da Metade dos } \\
\text { Casos }\end{array}$ & Todos os Casos \\
\hline
\end{tabular}

\section{OBJETIVOS INSTRUCIONAIS}

( ) 1. Descrição em termos de desempenhos observáveis.

( ) 2. Precisão na escolha do verbo de ação quanto à descrição do comportamento esperado.

( ) 3. Existência de critério.

( ) 4. Descrição clara do objeto de ação.

( ) 5. Definição clara das condições para a realização dos comportamentos esperados (quando essencial sua especificação)

\section{ADEQUAÇÃO DAS ESTRATÉGIAS INSTRUCIONAIS}

( ) 6. Adequação das estratégias instrucionais às características da clientela (escolaridade, cargo).

( ) 7. Adequação das estratégias utilizadas à natureza dos objetivos instrucionais (afetivo, cognitivo,

( ) psicomotor).

( ) 8. Adequação das estratégias utilizadas ao nível de complexidade dos objetivos instrucionais (com base

( ) nas taxonomias de Bloom e Simpson).

( ) 9. Diversificação das estratégias utilizadas ao longo do curso. (X ) Sim ( ) Não. Especifique no final.

( ) 10. Estratégias favorecem a interação entre os participantes (discussões presenciais e/ou virtuais, elaboração de trabalhos em grupos, etc.).

Fornecimento de exemplos que ilustrem na atuação profissional dos participantes. o curso oferecido.

( ) 11. Utilização de recursos de apoio à aprendizagem (equipamento de videoconferências, chats, fóruns, etc.).

( ) 12. Fidelidade dos recursos de apoio à aprendizagem (simulações, vídeos, estudos de caso, videoconferências, discussões em chats, fóruns, etc.) às situações reais de trabalho.

( ) 13. Linguagem dos módulos do curso compatível com o nível de escolaridade dos participantes.

( ) 14. Fidelidade dos conteúdos à situação real de trabalho.

( ) 15. Pertinência dos tópicos de informações adicionais (links de outros endereços, glossário, bibliografia). 


\begin{tabular}{|c|c|c|c|c|}
\hline \multicolumn{5}{|c|}{$\begin{array}{l}\text { Leia atentamente o material a ser analisado e registre suas observações nos par } \\
\text { cada afirmativa, utilizando a escala de } 5 \text { pontos apresentada abaixo. Utilize NA } \\
\text { aborde o conteúdo do item. Caso considere necessário, utiliza o espaço destinad } \\
\text { folha para justificar seu julgamento e detalhar suas considerações. }\end{array}$} \\
\hline 1 & 2 & $\mathbf{3}$ & 4 & 5 \\
\hline $\begin{array}{l}\text { Nenhum } \\
\text { dos Casos }\end{array}$ & $\begin{array}{c}\text { Menos da } \\
\text { Metade dos } \\
\text { Casos }\end{array}$ & $\begin{array}{l}\text { Metade dos } \\
\text { Casos }\end{array}$ & $\begin{array}{c}\text { Mais da Metade dos } \\
\text { Casos }\end{array}$ & Todos os Casos \\
\hline
\end{tabular}

\section{INSTRUÇÕES - PARTE 2}

Nos itens a seguir, registre suas observações nos parêntesis colocados à esquerda de cada afirmativa, utilizando os códigos: "S" (sim), diante dos itens que descrevem os materiais em estudo, "N" (não), diante das características que não descrevem este material e "NA" (não se aplica), diante dos casos que não sejam pertinentes para o curso em estudo. Caso considere necessário, utilize o espaço destinado a observações ou o verso desta folha para justificar seu julgamento e detalhar suas considerações.

\begin{tabular}{|c|c|}
\hline \multicolumn{2}{|r|}{ PLANEJAMENTO } \\
\hline $\begin{array}{l}\text { ( ) } \\
\text { ( ) } \\
\text { ( ) } \\
\text { ( ) }\end{array}$ & $\begin{array}{l}\text { 16. Adequação da carga horária sugerida com relação ao volume das disciplinas apresentadas. } \\
\text { 17. Informação ao aluno da estimativa de tempo a ser gasto em cada módulo/período por disciplina. } \\
\text { 18. Informação ao aluno da estimativa de tempo a ser gasto com as atividades teóricas e praticas de } \\
\text { cada disciplina. } \\
\text { 19. Existência de um programa. } \\
\text { 20. Disponibilização do programa no início do curso. } \\
\text { 21. Existência de avaliações de aprendizagem. } \\
\text { 22. Diversidade nas avaliações de aprendizagem. }\end{array}$ \\
\hline \multicolumn{2}{|r|}{ SEQUENCIACÃO DO ENSINO } \\
\hline $\begin{array}{l}\text { ( ) } \\
\text { ( ) } \\
\text { ( ) }\end{array}$ & $\begin{array}{l}\text { 23. Explicitação dos pré-requisitos necessários ao ingresso no curso. } \\
\text { 24. Sequenciação adequada das disciplinas dentro de cada período/semestre. } \\
\text { 25. Sequenciação das disciplinas atinge o nível de complexidade dos objetivos do curso. }\end{array}$ \\
\hline \multicolumn{2}{|r|}{ FONTES DE INFORMAÇÃO: BIBLIOGRAFIA E OUTROS MEIOS } \\
\hline $\begin{array}{l}\text { ( ) } \\
(\text { ) } \\
(\text { ) }\end{array}$ & $\begin{array}{l}\text { 26. Apresentação das fontes bibliográficas utilizadas. } \\
\text { 27. Utilização de bibliografia básica atualizada (ano } 2010 \text { em diante). } \\
\text { 28. Indicação de bibliografia complementar sobre os temas tratados na disciplina (livros, periódicos, } \\
\text { sites, etc.). }\end{array}$ \\
\hline \multicolumn{2}{|r|}{ INFORMAÇÕES GERAIS SOBRE O CURSO } \\
\hline $\begin{array}{l}\text { ( ) } \\
\text { ( ) } \\
\text { ( ) }\end{array}$ & $\begin{array}{l}\text { 29. Orientação geral sobre o uso do material (sequência de passos para utilizar o material). } \\
\text { 30. Flexibilidade do ambiente eletrônico na sequência de aprendizagem. } \\
\text { 31. Acesso ao PPC (Projeto Político Pedagógico) do curso }\end{array}$ \\
\hline
\end{tabular}




\section{ANEXO E - ROTEIRO DE BARREIRAS À CONCLUSÃO DE CURSOS DE PÓS-GRADUAÇÃO LATO SENSU A DISTÂNCIA}

1. Qual a sua idade, profissão, estado civil e renda familiar? Possui filhos? Estava trabalhando quando fez o curso? Qual era a carga horária de trabalho?

2. Ao iniciar o curso você sabia quais eram os objetivos e proposta do curso?

3. Como você avalia o conteúdo ministrado ao longo curso, considera adequado ao seu perfil como aluno que trabalha?

4. O curso atendeu às suas expectativas pessoais?

5. O curso auxiliou no desempenho das suas atividades no trabalho?

6. O tutor ofereceu o apoio necessário para sanar as dúvidas? O tutor promoveu a interação entre os alunos?

7. Como você avalia a didática dos professores que ministravam as aulas ao vivo?

8. As atividades oferecidas no curso possuíam relação entre a teoria e a prática? A regularidade das mesmas era adequada?

9. Como você avalia as ferramentas disponibilizadas para a interação dos alunos? Como avalia as ferramentas avaliativas dos mesmos? (Fóruns, trabalhos em grupo, mensagem da tutoria, pergunta dissertativa e encontros presenciais)?

10. Como você avalia o suporte prestado pela IES (Atendimento realizado pela área de Monitoria - Secretaria do Curso; Suporte técnico/informático)?

11. Como você avalia a interface gráfica do AVA (Ambiente Virtual de Aprendizagem)?

12. Em sua opinião, o curso oferecia conteúdo adequado para atingir os objetivos propostos por ele?

13. Em sua opinião, o curso oferecia carga horária adequado para atingir os objetivos propostos por ele?

14. Você se sentia motivado a participar das atividades propostas no curso? Por quê?

15. Você conseguia conciliar os compromissos de trabalho, família e estudos?

16. Como estava sua condição (física, mental, espiritual, financeira, relacionamentos, trabalho) durante a realização do curso?

17. Você possuía a estrutura necessária para a realização do curso (Internet, Computador, Local adequado para estudo)?

18. O curso atendeu às suas expectativas pessoais e profissionais?

19. Você conseguia se organizar para realizar as atividades propostas no curso?

20. Você já utilizava ferramentas virtuais antes de iniciar o curso (Internet, e-mails)?

21. Você dispunha de tempo para realizar as atividades de estudo?

22. Quais foram os principais fatores que influenciaram a sua decisão de evadir-se do curso? 


\title{
APÊNDICE A - TERMO DE CONSENTIMENTO LIVRE E ESCLARECIDO
}

\author{
Prezado participante,
}

Convido-o a participar voluntariamente na pesquisa intitulada Fatores influenciadores de evasão em cursos de pós-graduação ofertados a distância. A pesquisa faz parte do meu projeto de mestrado do curso de Pós-graduação em Psicologiada Faculdadede Filosofia,Ciências e Letras de RibeirãoPreto-UniversidadedeSãoPaulo (FFCLRP-USP).

$\mathrm{O}$ estudo em questão tem como objetivo fornecer informações que auxiliem na compreensão dos motivos que levam os estudantes a evadirem-se de cursos a distância. Para tanto, serão analisadas as possíveis relações existentes entre a variável critério evasão e as variáveis antecedentes pertencentes às características da clientela (dados sociodemográficos, uso das ferramentas eletrônicas e estratégias de aprendizagem) e a fatores relacionados à barreiras e facilitadores em EAD (contexto de estudo, desenho do treinamento e o próprio estudante) dos alunos de cursos de pós-graduação a distância lato sensu. Para tanto, preciso de sua colaboração para obtenção das informações necessárias.

A coleta destas informações consiste nas suas respostas a três questionários, os quais pretendem identificar fatores relacionados a barreiras e facilitadores em EAD e estratégias de aprendizagem e perfil sociodemográfioc.Após a leitura e aceite deste termo. A aplicação dos questionários será realizada via e-mail, após a leitura deste termo e aceite de sua parte em participar da pesquisa, serão enviados três questionários no seu e-mail, a duração para cada resposta dos questionários será entre 30 (trinta) e 40 (quarenta) minutos, após o preenchimento, os formulários deverão ser salvos e enviados à pesquisadora.

Como forma de sigilo, seu nome não será utilizado em qualquer fase da pesquisa, garantindo o seu anonimato.Outras informações são relevantes, a saber: não lhe será cobrado nada; não haverá gastos nem riscos decorrentes da su participação neste estudo; não estão previstas indenizações; não haverá benefícios imediatos na sua participação. No caso de eventuais despesas, fica garantido o ressarcimento.

Os resultados obtidos nesta pesquisa contribuirão como estudos sobre a evasão de cursos ofertados a distância, vislumbrando o aprimoramento de ações educacionais das instituições de ensino que oferecem cursos a distância.

Registro mais uma vez que sua participação é voluntária e que você poderá se recusar a participar da pesquisa,retirar seu consentimento,ou ainda descontinuar sua participação a qualquer momento. Este termo será assinado em duas vias, sendo uma das delas sua.

Sua colaboração é muito importante e agradeço pela atenção e disponibilidade. Coloco-me à disposição para maiores informações pelo telefone(16) 99141-8623 ou pelo email priscila.miquelino@usp.br. Em caso de dúvidas e outros esclarecimentos sobrea pesquisa você também poderá entrar em contato coma Prof $^{a}$.Dr ${ }^{a}$.Thaís Zerbini, responsável pela orientação deste projeto, através do telefone( 16)3315-4687 ou peloe -mail thaiszerbini@ffclrp.usp.br.

Ademais, eventuais dúvidas sobre questões éticas deste estudo poderão ser esclarecidas pelo Comitê de Ética em Pesquisa da Faculdade de Filosofia, Ciências e Letras de Ribeirão Preto - USP, situado na Avenida Bandeirantes, 3900 - Bloco 23 - Casa 37 - CEP: 14040-901 - Ribeirão Preto/SP - Brasil, telefones para contatos é o (16) 3315-4811 / Fax: (16) 3633-266 e E-mail: coetp@ffclrp.usp.br.

Confirmo que Priscila Miquelino da Silva me explicou os objetivos desta pesquisa, bem como a forma de participação. As alternativas para a minha participação também foram 
discutidas. $\mathrm{Eu}$, li e compreendi este termo de consentimento livre e esclarecido, portanto, concordo em dar meu consentimento para participar como voluntário desta pesquisa.

Assinatura do Participante e Data

Assinatura do Pesquisador e Data 